DANIELA ABREU DE MORAES

ESTUDO DA FUNÇÃO DE CD9O NA PROLIFERAÇÃO E DIFERENCIAÇÃO DE CÉLULAS-TRONCO MESENQUIMAIS HUMANAS

BRASÍLIA

2016 


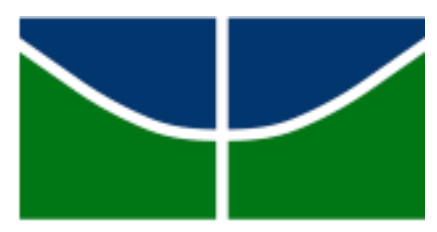

UNB

UNIVERSIDADE DE BRASÍLIA

FACULDADE DE CIÊNCIAS DA SAÚDE

PROGRAMA DE PÓS GRADUAÇÃO EM CIÊNCIAS DA SAÚDE

DANIELA ABREU DE MORAES

ESTUDO DA FUNÇÃO DE CD9O NA PROLIFERAÇÃO E DIFERENCIAÇÃO DE CÉLULAS-TRONCO MESENQUIMAIS HUMANAS.

Tese apresentada como requisito parcial para a obtenção do Título de Doutora em Ciências da Saúde pelo Programa de Pós-Graduação em Ciências da Saúde da Universidade de Brasília.

Orientador: Prof. Dr. Orlando Ayrton de Toledo

Co-orientadora: Profa. Dra. Daniela Mara de Oliveira

Brasília

2016 
ESTUDO DA FUNÇÃO DE CD90 NA PROLIFERAÇÃO E DIFERENCIAÇÃO DE CÉLULAS-TRONCO MESENQUIMAIS HUMANAS.

Tese apresentada como requisito parcial para a obtenção do Título de Doutora em Ciências da Saúde pelo Programa de Pós-Graduação em Ciências da Saúde da Universidade de Brasília.

Aprovada em 08/09/2016

\section{BANCA EXAMINADORA}

Prof. Dr. Orlando Ayrton de Toledo - Presidente Orientador Universidade de Brasília

Prof. Dr. Felipe Saldanha Araújo Universidade de Brasília

Prof. Dr. Bernardo Petriz de Assis Centro Universitário do Distrito Federal-UDF

Prof. Dra. Eneida Franco Vêncio Universidade Federal de Goiás

Prof. Dra. Denise Pinheiro Falcão da Rocha Universidade de Brasília

Profa. Dra. Ana Cristina Barreto Bezerra-suplente Universidade de Brasília 
Dedico este trabalho à Deus, à minha filha Rafaela, aos meus pais, irmãos e irmãs pela companhia e apoio constante. 


\section{AGRADECIMENTOS}

Agradeço a Deus pelo dom da vida.

À minha filha Rafaela Abreu de Almeida, por ser o meu estímulo em todos os momentos. Aos meus pais: João Batista de Moraes e Joaquina Elaine Abreu de Moraes, sobrinhos, sobrinhas, irmãos (Marcelo Abreu e Adriano Abreu) e irmãs (Adriana Abreu, Bibiana Abreu e Vivianne Abreu, obrigada por tudo!!!), exemplos de amor, força e coragem. Ao Diule Vieira, obrigada pelo apoio e carinho nessa etapa tão importante!

Ao meu querido orientador Prof. Dr. Orlando Ayrton de Toledo pela oportunidade de aprendizado, por me fazer acreditar que podemos sempre superar nossos limites. À querida Profa. Dra, Ana Cristina Barreto Bezerra pelo apoio constante e pelo valioso exemplo de atenção e amizade.

À minha co-orientadora Profa. Dra. Daniela Mara de Oliveira pelas orientações e colaborações durante a realização da pesquisa.

Ao Prof. Dr. Ricardo Bentes de Azevedo pela disponibilização do laboratório e da sala de cultivo celular, imprescindível para a realização dos experimentos.

Ao Prof. Dr. Felipe Saldanha de Araújo pela gentil colaboração, discussões e contribuições em momentos importantes dos ensaios de proliferação linfocitária.

Ao Prof. Dr. Bernardo Petriz de Assis, pelo constante incentivo na área científica e pelo exemplo de excelência na profissão de pesquisador.

Aos estimados colegas Raffael Castro e Rafael Correa, pela grande colaboração na citometria de fluxo e ao Prof. Dr. Daniel Ardisson pela grata amizade. Ao colega Raphael Bonadio pela contribuição nos experimentos de qRT-PCR.

Meus agradecimentos a todos os colegas do Laboratório de Genética e Morfologia da UNB: Dra. Luciana Pereira, Ana Luiza Gouvêa, Andressa Fabro, Antônio Djalma, Ludmila David, Sebastian Biswaro, Marina Sampaio, Jaqueline Rodrigues e a todos aqueles profissionais dedicados que primam pela pesquisa no Brasil.

Ao corpo diretivo-acadêmico da UDF, Profa. Dra. Beatriz Eckert-Hoff, reitora, Prof. Dr. Bernardo Petriz de Assis, Coordenador de Pesquisa e Pós-Graduação, Prof. Dr. Emílio Barbosa, coordenador do curso de odontologia, a todos os colegas incluindo a Profa. Caroline Piske, Prof. Antônio Ramos, Profa. Thais Benevenuto, Profa. Ludmila Madeira e aos meus alunos do curso de odontologia, que também foram um estímulo importante nessa caminhada.

Aos colegas cirurgiões-dentistas: Profa Lília Aguiar, Prof. Heitor de Brito, Profa. Érika Mendonça, Vanessa Guandalim, Carlos Augusto. Obrigada pela amizade! 
Aos estimados professores e grandes profissionais Dra. Eneida Franco Vêncio, Dra. Denise Pinheiro Falcão da Rocha, Dr. Bernardo Petriz de Assis, Dr. Felipe Saldanha de Araújo, Dr. Orlando Ayrton de Toledo, Dra. Ana Cristina Barreto Bezerra que compuseram a banca examinadora dessa tese, pelas preciosas contribuições.

Aos demais professores do laboratório de Genética e Morfologia.

Ao laboratório Sabin pelo auxílio com a análise de cálcio.

À Universidade de Brasília e aos mestres dessa instituição.

Ao Centro Universitário do Distrito Federal-UDF pelo grande apoio à pesquisa científica.

À CNPq pelo apoio financeiro. 
"Procuro semear otimismo e plantar sementes de paz e justiça. Digo o que penso, com esperança. Penso no que faço, com fé. Faço o que devo fazer, com amor. Eu me esforço para ser cada dia melhor, pois bondade também se aprende. Mesmo quando tudo parece desabar, cabe a mim decidir entre rir ou chorar, ir ou ficar, desistir ou lutar; porque descobri, no caminho incerto da vida, que o mais importante é o decidir".

Cora Coralina 
Introdução: Células-tronco mesenquimais (MSCs) são células progenitoras multipotentes potencial fonte para várias terapias celulares. MSCs são caracterizadas pela expressão dos marcadores celulares CD73, CD90 e CD105, e ausência de expressão dos marcadores CD34, CD45, CD11a, CD19 e HLA-DR. CD90 é uma glicoproteína presente na membrana de MSC, várias células adultas e células-tronco de câncer. A função de CD90 em MSC ainda é pouco elucidada. Objetivo: Obter MSCs com expressão reduzida de CD90 para investigar a função desse marcador na morfologia, proliferação e diferenciação de MSCs humanas. Metodologia: Foi avaliada a função de CD90 na morfologia, proliferação, supressão da proliferação de células T e diferenciação osteogênica e adipogênica de MSCs por meio da redução da expressão desse marcador, usando vetores lentivirais que expressam shRNA contra CD90. Resultados: O estudo mostrou que a redução da expressão de CD90 resultou em maior eficiência das diferenciações osteogênica e adipogênica de MSCs in vitro e, inesperadamente, resultou também no decréscimo da expressão dos marcadores CD44 e CD166. Conclusão: O estudo sugere que CD90 controla a diferenciação de MSCs e possa agir como um obstáculo a ser superado para que haja diferenciação e a manipulação de CD90, na presença de um correto estímulo para a diferenciação pode levar a taxas de diferenciação in vitro de MSCs mais eficientes.

Palavras-chave: Células-tronco mesenquimais, células-tronco estromais, CD90, Thy1, fibroblasto, diferenciação. 


\begin{abstract}
Introduction: Mesenchymal Stromal Cells (MSCs) are multipotent progenitor cells used in several cellular therapies. MSCs are characterized by the expression of CD73, CD90 and CD105 cell markers, and the absence of CD34, CD45, CD11a, CD19 and HLA-DR cell markers. CD90 is a glycoprotein present in the MSC membranes, various adult cells and cancer stem cells. The role of CD90 in MSCs remains unknown. Here, we sought to analyse the role of CD90 plays in the characteristic properties of in vitroexpanded human MSCs. Methodology: We investigated the function of CD90 in: the morphology; proliferation rate; suppression of $\mathrm{T}$ cell proliferation; and osteogenic/adipogenic differentiation of MSCs by reducing the expression of this marker using CD90 target shRNAs lentiviral vectors. Results: The present study shows that a reduction in CD90 expression enhances the osteogenic and adipogenic differentiation of MSCs in vitro and, unexpectedly, causes a reduction the expression of CD44 and CD166. Conclusion: Our study suggests that CD90 controls the differentiation of MSCs by acting as an obstacle in the pathway of differentiation commitment which may be overcome, in the presence of the correct differentiation stimuli, supporting the idea that CD90 level manipulation may lead to more efficient differentiation rates in vitro.
\end{abstract}

Keywords: Mesenchymal stem cells, mesenchymal stromal cells, CD90, Thy-1, fibroblast, differentiation. 


\section{LISTA DE FIGURAS}

Figura 1 - Imagem representativo da definição de células-tronco.

Figura 2 - Imagem representativa de célula-tronco embrionária e seu potencial de diferenciação.

Figura 3 - Fontes diversas de células-tronco mesenquimais adultas. 19

Figura 4 - Unidades formadoras de colônias (UFC) de fibroblastos de medula óssea e morfologia das MSCs.

Figura 5 - MSC e seus principais marcadores imunofenotípicos.............................26

Figura 6 - Transdução celular e mecanismo de RNA interferência. .........................33

Figura 7 - Delineamento experimental do isolamento, purificação e caracterização de MSCs. .38

Figura 8 - Eficiência de transdução de MSCs por partículas lentivirais. 47

Figura 9 - Análise da expressão de CD90 em MSC e shRNA CD90 MSC por citometria de fluxo..

Figura 10 - Análise da intensidade de fluorescência de CD90 em MSC e shRNA CD90

Figura 11 - Nível de expressão relativa de mRNA em MSC, shRNA Controle MSC e shRNA CD90 MSC

Figura 12 - Seleção negativa de shRNA CD90 MSCs.

Figura 13 - Análise da intensidade de fluorescência (MFI) do marcador CD90

(MFI=MFI do marcador-MFI do isótipo) nas células. 50

Figura 14 DPSCs coradas com corante panóptico.................................................52

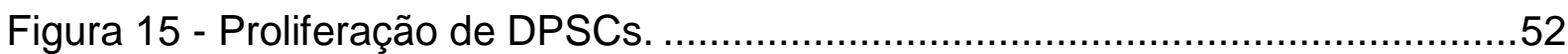

Figura 16 - Ensaio de proliferação de células T...................................................53

Figura 17- Número de PBMCs ativados com CFSE..........................................54

Figura 18 - Porcentagem de proliferação de células T expressando CD8 ................54

Figura 19 - Imunofenotipagem de DPSC, AF-MSC e ADSC por citometria de fluxo. 56

Figura 20 - Expressão de CD44 e CD166 em DPSC, AF-MSC e ADSC. ….............57

Figura 21 - Análise da média de intensidade de fluorescência de CD44 ..................58

Figura 22 - Análise da média de intensidade de fluorescência de CD166 ................58

Figura 23 - Ensaio de diferenciação osteogênica-análise qualitativa. ......................60

Figura 24 - Ensaio de diferenciação osteogênica-análise quantitativa do tecido mineralizado..

Figura 25 - Ensaio de diferenciação osteogênica-análise da atividade de fosfatase alcalina.

Figura 26 - Ensaio de diferenciação osteogênica-análise da concentração de cácio.

Figura 27 - Ensaio de diferenciação adipogênica-análise qualitativa. 62

Figura 28 - Ensaio de diferenciação adipogênica-análise quantitativa. 63 


\section{LISTA DE TABELAS}

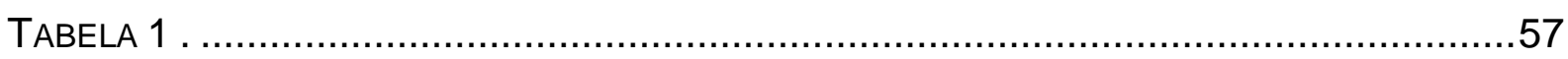




\section{LISTA DE ABREVIATURAS E SIGLAS}

ADSC Células-tronco mesenquimais do tecido adiposo

AF-MSC Células-tronco mesenquimais do líquido amniótico

ALCAM Molécula de adesão de leucócitos ativados

ALP Fosfatase alcalina

ANOVA Análise de variância

APC Aloficocianina

BMSC Célula-tronco mesenquimal da medula óssea

BSA Proteína albumina do soro bovino

${ }^{\circ} \mathrm{C} \quad$ Graus Celsius

CD Grupamento de diferenciação (Cluster of differentiation)

CFSE Carboxifluoresceína succinimidil Ester

UFC Unidade formadora de colônias fibroblásticas

Cm Centímetro

CSC Célula-tronco de câncer

DMEN Meio sintético complexo de Eagle modificado por Dulbecco

DMSO Dimetilsufóxido

DNA Ácido desoxirribonucleico

DPSC Células-tronco da polpa dental

EDTA Ácido diaminotetracético

FITC Isotiocianato de fluoresceína

g Grama

GFP Proteína verde fluorescente 


\begin{tabular}{ll} 
h & Hora \\
HLA-DR & Antígeno leucocitário humano-relacionado ao antígeno D \\
HLA- I & Antígeno leucocitário humano-I \\
HLA-II & Antígeno leucocitário humano-II \\
IgG & Imunoglobulina G \\
IgM & Imunoglobulina M \\
L & Litro \\
M & Molar \\
MSC & Células-tronco mesenquimais (Mesenchymal stem cell) \\
mL & Mililitro \\
mM & Milimolar \\
min & Minuto \\
mRNA & Ácido ribonucleico mensageiro \\
ng & Nanograma \\
nm & Nanômetro \\
nM & Nanomolar \\
o-CPC & Orto-cresoftaleína complexona \\
PBMC & Células mononucleares de sangue periférico \\
PBS & Solução salina tamponada \\
PE & Proteína ficoeritrina \\
PerCP & Proteína piridina de clorofila \\
PHA & Fitohemaglutinina \\
p-NF & p-Nitrofenol fosfato \\
RNA & Ácido ribonucleico \\
RNAi & RNA interferência \\
RNAm & RNA messageiro \\
\hline
\end{tabular}




$\begin{array}{ll}\text { RPMI } & \text { Meio sintético complexo criado pelo Instituto Memorial Roswell Park } \\ \text { SFB } & \text { Soro fetal bovino } \\ \text { shRNA } & \text { Pequenos grampos de RNA (Small hairping RNA) } \\ \text { pb } & \text { Pares de base } \\ \text { PCR } & \text { Reação da polimerase em cadeia (Polimerase chain reaction) } \\ \text { pH } & \text { Potencial hidrogeniônico } \\ \text { TGF- } \beta & \text { Fator de transformação do crescimento } \beta \\ \text { TNFa } & \text { Fator de necrose tumoral } \alpha \text { (Tumor necrosis fator } \alpha \text { ) } \\ \mu \mathrm{g} & \text { Micrograma } \\ \mu \mathrm{L} & \text { Microlitro } \\ \mu \mathrm{m} & \text { Micrômetro } \\ \mu \mathrm{M} & \text { Micromolar } \\ \% & \text { Por cento }\end{array}$




\section{SUMÁRIO}

1 INTRODUÇÃO

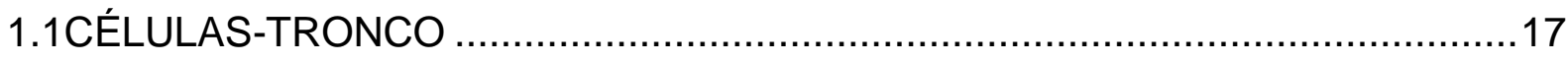

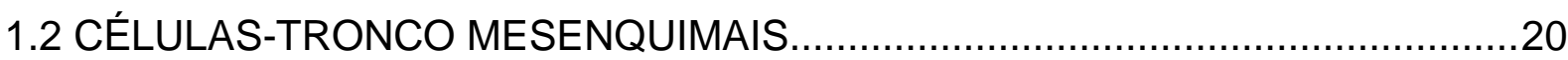

1.2.1 CÉLULAS-TRONCO MESENQUIMAIS PULPARES ....................................22

1.2.2 CÉLULAS-TRONCO MESENQUIMAIS DO LÍQUIDO AMNIÓTICO: ...............24

1.2.3 CÉLULAS-TRONCO MESENQUIMAIS DO TECIDO GORDUROSO:.............25

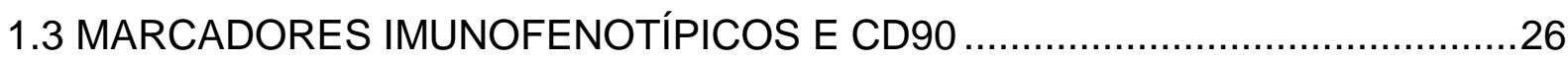

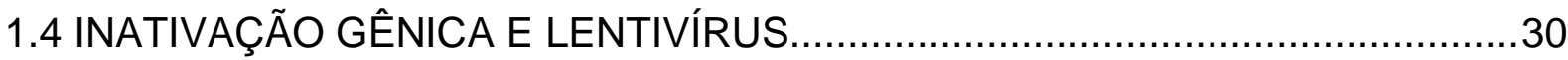

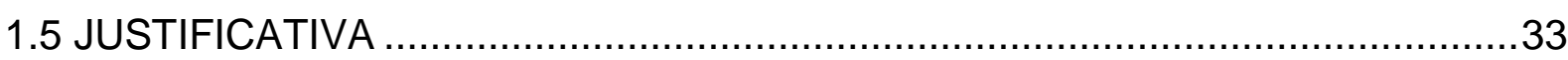

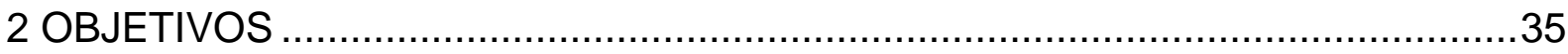

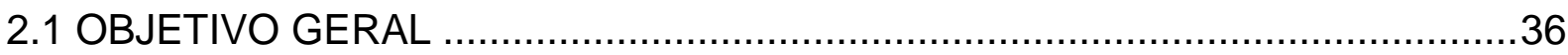

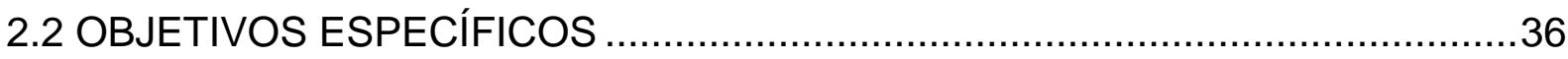

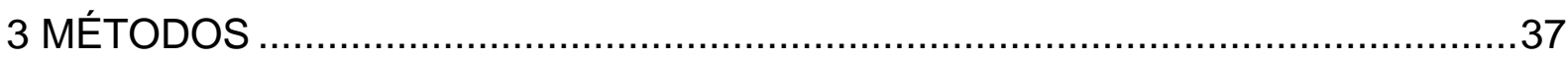

3.1 ISOLAMENTO DE MSCS HUMANAS E CULTURA CELULAR ….....................38

3.2 TRANSDUÇÃO LENTIVIRAL PARA REDUÇÃO DA EXPRESSÃO DE CD90 ...39

3.3. SEPARAÇÃO MAGNÉTICA DE MSC PARA SELEÇÃO NEGATIVA DE CD90 40

3.4.CARACTERIZAÇÃO IMUNOFENOTÍPICA DAS MSCS POR CITOMETRIA DE FLUXO

3.5 ANÁLISE DA MORFOLOGIA DE MSC

3.6 AVALIAÇÃO DA PROLIFERAÇÃO DE MSC APÓS REDUÇÃO DA EXPRESSÃO DE CD90

3.7 ANÁLISE DA INIBIÇÃO DA PROLIFERAÇÃO DE LINFÓCITOS .......................42

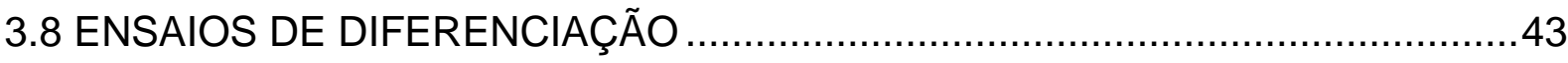

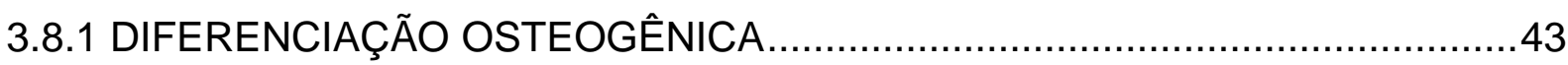

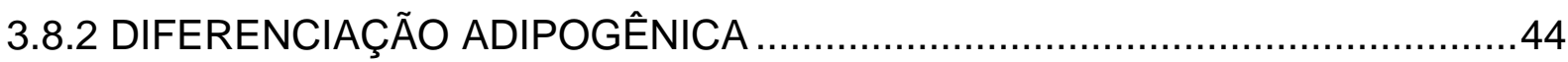

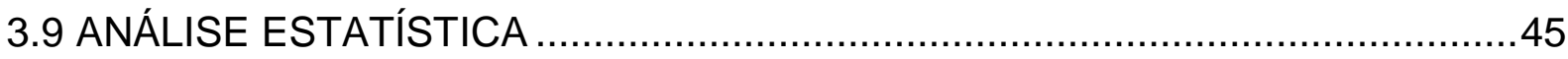

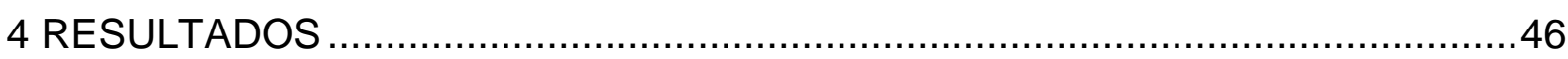

4.1 ANÁLISE DA EFICIÊNCIA DA TRANSDUÇÃO E REDUÇÃO DA EXPRESSÃO

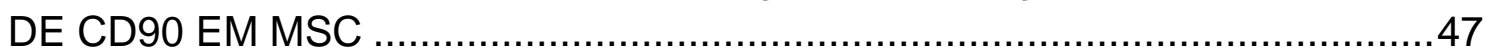

4.2 SELEÇÃO NEGATIVA PARA CD90 NAS SHRNA CD90 MSCS ......................49 
4.3 ENSAIO DE MORFOLOGIA E PROLIFERAÇÃO ....................................... 51

4.3 ANÁLISE DE PROLIFERAÇÃO DE LINFÓCITOS .......................................53

4.4 CARACTERIZAÇÃO IMUNOFENOTÍPICA POR CITOMETRIA DE FLUXO ......55

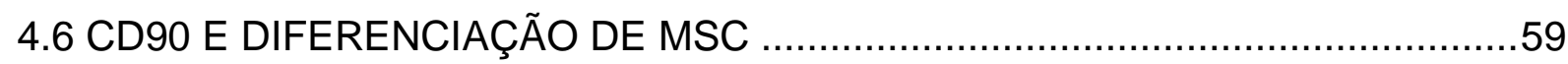

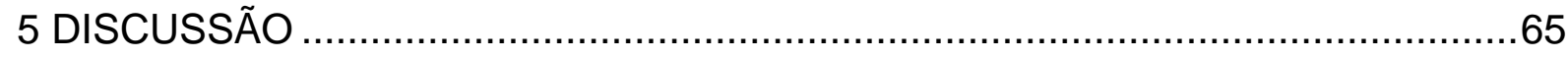

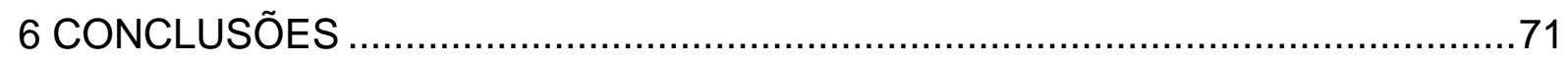

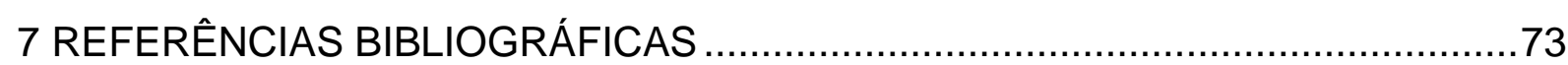

APÊNDICE A- TERMO DE CONSENTIMENTO LIVRE E ESCLARECIDO .............87

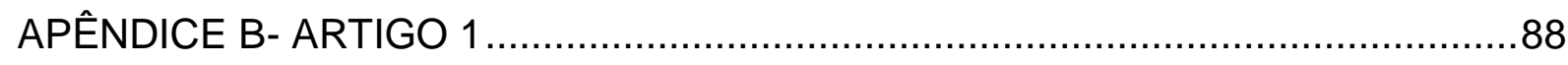

ANEXO A- DOCUMENTO DE APROVAÇÃO PELO COMITÊ DE ÉTICA DA

FACULDADE DE CIÊNCIAS DA SAÚDE-UNIVERSIDADE DE BRASÍLIA ....103 
1 INTRODUÇÃO 


\section{INTRODUÇÃO}

\subsection{CÉLULAS-TRONCO}

Células-tronco são células indiferenciadas presentes no organismo, que possuem duas propriedades características: auto-renovação e diferenciação (Figura 1) A auto-renovação refere-se à proliferação por longos períodos com manutenção do seu estado indiferenciado e a diferenciação é a capacidade de gerar tipos celulares especializados com a finalidade de promover o crescimento e a maturação do organismo ou a regeneração de um tecido após trauma ou lesão $(1,2)$. Vários estudos a respeito da biologia de células-tronco evidenciaram a presença de populações celulares hierárquicas organizadas em um sistema originado a partir de uma célula indiferenciada com elevada capacidade de diferenciação

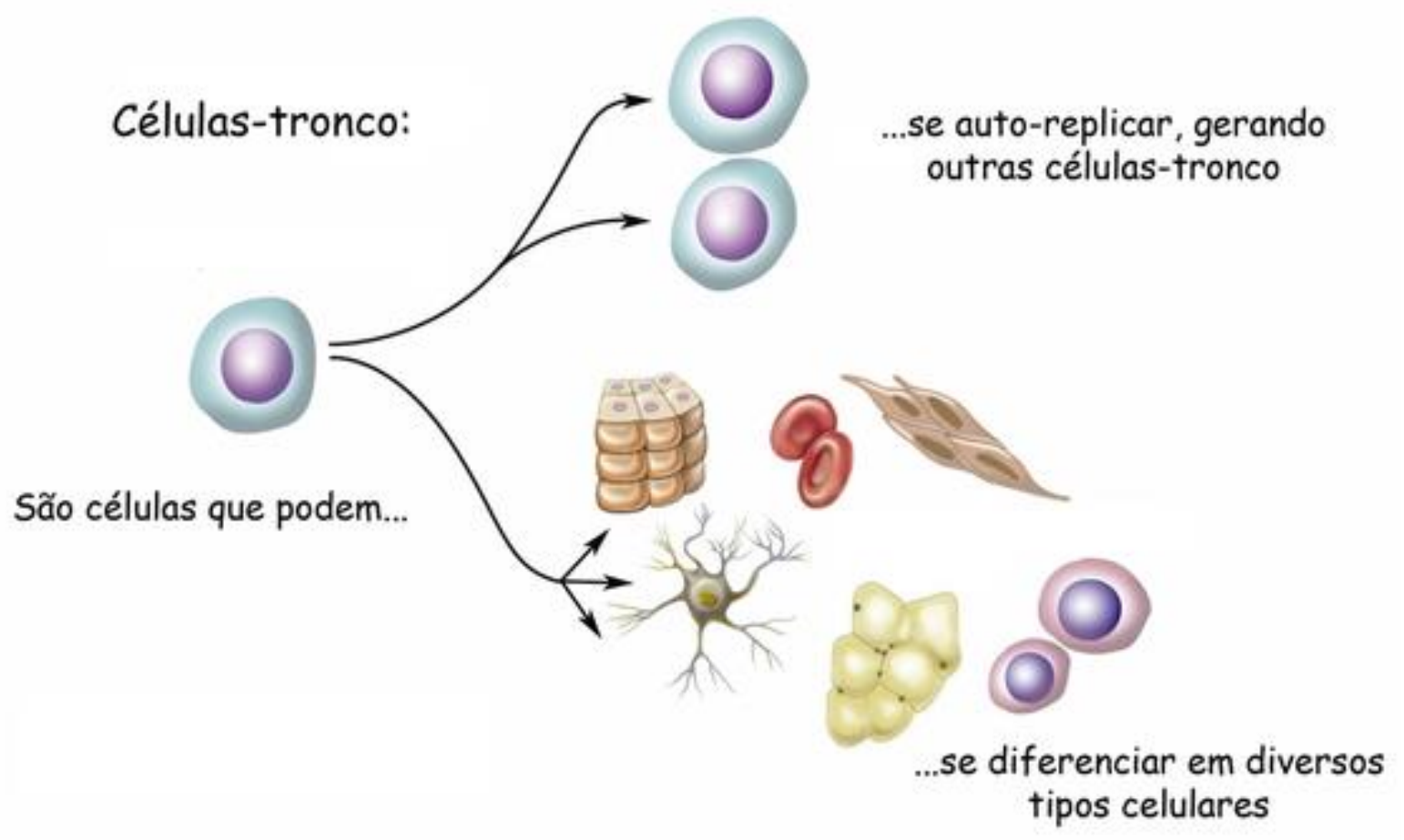

Figura 1 - Imagem representativo da definição de células-tronco. Fonte: www.lance-ufrj.org

Dessa forma, as células-tronco são classificadas de acordo com seu potencial de autorrenovação e diferenciação como: totipotentes, pluripotentes, 
multipotentes, oligopotentes e unipotentes. As células totipotentes possuem capacidade de originar células embrionárias e adultas, já as pluripotentes originam todas as células do embrião, com exceção da placenta e anexos embrionários e estão presentes na camada interna do blastocisto. As multipotentes são capazes de originar células do seu tecido de origem e estão presentes no organismo adulto como fonte de constante renovação celular. As oligopotentes se diferenciam em linhagem celular mais restrita e as unipotentes originam um único tipo celular especializado (3-5).

Outro tipo de classificação é quanto à natureza das células-tronco, que podem ser classificadas como embrionárias e adultas. As células-tronco embrionárias são derivadas de embriões, na fase de blastocisto. Nesta fase, o embrião possui uma camada externa e uma massa celular interna, que possui células que podem ser retiradas e cultivadas originando linhagens de células-tronco embrionárias que possuem potencial de diferenciação em todos tecidos adultos (6) (Figura 2).

A capacidade de proliferação e diferenciação de células-tronco embrionárias em diversas linhagens celulares demonstram o grande potencial terapêutico dessas células. Entretanto, a instabilidade genética, o transplante para hospedeiros imunocomprometidos para evidenciar a capacidade de diferenciação, o risco de formação de teratocarcinomas e questões éticas relacionadas a utilização de embriões humanos são obstáculos vistos em sua utilização (7-9).

Além de tecidos embrionários, as células-tronco podem ser encontradas em pequenas quantidades nos tecidos fetais ou de indivíduo adulto. Estas células, conhecidas como células-tronco adultas são caracterizadas como clonogênicas, capazes de autorregenerar e manter ou reparar tecidos de origem, promovendo um balanço fisiológico no organismo (10) (Figura 3).

A célula-tronco adulta mais bem caracterizada é a células-tronco hematopoética, que é um tipo celular amplamente utilizado em terapia celular em humanos desde a década de cinquenta do século XX. As células-tronco hematopoiéticas originam todas as células da linhagem sanguínea e sistema imune e são encontradas na medula óssea, no sangue periférico de adultos e no sangue de cordão umbilical (11). Outro tipo de célula-tronco adulta presente em pequenas frações na medula óssea é a célula-tronco mesenquimal (MSC) $(12,13)$. 


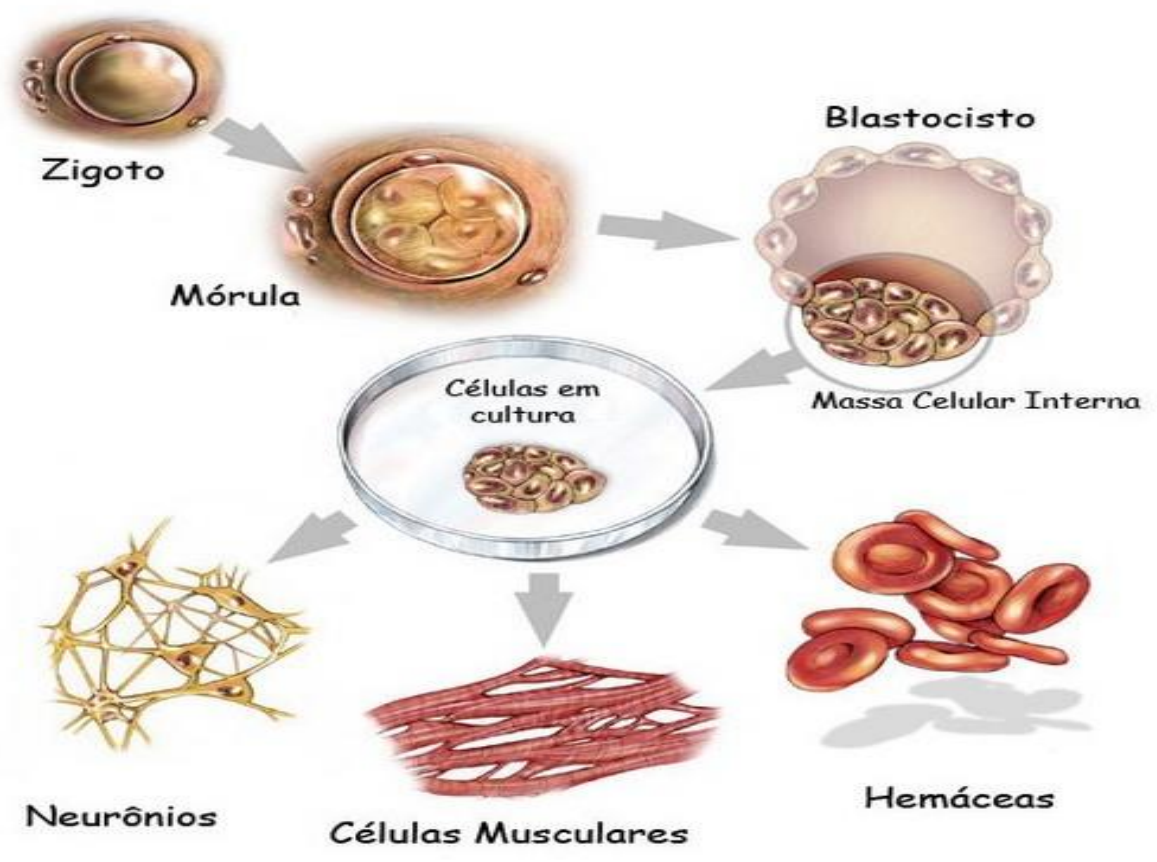

Figura 2 - Imagem representativa de célula-tronco embrionária e seu potencial de diferenciação. Fonte: www.lance-ufri.org

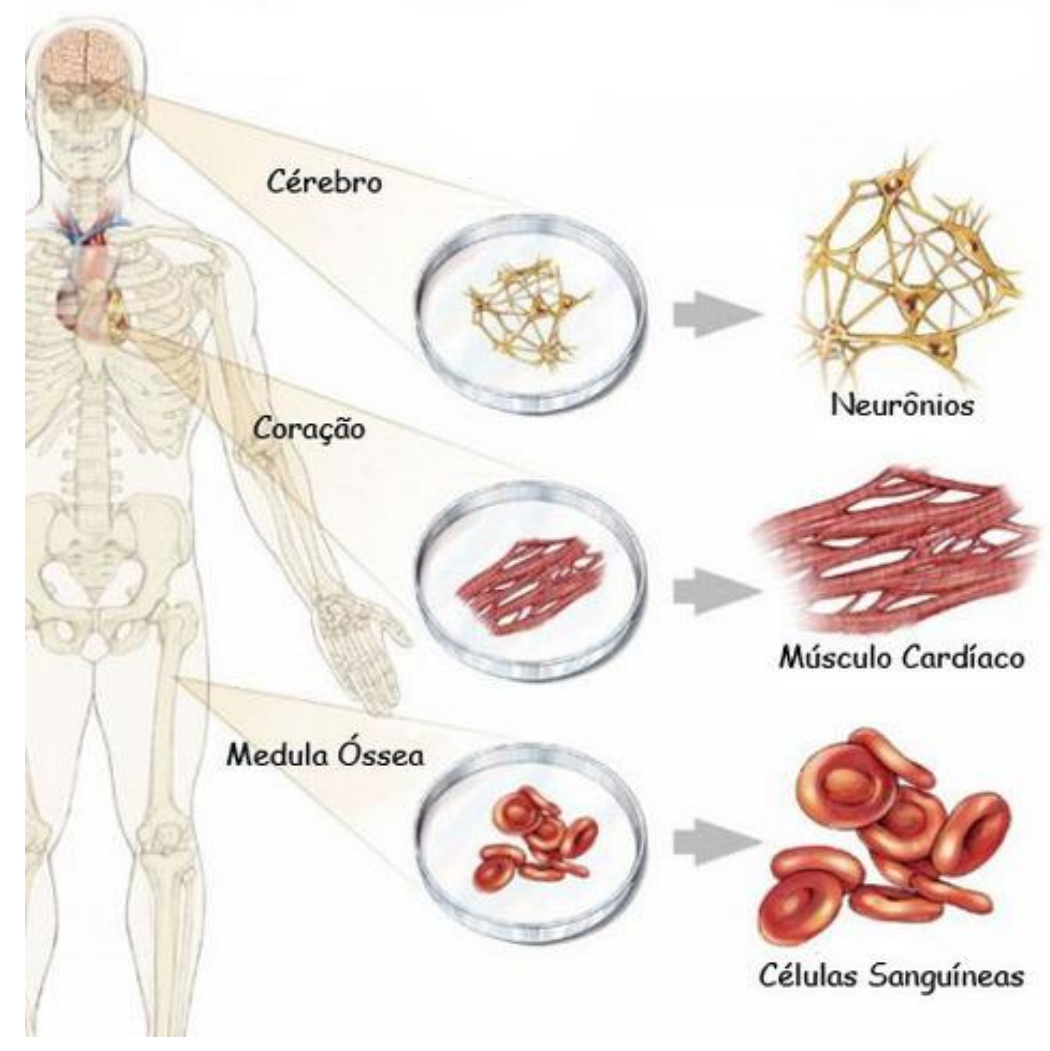

Figura 3 - Fontes diversas de células-tronco mesenquimais adultas.Fonte: www.lance-ufri.org 


\subsection{CÉLULAS-TRONCO MESENQUIMAIS}

Células-tronco mesenquimais (MSCs) são definidas como células-tronco progenitoras capazes de se diferenciar em múltiplas linhagens mesodérmicas e de se autorrenovar em sua forma indiferenciada, com elevada capacidade proliferativa (13).

As MSCs foram primariamente identificadas na medula óssea de camundongos. Friedestein et al (13) evidenciaram que, dentre as células da medula óssea que aderiam ao plástico, uma rara população celular com aspecto fenotípico semelhante a fibroblastos se desenvolvia em comunidades formadoras de colônia (Figura 4) (14). Estas células passaram a ser chamadas de células-tronco estromais da medula óssea, por possuírem natureza de células-tronco e por se originarem a partir de células do estroma da medula óssea (14).

A
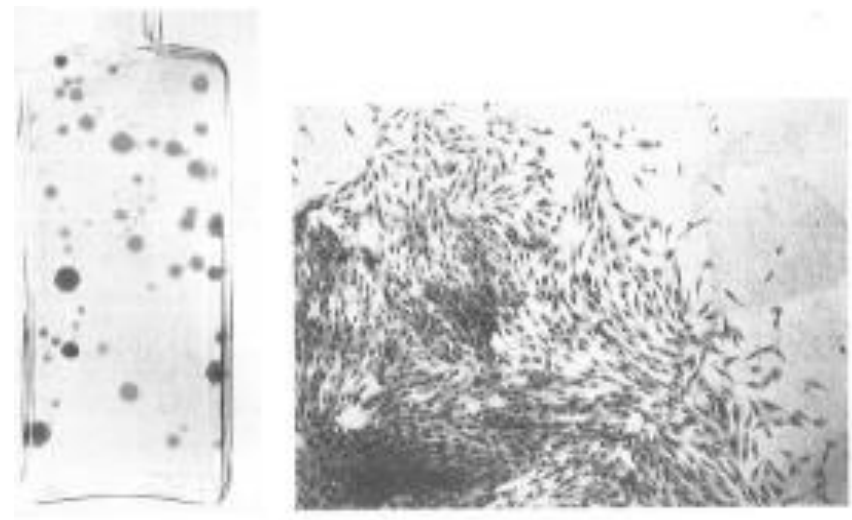

B

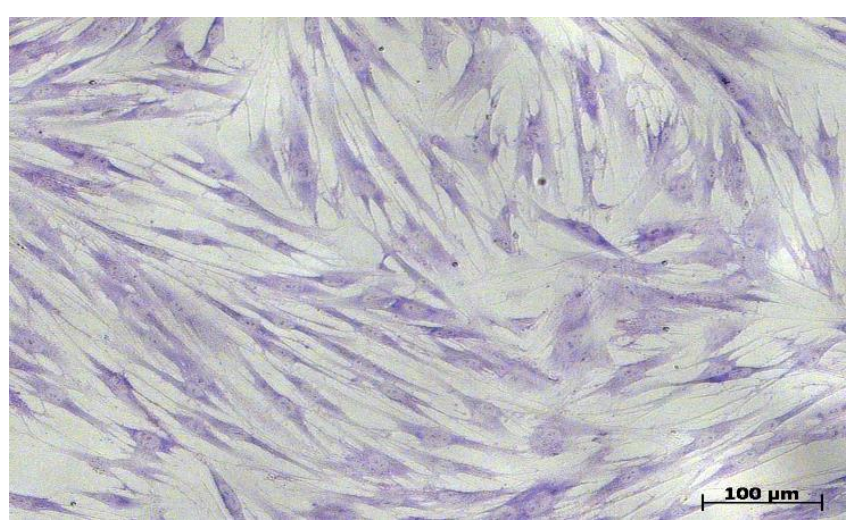

Figura 4 - Unidades formadoras de colônias (UFC) de fibroblastos de medula óssea e morfologia das MSCs. A. Unidades formadoras de colônias (UFC) de fibroblastos de medula óssea. Fonte: Friedestein et al (1974) (14). B. Morfologia MSCs. 
O termo célula-tronco mesenquimal foi proposto por Caplan (16) para evidenciar a natureza não hematopoiética das células-tronco derivadas da medula óssea, assim como à capacidade dessas células de se diferenciar em todas as células da linhagem mesodermal, abrangendo o tecido conjuntivo, sanguíneo, urogenital e músculo-esquelético (15-17). Outros estudos, alguns controversos, ampliam o comprovado potencial de diferenciação mesodermal das MSCs, demonstrando que essas células também são capazes de se diferenciar em linhagens não mesodermais, como células neuronais $(18,19)$ e hepatócitos $(20)$.

Com o avanço das pesquisas foi necessário estabelecer uma padronização na definição de MSCs para a comunidade científica. Dessa forma, o Comitê de célulastronco mesenquimais e teciduais da Sociedade Internacional de Terapia Celular (ISCT) estabeleceu critérios mínimos para defini-las. Estes critérios são: 1) aderência ao plástico; 2) capacidade de formação de unidades formadoras de colônias quando mantidas em condições ideais de cultura; 3) diferenciação in vitro em linhagens adipogênica, condrogênica e osteogênica na presença de indutores específicos; 4) expressão dos marcadores CD105 (endoglina, SH2), CD73 (ecto-5' nucleotidase) e CD90 (Thy-1) e a ausência de marcadores CD45, CD19, CD19 ou CD79, CD14 ou CD11b e HLA-DR $(21,22)$.

Em relação ao aspecto morfológico, as culturas de MSCs humanas possuem células fibroblastóides (Figura 4), com grande potencial de expansão (23). Mas a capacidade de proliferação é variável, podendo estar relacionada à baixa freqüência de MSCs nos nichos (24), à condição física e à idade do doador, já que MSCs advindas de doadores mais velhos apresentam menor taxa de proliferação e alterações tanto na morfologia, quanto no potencial de diferenciação $(25,26)$.

Como as primeiras MSCs foram isoladas do estroma da medula óssea (BMSC) $(13,27)$, esta passou a ser a fonte dessas células mais utilizada para ensaios clínicos e laboratoriais (28-30). Apesar de as BMSCs serem consideradas padrão ouro para pesquisas in vitro e in vivo, existem algumas limitações em relação ao isolamento dessas células, como por exemplo, o procedimento de obtenção das células ser desconfortável para o doador, risco de infecção na coleta de células e a quantidade de células obtidas ser limitada em comparação com outras fontes $(9,29,31,32)$. Diante disso, vários pesquisadores passaram a buscar fontes alternativas para isolar MSCs, demonstrando que essas células podem ser isoladas a partir de outras fontes 
advindas tanto de tecidos de indivíduos adultos, como por exemplo; polpa dental (33), tendões (34), pele (35), tecido adiposo (36), membrana sinovial (37), leite materno (38); quanto de tecido fetal; como placenta (39), sangue do cordão umbilical (40), células perivasculares do cordão umbilical (41), Geléia de Wharton (42) e líquido amniótico (43). Alguns estudos evidenciaram variação quanto ao potencial de diferenciação entre as MSCs de diferentes fontes de tecidos $(32,33,44,45)$, mas essas células demonstraram características comuns a todas as MSCs.

Estudos comprovaram que MSCs são células com propriedades imunológicas únicas, tanto in vitro quanto in vivo, inibindo a proliferação linfocitária. Diante da interação dessas células com interferon-gama (INF- $\gamma$ ), que é uma proteína produzida por células do sistema imune, ou mesmo em virtude do contato direto dessas células com tecidos transplantados, as MSCs potencializam a liberação de fatores solúveis que irão atuar nas células do sistema imunológico, inibindo a produção e proliferação de linfócitos $\mathrm{T}$ e $\mathrm{B}$, evitando estímulos de aloreatividade e escapando da atividade citotóxica de células natural killer e linfócitos T. As MSCs são descritas como positivas para HLA de classe I e negativas para moléculas co-estimulatórias CD40, CD80, CD86 e HLA de classe II. Esse perfil imunológico, com reduzida capacidade imunogênica faz com que a utilização de MSCs em pesquisas e ensaios clínicos seja adequada para o uso em terapias celulares $(46,47)$. As MSCs cultivadas ex vivo já foram administradas em humanos para auxiliarem no transplante de medula óssea e como tratamento para osteogênese imperfeita e para doenças que afetam o armazenamento de glicogênio, condições clínicas para as quais não existem muitas opções terapêuticas disponíveis $(48,49)$.

Dessa forma, devido ao seu potencial de proliferação em cultura, multidiferenciação, baixa antigenicidade, capacidade de modulação da resposta imune e habilidade inerente de migração ao sítio de inflamação, o estudo da biologia de MSCs é de grande interesse científico, pois está associada a um novo conceito clínico em pesquisas e terapias celulares $(28,50,51)$.

\subsubsection{Células-tronco mesenquimais pulpares}

A formação dos tecidos dentais, precedido pelo desenvolvimento do dente na vida intra-uterina inicia-se através de estímulos moleculares específicos. Na fase intra- 
uterina, a proliferação epitelial ocorre de forma contínua e concomitante à diferenciação das células do epitélio interno do órgão do esmalte em ameloblastos que secretarão posteriormente o esmalte. Anteriormente ao processo de formação do esmalte, as células presentes na periferia da papila dental diferenciam-se em odontoblastos. Estas mesmas células ectomesenquimais indiferenciadas irão se diferenciar em cementoblastos, que depositam a matriz orgânica do cemento. Esse evento ocorre de forma concomitante à diferenciação das células ectomesenquimais do saco dentário em fibroblastos, que sintetizam as fibras e a substância fundamental do ligamento periodontal (52).

Essas células indiferenciadas presentes na polpa e que são responsáveis pelo desenvolvimento dos tecidos dentais foram identificadas como as células-tronco mesenquimais presentes em vários tecidos adultos.

No processo de formação do dente, células da papila dental e do epitélio se interagem e iniciam a morfogênese dental. Esse processo é intermediado pelo estímulo da subpopulação de células mesenquimais para diferenciar em odontoblastos secretores de dentina $(33,53)$.

Gronthos et al. (33), baseados em algumas evidências científicas, iniciaram no final da década de 90 o isolamento de células precursoras estimuladoras de odontoblastos presentes na polpa e evidenciaram que estas células são as mesmas células ectomesenquimais indiferenciadas, também chamadas de células-tronco de polpa dental (DPSC). Eles avaliaram a eficiência clonogênica, a rapidez da proliferação da população de células da polpa dental humana e estas células demonstraram habilidade em formar o complexo dentino-pulpar e foram comparadas com células do estroma da medula óssea, como precursoras de odontoblastos. Em contraste, as células do estroma da medula óssea formaram osso lamelar contendo osteócitos e osteoblastos, circundando tecido vascular fibroso com hematopoese ativa e adipócitos. As células foram transplantadas em ratos imunocomprometidos e geraram estrutura de dentina semelhante aos odontoblastos que circundam o tecido intersticial da polpa.

Os pesquisadores utilizaram células isoladas de tecido pulpar de terceiros molares extraídos e células da medula óssea de voluntários, como controle. As suspensões celulares foram obtidas, estimuladas com fatores de crescimento com posterior avaliação da taxa de crescimento. Este trabalho demonstrou a presença de uma população celular clonogênica na polpa dental e as células presentes em cada 
colônia foram caracterizadas por uma morfologia típica de células fibroblásticas, análogas às células progenitoras presentes na medula óssea. Foi evidenciado também que a frequência de unidades formadoras de colônias presentes na polpa dental (2270 colônias $/ 10^{4}$ placas de células) foi significantemente maior em comparação com as unidades formadoras de colônias da medula óssea (2,4-3,1 colônias/ $10^{4}$ placas de células) e a proliferação de células da polpa dental foi significantemente maior que a proliferação de células da medula óssea. Houve também a diferenciação in vitro das células em adipócitos e a diferenciação das células-tronco em odontoblastos foi realizada in vivo após transplante de células em ratos imunocomprometidos (33).

Gronthos et al (1) promoveram outro estudo para caracterizar a capacidade de autorrenovação, diferenciação em multi-linhagem de células e eficiência clonogênica de células-tronco de polpa dental humana. Neste estudo foi observada a habilidade destas células na formação das estruturas do complexo dentino-pulpar e capacidade de autorrenovação após transplante em ratos imunocomprometidos. Foi observada também a expressão de marcadores específicos para adipócitos e para células neurais. Esses achados ampliaram os limites de desenvolvimento de diferentes linhagens celulares a partir de células-tronco pulpares. Outro estudo subsequente incorporou 0 desenvolvimento de multi-linhagens celulares a partir de células-tronco pulpares com potencial de diferenciação neurogênico, odontogênico, adipogênico, miogênico e condrogênico (54).

\subsubsection{Células-tronco mesenquimais do líquido amniótico:}

As MSCs provenientes do líquido amniótico (AF-MSCs), consideradas MSCs fetais, foram primeiramente isoladas por Tsai et al (43). Os autores isolaram com sucesso MSCs do líquido amniótico no segundo trimestre de gestação. $A$ análise das AF-MSCs por citometria de fluxo apresentou expressão positiva para os marcadores de MSCs e uma subpopulação de células com expressão positiva para Oct-4, que é um fator de transcrição expresso em células-tronco embrionárias indiferenciadas, apresentando similaridade com essas células. As células também foram capazes de se diferenciar em adipócitos, osteócitos e células neurais.

Posteriormente, Sessarego et al (55) expandiram AF-MSCs acima de 6 passagens usando diferentes condições de cultura para otimizar a produção de AF- 
MSCs em larga escala, resultando em uma população celular homogênea, com propriedades imunossupressivas e grande potencial de proliferação. As células não apresentaram anormalidades ou potencial de transformação in vitro na análise do cariótipo e na análise in vivo, após a administração de AF-MSCs via intravenosa e subcutânea em ratos (NOD-SCID) e não houve formação de tumor após 3 meses de observação, evidenciando boas perspectivas para aplicação em terapias celulares.

Dessa forma, as AF-MSCs expressam marcadores de células-tronco adultas e embrionárias, caracterizadas como uma fonte de células pluripotentes, de forma similar às células-tronco embrionárias, possuindo capacidade de diferenciação em células das linhagens osteogênica, adipogênica, condrogênica, miogênica, endotelial, neuronal e hepática (9). As AF-MSCs são uma fonte de MSCs com grande potencial de aplicação terapêutica, já que, diferentemente das células-tronco embrionárias possuem a vantagem de não possuir efeito teratogênico e de ser capazes de expandir por longos períodos mantendo o comprimento dos telômeros e apresentando um cariótipo cromossômico normal (9).

\subsubsection{Células-tronco mesenquimais do tecido gorduroso:}

Zuk et al (36) isolaram com êxito MSCs provenientes do tecido adiposo subcutâneo (ADSCs), obtidas a partir de procedimento cirúrgico de lipoaspiração. As células expressaram os marcadores positivos para MSCs, assim como marcadores consistentes com o fenótipo neurogênico. Os autores relataram o potencial de diferenciação em multi-linhagem das ADCS, assim como as BMSCs.

Outras evidências relacionaram a capacidade de diferenciação das ADCSs não apenas em linhagem mesodermal como adipócitos, fibroblastos, miócitos, osteócitos, condrócitos, mas também em células de origem não mesodermal, como neurônios, células pancreáticas endócrinas, hepatócitos, células endoteliais e cardiomiócitos (56). Dessa forma, as ADSCs passaram a ser uma fonte alternativa de células-tronco adultas autólogas, com características semelhantes às BMSCs, podendo ser isoladas em grande quantidade, sob anestesia local e com o mínimo desconforto ao paciente, 
representando um grande interesse em estudos de terapias celulares e engenharia tecidual.

\subsection{MARCADORES IMUNOFENOTÍPICOS E CD90}

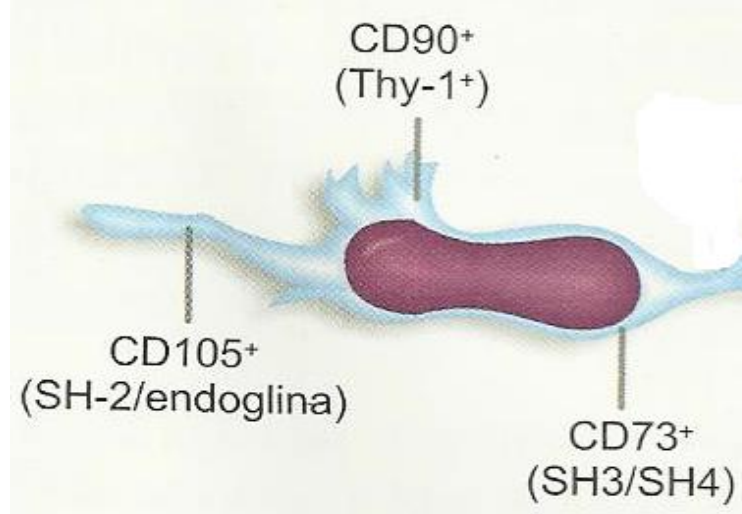

Figura 5 - MSC e seus principais marcadores imunofenotípicos. Fonte: Covas e Zago, 2006. Adaptado.

A identificação das MSCs ocorre por um conjunto de fatores. Além de sua propriedade de aderir à superfície plástica e de formar colônias fibroblásticas e da capacidade de diferenciação nas três linhagens mesodérmicas (osteoblastos, condrócitos e adipócitos), torna-se necessária a determinação da presença e ausência de certos marcadores de superfície celular por citometria de fluxo $(12,57)$.

A caracterização imunofenotípica de MSCs apresenta-se positiva para os marcadores CD90 (Thy-1), CD105 (endoglina, SH2), CD73 (ecto-5' nucleotidase), CD117, CD44, CD166, CD29 e STRO-1 e negativa para os marcadores CD45, CD34, CD31 e CD14. Entretanto, apenas a expressão dos marcadores CD105, CD73 e CD90 associada à ausência de expressão dos marcadores hematopoiéticos: CD45, CD19, CD19 ou CD79, CD14 ou CD11b e HLA-DR é suficiente para a caracterização imunofenotípica das MSCs $(21,22)$.

Atualmente, não há um marcador único para definir as MSCs. No processo de isolamento de MSCs nos distintos tecidos, evidencia-se que apenas a subpopulação de MSCs, diante de outras células que fazem parte dos tecidos, apresenta aderência à superfície plástica e multipotencialidade (58). Esse fato demonstra a necessidade 
de se buscar um marcador ideal e definitivo, mesmo que não seja específico para essas células, mas que seja correlacionado ao estado stemness (59).

Embora CD90 e STRO-1 sejam dois marcadores de superfície celular amplamente utilizados para identificar MSCs, ambos não são específicos para MSCs (60-62). STRO-1 é expresso em uma pequena porcentagem de MSCs e alguns autores discutem a ausência desse marcador em MSCs de algumas fontes $(59,63,64)$, além de não estar claro na literatura se a expressão de STRO-1 é correlacionada ao estado indiferenciado de MSCs. Por outro lado, CD90 possui elevada expressão em MSCs de diferentes fontes e é um bom marcador para Unidades formadoras de colônias (CFU-F) enriquecidas (65).

O estudo de Sibov et al (66) evidenciou um importante resultado em relação ao CD90, correlacionando a elevada expressão de CD90 ao estado indiferenciado de MSCs. Na pesquisa, o decréscimo da expressão do nível de CD90 foi relacionado à diferenciação em linhagens temporais in vitro.

A literatura relata que CD90, ou Thy-1, é uma glicoproteína localizada na superfície celular (25-37 kDa GPI), inicialmente detectado em células T de ratos (67), e posteriormente em membranas de timócitos (precursores de células T no timo), linfócitos T, células natural killer, neurônios, várias células-tronco adultas (mesenquimais, hematopoéticas, pancreáticas, hepáticas), mioblastos, fibroblastos, células de câncer natural, células do carcinoma nasofaríngeo e células de melanoma circulante $(68,69)$. Thy-1 localiza-se no cromossomo 11 q22.3 em humanos $(68,70,71)$ e seu gene é um membro da superfamília de imunoglobulinas de genes e codifica a glicoproteína de superfície de 112 aminoácidos.

Embora CD90 apresenta-se bem conservado entre diferentes espécies, sua função parece variar de acordo com o tipo celular (69). Um exemplo são as células da medula óssea com CD90+ que possuem potencial para gerar genes específicos do fígado in vitro e podem se diferenciar em hepatócitos maduros em fígado adulto in vivo (72).

CD90 possui várias funções relacionadas à maquinaria celular de diversas células adultas. Por exemplo, tem sido reportado na ativação de células T quando expresso nessa linhagem celular (73), desenvolvimento imunológico (74) e também foi capaz de provocar apoptose em timócitos (75-77). 
Quando expresso em células ovarianas cancerosas e células do carcinoma nasofaríngeo, CD90 associado a outros fatores, regulou a tumorigenicidade, sendo considerado um gene de supressão de tumor ovariano em humanos (78) e um gene de supressão de tumor em carcinoma nasofaríngeo (79).

CD90 presente em células endoteliais interage com avß3 (CD51/CD61) expresso em células do melanoma e $\alpha \times \beta 2$ e $\alpha M \beta 2$ em leucócitos. Essas interações promovem a migração de leucócitos e células do melanoma na camada celular endotelial, sugerindo que a sinalização de CD90 é um importante mecanismo para mediação do endotélio ativado e pode ser associado com progressão de tumor e metástase do melanoma, além da função relacionada ao recrutamento e extravasamento de leucócitos $(80,81)$.

Outra função de CD90 é relacionado à proliferação e migração de fibroblasto (82), mediando sinais moleculares e efeitos em múltiplas cascatas de sinalização $(68,81,83)$, além de regular a adesão focal de fibroblastos, organização do citoesqueleto e migração pela modulação da atividade de p190 RhoAP e Rho GTpase (84). Estudos experimentais in vivo demonstraram que em modelos de ratos, a ativação da expressão de CD90 pôde ser observada em inflamação, cicatrização de feridas e desenvolvimento de tumor, comprovando os resultados dos estudos prévios in vitro (85).

Quando esse marcador está presente em monócitos e leucócitos polimorfonucleares tem a função de mediar a ligação para fibroblastos e células endoteliais microvasculares com CD90+ $(80,81)$, bem como regular o extravasamento de leucócitos (granulócitos e monócitos) do sangue aos tecidos periféricos e 0 condicionamento do microambiente inflamatório (86). A interação entre CD90 humano expresso em células endoteliais ativadas e o correspondente ligante (Mac-1) em monócitos e células polimorfonucleares tem sido associada com adesão de leucócitos AP endotélio ativado (87).

Outra função importante de CD90 está relacionada à modulação do fenótipo de fibroblasto, relevante na cicatrização de feridas e fibrose. De acordo com Zhou et al (88), a expressão diferencial de CD90 ligada a glycophosphatidylinositol afetou a proliferação e diferenciação de miofibroblastos, que é uma fonte primária de matriz extracelular no desenvolvimento de fibrose pulmonar. Hagood et al (89) confirmaram que a injúria fibrogênica promoveu a perda da expressão de CD90 em fibroblastos do 
pulmão, o que resultou em aumento da fibrogênese. Leis et al (90), também observaram que a expressão de CD90 em fibroblastos humanos decresceu significativamente durante infecção com citomegalovírus (HCMV), sugerindo que essa infecção poderia provocar deslocamento de fibroblastos dos componentes da matriz extracelular e injuriar o vaso e que CD90 também poderia ser um fator contribuinte para patologias celulares induzidas por citomegalovírus. Além disso, CD90 pode ter um papel central na mediação da infectividade de HCMV, acoplando integrina/paxilina, sinalizando o extravasamento de leucócitos e ligando o processo de entrada do vírus à modulação dos sinais da célula do hospedeiro, que leva à replicação viral (91).

Estudos recentes demonstraram a relação de CD90 na oncogênese como candidato a marcador de células-tronco tumorais (CSCs) e fibroblastos associados ao carcinoma. O aumento da expressão de CD90 foi observado em CSC de câncer de fígado (92-94), câncer gástrico (95), câncer de colo (96), fibroblastos associados ao câncer de próstata $(97,98)$, glioma $(99)$, adenocarcinoma pancreático (100).

CD90 também foi apontado como um possível regulador em metástase de câncer via vasos linfáticos, já que foi evidenciada a expressão dessa glicoproteína em vasos linfáticos associado a tumor. Além disso, a adesão de vários tipos celulares do tumor às monocamadas de células endoteliais linfáticas foi reduzida quando CD90 foi bloqueado (101). CD90 também foi enfatizado como uma oportuna ferramenta terapêutica contra células-B do linfoma. Foi evidenciada a expressão de CD90 nas células B do linfoma e o potencial tratamento com anticorpos contra essa malignidade, já que o anticorpo anti-Thy-1 inibiu a proliferação dessas células com mais eficácia e especificidade, quando comparado com a terapia de uso corrente através da $\mathrm{Ab}$ rituximab (102).

Já os neurônios que não expressavam CD90 em sítios específicos da membrana, tiveram inibição do crescimento de neuritos em astrócitos maduros, mas não em células de Schwan ou células embriônicas da glia. Esse dado sugeriu que CD90 estabilizaria sinapses neuronais além de bloquear o reparo neuronal após injúrias, em regiões do cérebro ricas em astrócitos (103). Essa glicoproteína possui também uma importante função na regulação de neurotransmissores nas sinapses (104), além de interagir com a integrina $\beta 3$ promovendo adesão focal de astrócitos (105). O bloqueio de CD90 em ratos evidenciou a importância dessa proteína em 
funções neurológicas e imunológicas e na remodelação de tecidos em resposta à injúria $(103,106)$.

Em relação à função de CD90 em MSCs, que foi o objetivo deste trabalho, Campioni et al (107) mostraram que o estímulo angiogênico em MSCs da medula óssea (BMSC) gerou a perda de expressão de CD90 in vitro. E ao estudarem o decréscimo da positividade de CD90 em MSC em relação à imunossupressão, Campioni et al (108) evidenciaram que a expressão de CD90 reduzida em MSCs foi associada à perda da atividade imunossupressiva das MSCs. Os autores consideraram CD90 um novo marcador preditivo para a habilidade inibitória de BMSC, podendo auxiliar a molécula HLA-G em regular propriedades estimulatórias versus supressivas das BMSCs.

Mesmo havendo um aumento no número de estudos sugerindo a participação de CD90 na proliferação e diferenciação de MSCs (109), a função desse marcador na biologia de MSCs ainda é desconhecida, mas sugere-se que esteja envolvido em adesão, proliferação e migração e sua descoberta poderia facilitar a manipulação das células in vitro para terapias celulares.

\subsection{INATIVAÇÃO GÊNICA E LENTIVÍRUS}

As técnicas de inativação genética tiveram início a partir da década de setenta com a difusão da tecnologia do DNA recombinante. Essa técnica utilizava vetores de clonagem (plasmídios e genomas virais) que permitiram, desde então, o corte do DNA para inserção de genes exógenos. Dessa forma, o gene de interesse passou a ser inserido na molécula de DNA ou RNA do vetor e posteriormente transferido para células ou organismos vivos (110).

Na tecnologia do DNA recombinante, tanto a estabilidade no processamento transcricional e pós-transcricional, quanto a síntese e secreção proteicas devem corroborar para a expressão eficiente de genes exógenos. Dessa forma, o uso dos vetores virais, dentre várias metodologias utilizadas, é uma das técnicas de transferência gênica mais eficaz quanto à expressão gênica e utiliza em sua maioria retrovírus, adenovírus e vírus adeno-associados (111-114).

Após o processo de integração do DNA do vetor no genoma celular, o nível e o tempo de expressão do gene de interesse dependerão do promotor utilizado no vetor 
e a integração do DNA exógeno no genoma celular acontece de forma randômica, o que altera a variabilidade clonal em relação ao nível e estabilidade de expressão (112). Isso evidencia a necessidade da escolha precisa do vetor, e deve-se observar a geração e o envelope do vetor, bem como o tipo de promotor utilizado (113).

A maioria dos estudos de transferência gênica em ensaios de terapia gênica pré-clínicos e clínicos utilizam vetores oncoretrovirais baseados no vírus da leucemia murina de Moloney (MoMLV) para estabilidade de transferência gênica para célulastronco hematopoiéticas. A desvantagem do uso desses vetores encontra-se na necessidade de marcar a divisão celular para a transdução. Já o uso de vetores lentivirais baseados no vírus da imunodeficiência humana (HIV) é um método eficiente para modificar geneticamente células-tronco humanas, promovendo estabilidade transducional para células em divisão e em não divisão (115). A transdução com o uso de vetores lentivirais apresentou excelentes resultados em MSCs, ao ser comparado com outros métodos, como o uso de adenovírus, transfecção por lipídios e eletroporação $(113,114,116)$.

Outra vantagem é que os vetores lentivirais são integrados no genoma das células hospedeiras, apresentando resistência à supressão epigenética da transcrição, com uma expressão por longo tempo dos transgenes. A atividade promotora interna estabelecida é mantida e a atividade promotora do lentivírus é bloqueada (117)

Uma forma de modificação genética das células pode ser a inativação de genes, com knock-out do gene- alvo, mas demanda tempo maior para a técnica e possui custo elevado.

Outra ferramenta utilizada para a manipulação de genes de células de mamíferos é a tecnologia de RNA interferência (RNAi), um mecanismo de genética reversa pós-transcricional, que promove a perda da função do gene específico e impede a tradução dos transcritos do RNA mensageiro (RNAm) em proteínas (118)

O mecanismo de RNAi surgiu posteriormente aos avanços da tecnologia do DNA recombinante e permitiu analisar a função da proteína bloqueada em células, tecidos e organismos inteiros. As duas técnicas podem ser associadas, na medida em que o gene que contém o RNA interferente pode ser inserido no genoma da célulaalvo, pelo mecanismo de DNA recombinante. Vetores retrovirais são eficientes e podem expressar shRNAs estáveis em células primárias e transformadas. 
$\mathrm{Na}$ RNAi, pequenas moléculas de RNA dupla-fita, conhecidas como short interfering RNAs (siRNA) são intermediárias nesse processo, reconhecendo seu homólogo RNAm, o que provoca sua degradação. No citoplasma celular, o RNA dupla-fita é clivado por uma endoribonuclease (dicer) em fragmentos de nucleotídeos que se associam às proteínas celulares (119).

Entretanto, o silenciamento gênico por siRNA em células de mamíferos ocorre em breves períodos de tempo, dependendo da concentração de siRNA, da meia vida do alvo e da proliferação das células (120). Existe um grande desafio na entrega das moléculas de siRNA aos tecidos e órgãos de interesse, porque o siRNA pode ser facilmente eliminado no organismo pelas RNAses após injeção intravenosa quando não for associado a outras moléculas e também pode estimular a resposta imune por receptores específicos (TLRs) (121).

Já a transdução das células alvo com vetores virais que carreiam cassetes para a expressão de determinados shRNA possuem a grande vantagem em relação ao siRNA devido à dificuldade de serem degradados pelas RNAses e maior facilidade para produzir silenciamento eficiente e estável da expressão gênica. Os promotores mais utilizados para expressar shRNAs são os da polimerase III, shRNA (small nuclear RNA) H1 e U6. Esses promotores apresentam vantagens em gerar elevados níveis de transcritos de RNA não codificantes e possuírem alta atividade em todos os tipos de células (120).

Para o sucesso da técnica de RNAi, deverá ser feita a seleção de clones celulares estáveis, ou seja, aqueles aos quais os genes de interesse foram integrados ao genoma a partir de uma população celular transduzida (Figura 6). Essa seleção é feita pela incorporação de um gene que confere a essas células resistência à determinada substância, geralmente antibióticos específicos. Desse modo, as células que não incorporaram os genes de interesse são, portanto, eliminadas quando expostas à essa substância por um tempo regular, sobrevivendo apenas aquelas linhagens modificadas geneticamente. 


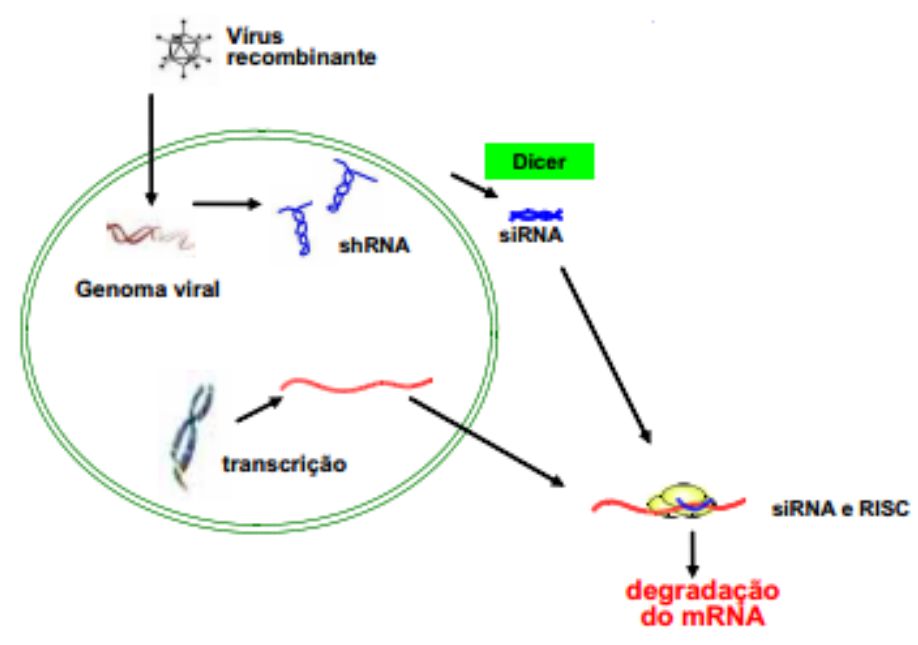

Figura 6 - Transdução celular e mecanismo de RNA interferência. Fonte: Menck, 2007. Adaptado.

\subsection{JUSTIFICATIVA}

Estudos sobre a biologia das MSCs são recentes e as evidências sobre a sua maquinaria celular, bem como a real função da glicoproteína CD90 poderá ampliar o potencial uso terapêutico dessas células e ajudará a elucidar se CD90 afeta os mecanismos de diferenciação e proliferação de MSCs humanas. Dessa forma, as MSCs poderão ser manipuladas com mais segurança, buscando eficácia nos ensaios clínicos de terapias teciduais.

O presente estudo buscou evidenciar a função de CD90 na biologia de MSCs humanas, investigando a relação de CD90 na proliferação, morfologia e diferenciação de MSCs provenientes da polpa dental (DPSC), tecido adiposo (ADSC) e líquido amniótico (AF-MSC).

\subsection{HIPÓTESE}

CD90 está relacionado ao estado indiferenciado de MSCs e não altera a morfologia, proliferação e diferenciação de MSCs, além de inibir a proliferação de linfócitos. 
2 OBJETIVOS 


\section{OBJETIVOS}

\subsection{OBJETIVO GERAL}

Investigar a função de CD90 em MSCs humanas, através do uso da tecnologia de genética reversa (RNA interferência), com a finalidade de desvendar a função desta glicoproteína quanto na biologia de MSCs.

\subsection{OBJETIVOS ESPECÍFICOS}

1. Obter MSCs deficientes na expressão de CD90;

1.1. Determinar o efeito da inibição da expressão de CD90 na proliferação e morfologia das MSCs.

1.2. Determinar o efeito da inibição da expressão de CD90 na diferenciação de MSCs.

1.3. Determinar se há inibição da proliferação de linfócitos na presença de MSCs com expressão de CD90 reduzida. 
3 MÉTODOS 


\section{MÉTODOS}

Delineamento experimental

Fontes teciduais utilizadas

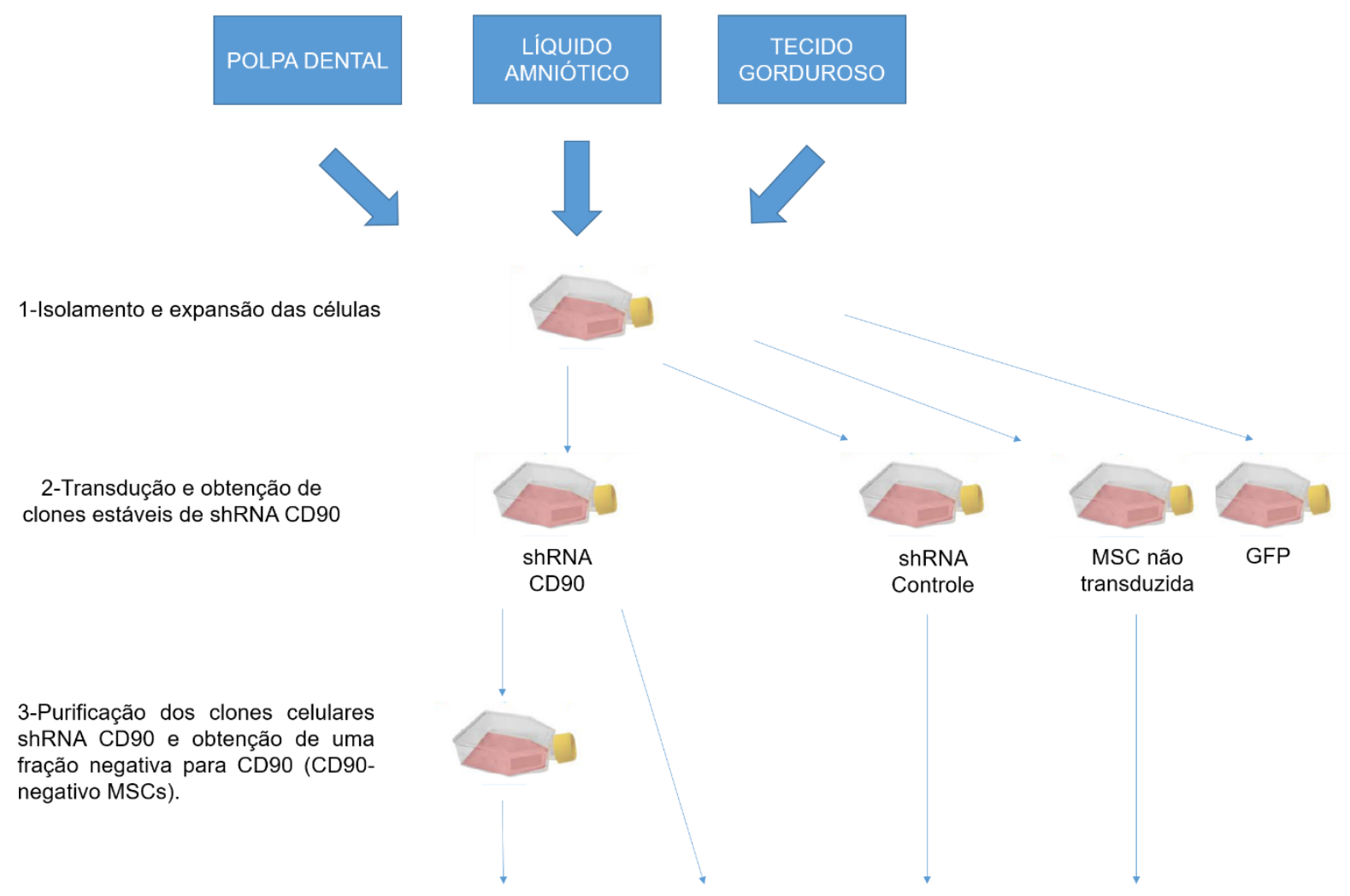

4-Caracterização das células não transduzidas (MSCs), transduzidas (shRNA Controle MSC, shRNA CD90 MSC) e da fração negativa (CD90negativo MSC):

-Citometria de fluxo

-PCR

-Morfologia

-Diferenciação osteogênica e Adipogênica.

Figura 7 - Delineamento experimental do isolamento, purificação e caracterização de MSCs.

\subsection{ISOLAMENTO DE MSCS HUMANAS E CULTURA CELULAR}

As MSCs desse estudo foram utilizadas entre as passagens P3 e P5 e foram isoladas e purificadas como descrito previamente $(33,36,43)$.

As MSCs dos tecidos pulpares foram obtidas a partir de terceiros molares permanentes sob aprovação do Comitê de Ética da Faculdade de Ciências da Saúde 
da Universidade de Brasília (Brasil; CAAE 0020.0.012.000-08 e CAAE 13962813.5.0000.0030). Já as MSCs do tecido gorduroso e do líquido amniótico foram doadas e obtidas sob a aprovação do Comitê de Ética da Universidade de São Paulo.

As células foram descongeladas e expandidas em meio completo: Dulbecco's Modified Eagle's Medium (DMEM-LG, Sigma-Aldrich), suplementado com 10\% de soro bovino fetal (SFB; Gibco), antibiótico-antimicótico $(100 \mu \mathrm{g} / \mathrm{ml}$ de penicilina e estreptomicina e $25 \mu \mathrm{g} / \mathrm{ml}$ de anfotericina B- Gibco) e L-glutamina (10 $\mu \mathrm{l} / \mathrm{ml}-$ Gibco) e mantidas em estufa a $5 \% \mathrm{CO} 2$, a $37^{\circ} \mathrm{C}$.

O meio foi modificado a cada $48 / 72 \mathrm{~h}$ e ao atingir a confluência de $80 \%$, as MSCs foram tripsinizadas (0,25\% tripsina, $4 \mathrm{mM}$ EDTA, Gibco) e ressuspensas em $1 \mathrm{ml}$ de meio completo. Esse volume final foi dividido em 4 frascos de cultura de $75 \mathrm{~cm}^{2}$ e as células estavam na passagem 3. O primeiro frasco de cultura manteve as MSCs que foram as células-controle do experimento, ou seja, as células não transduzidas. O segundo frasco manteve as MSCs que foram transduzidas com vetores lentivirais que carreavam sequências aleatórias de shRNA Controle; o terceiro frasco manteve MSCs que foram transduzidas com vetores lentivirais que carreavam shRNA contra CD90. O último frasco continha MSCs que foram transduzidas com vetores lentivirais que carreavam a proteína verde fluorescente GFP, para evidenciar a eficiência da transdução das MSCs.

\subsection{TRANSDUÇÃO LENTIVIRAL PARA REDUÇÃO DA EXPRESSÃO DE CD90}

Para a transdução lentiviral, MSCs foram cultivadas em frascos de $75 \mathrm{~cm}^{2} \mathrm{em}$ meio completo a $37^{\circ} \mathrm{C}$ e $5 \% \mathrm{CO}_{2}$. Quando as células atingiram $60 \%$ de confluência em passagem 3, foi realizada a transdução em presença de $8 \mu \mathrm{g} / \mathrm{ml}$ de Polibreno (Sigma-Aldrich) de acordo com as instruções do fabricante (Santa Cruz Biotechnology). Partículas lentivirais expressando shRNA CD90 ou expressando sequências aleatórias de shRNA Controle foram adicionadas em frascos de cultura distintos com a multiplicidade de infecção de 10. Em um terceiro frasco de cultura, partículas lentivirais com GFP foram adicionadas para verificar a eficiência da transdução. O último frasco de cultura foi para as células não transduzidas, que foram o controle do experimento. Todos os lentivírus foram obtidos pelo laboratório Santa Cruz Biotecnology (Santa Cruz Biotechnology, INC). O meio foi trocado após 24h e 
após o terceiro dia da transdução, clones estáveis de MSCs expressando shRNA CD90 e shRNA Controle foram selecionados usando $5 \mu \mathrm{g} / \mathrm{ml}$ de Puromicina (SigmaAldrich) por 10 dias. O meio foi trocado a cada 48h. Os clones celulares obtidos que passaram a expressar shRNA CD90 foram chamados de shRNA CD90 MSCs e os clones celulares que passaram a expressar shRNA Controle foram chamados shRNA Controle MSCs.

\subsection{SEPARAÇÃO MAGNÉTICA DE MSC PARA SELEÇÃO NEGATIVA DE CD90}

Considerando a importância para esse estudo da obtenção de uma população de MSCs com expressão de CD90 mais negativa que as células obtidas após a transdução, utilizou-se o método de purificação celular magnética, realizada de acordo com as instruções do fabricante (MiltenyiBiotec). Dessa forma, para isolar a população de MSCs negativa para CD90, MSCs expressando shRNA CD90 (shRNA CD90 MSCs) foram soltas do fundo do frasco de cultura utilizando tripsina-EDTA e em seguida as células foram contadas. A concentração de $10^{7}$ células foi ressuspensa em $80 \mu l$ de solução tampão (PBS contendo $0,5 \%$ de BSA), incubada com $20 \mu$ l de volume de micro-esferas magnéticas acopladas a anti-CD90 (Miltenyi Biotec, Alemanha) por 15 minutos a $4^{\circ} \mathrm{C}$ e posteriormente lavadas. As células foram novamente ressuspensas em $0,5 \mathrm{ml}$ de solução tampão e passadas na coluna magnética. As células com expressão positiva para CD90 foram capturadas pela coluna magnética, sendo posteriormente desprezadas. Já a fração obtida de MSCs negativa para CD90 (CD90-negativo MSCs) foi coletada e cultivada em frasco de cultura de $75 \mathrm{~cm}^{2}$.

O nível de expressão de CD90 nas células CD90-negativeo MSCs após purificação foi testado pela citometria de fluxo (FACSVERSE-BD Biosciences, San Jose, CA) e realizado posteriormente a análise pelo software FlowJo (TreeStar, Ashland, OR, USA).

\subsection{CARACTERIZAÇÃO IMUNOFENOTÍPICA DAS MSCS POR CITOMETRIA DE FLUXO}

A caracterização celular foi realizada para as MSCs do tecido pulpar, do tecido gorduroso e do líquido amniótico. Células na terceira passagem foram descoladas do 
fundo do frasco utilizando-se solução de tripsina-EDTA e plaqueadas em placas de 6 poços numa densidade de $6 \times 10^{4}$ células $/ \mathrm{ml}$. Ao atingirem a confluência de $80 \%$, as células foram soltas da placa usando TrypLE (Invitrogen, Carlsbad, CA) e centrifugadas por $5 \mathrm{~min}$ a $1000 \mathrm{rpm}$. O sobrenadante foi descartado e as células foram incubadas por $30 \mathrm{~min}$ em solução tampão de bloqueio (PBS, $2 \% \mathrm{FBS}$ ) a $4^{\circ} \mathrm{C}$, contendo anticorpos monoclonais contra moléculas de superfície e seus respectivos isótipos controles, em ausência de luz. Os anticorpos usados foram: CD14-FITC; CD29-PE, CD31-PE; CD34-PE; CD44-PE; CD73-PE; CD90-APC; CD90-FITC; CD106-FITC; CD166-PE e CD166-PerPC-Cy5.5 (Biosciences, San Jose, CA); CD45-PerCP-Cy5.5; HLA-DR-PerCP-Cy5.5 (Biosciences, San Jose, CA); e CD105-PE (clone 8E11; Chemicon, Temecula, CA, USA). Mouse IgG1-FITC, IgG1-PE, IgG1 PerCP-Cy5.5, IgG1-APC (Biosciences, San Jose, CA) e IgG2A-FITC (AbDSerotec, UK) foram usados como isótipos controles.

Foram adquiridos 10.000 eventos, utilizando o citômetro de fluxo (CyFlowSpace- Partec, Germany; FACSVERSE-BD e FACSARIA- ambos da BD Biosciences, San Jose, CA) e os dados foram analisados usando o software FlowJo (TreeStar, Ashland, OR).

\subsection{ANÁLISE DA MORFOLOGIA DE MSC}

MSCs não transduzidas e transduzidas em passagem 3 foram plaqueadas em triplicata, em placas de cultura de 24 poços ( $5 \times 10^{4}$ cells/well). Após a concentração celular atingir a confluência de $70 \%$, o meio foi removido e as células foram fixadas em solução de paraformaldeído a $4 \%$ por 15 min à temperatura ambiente. As células foram lavadas em PBS, coradas com o Kit Instant Prov (NewProv, Brasil) de acordo com as recomendações do fabricante e lavadas por 5 vezes com PBS para remover o excesso do corante. Após serem lavadas, $0,5 \mathrm{ml}$ de solução tampão (PBS) foi deixado nos poços e as células foram analisadas e fotografadas ao microscópio invertido Axiovert (Zeiss, Alemanha) com objetiva de 32x e sistema de captura digital.

\subsection{AVALIAÇÃO DA PROLIFERAÇÃO DE MSC APÓS REDUÇÃO DA EXPRESSÃO DE CD90}


Com a finalidade de comparar o potencial proliferativo das células com expressão reduzida de CD90 (CD90-negativo MSC e shRNA CD90 MSC) e células com expressão regular desse marcador (MSC, shRNA Controle MSC), foram plaqueadas $1 \times 10^{5}$ células na terceira passagem de cada condição em frascos de cultura de $75 \mathrm{~cm}^{2}$ em meio completo e mantidas em estufa a $5 \% \mathrm{CO} 2$, a $37^{\circ} \mathrm{C}$.

A cada 48 horas, frascos em triplicata de células não transduzidas e transduzidas foram tripsinizadas e contadas no mesmo horário com um contador automático (2.0 Scepter Millipore) por 11 dias.

\subsection{ANÁLISE DA INIBIÇÃO DA PROLIFERAÇÃO DE LINFÓCITOS}

Células mononucleares de sangue periférico (PBMC) foram isoladas e separadas usando o método standart com Ficoll-Paque PLUS (Amersham Biosciences, Uppsala, Sweden) (122). As PBMCs foram lavadas duas vezes com PBS contendo $0,1 \%$ de albumina humana, posteriormente contadas em um contador automático (2.0 Scepter Millipore) e ressuspensas em solução tampão a uma concentração final de $10^{4} \mathrm{cells} / \mathrm{ml}$. As PBMCs foram marcadas com o éster fluorescente CFSE (CellTrace CFSE dye, Life Technologies), previamente ajustado a uma concentração final de $5 \mu \mathrm{M}$. As células foram incubadas por 10 minutos a $37^{\circ} \mathrm{C}$, em seguida a reação foi interrompida pela adição de RPMI gelado contendo $10 \%$ de SBF e novamente as PBMCs foram incubadas por 5 minutos em ausência de luz. As células foram lavadas por três vezes com 20ml de RPMI a 10\% de SBF e ressuspensas em $1 \mathrm{ml}$ de RPMI. Em uma sucessão imediata, 2x10 4 PBMCs foram cultivados com ou sem $5 \times 10^{4}$ MSCs previamente adicionadas aos poços da placa de 24 , em um volume total de $1 \mathrm{ml}$ por poço de meio RPMI, suplementado com $10 \%$ de SBF, antibiótico-antimicótico e L-glutamina, onde o co-cultivo foi mantido por 5 dias. Para avaliar a taxa de proliferação de linfócitos na presença de MSCs, a suspensão celular foi ativada com estímulo de fitohemaglutinina (lectina da espécie Phaseolus vulgaris) (Sigma-Aldrich), a uma concentração final de $1 \mu \mathrm{g} / \mathrm{ml}$, a $37^{\circ} \mathrm{C}$, com $5 \% \mathrm{CO}_{2}$ por 5 dias para subsequente análise pela citometria de fluxo (CyFlowSpace-Partec, Alemanha). Os dados obtidos foram analisados no softwareFlowJo (TreeStar, Ashland, OR) (122). 


\subsection{ENSAIOS DE DIFERENCIAÇÃO}

Para avaliar o potencial de diferenciação de MSCs, as células foram submetidas a diferenciação osteogênica e adipogênica in vitro, de acordo com protocolos previamente estabelecidos (12).

MSCs transduzidas e não transduzidas em passagem 3 foram plaqueadas em placas de 24 poços, com densidade de $5 \times 10^{4}$ células por poço. Quando a confluência de $80 \%$ foi atingida, o meio regular com os indutores foi adicionado a cada $72 \mathrm{~h}$ por 21 dias. Células cultivadas com meio regular foram utilizadas como controles.

\subsubsection{Diferenciação Osteogênica}

MSCs foram plaqueadas em triplicata em placas de 24 poços, em densidade de $5 \times 10^{4}$ cells $/ \mathrm{cm}^{2}$. Após atingida a confluência celular, as MSCs foram tratadas com meio de cultura completo (DMEM-LG-Sigma-Aldrich, suplementado com 10\% de SFBGibco, antibiótico-antimicótico:100 $\mu \mathrm{g} / \mathrm{ml}$ de penicilina e estreptomicina e $25 \mu \mathrm{g} / \mathrm{ml}$ de anfotericina B-Gibco e L-glutamina:10 $\mu \mathrm{l} / \mathrm{ml}$-Gibco) contendo os indutores osteogênicos: $100 \mathrm{Nm}$ dexametasona (Sigma-Aldrich), $10 \mathrm{mM}$ 2- $\beta$-glicerol-fosfato (Sigma-Aldrich) e 50 $\mathrm{M}$ de ácido ascórbico (Sigma-Aldrich). A diferenciação osteogênica foi avaliada pela atividade de fosfatase alcalina, determinação da concentração de cálcio e pelo método colorimétrico de vermelho de Alizarina.

A formação de matriz mineralizada após a diferenciação osteogênica foi detectada como previamente descrito (12). Amostras foram fixadas com paraformaldeído a $4 \%$ por 15 minutos, lavadas com PBS e coradas por 20 minutos $40 \mathrm{mM}$ de solução de vermelho de Alizarina (Sigma-Aldrich), $\mathrm{pH} 4.2$, a temperatura ambiente. Células foram lavadas 5 vezes com água destilada e posteriormente com PBS para reduzir a coloração inespecífica. Os resultados das amostras foram analisados e fotografados através do microscópio invertido Axiovert (Zeiss, Alemanha). Para determinar a concentração de vermelho de Alizarina, as amostras foram descoloradas com $0,5 \mathrm{ml}$ de cloreto de cetilpiridínio $10 \%$ em solução de fosfato de sódio $10 \mathrm{Mm}, \mathrm{pH} 7.0$, por 15 min à temperatura ambiente. A concentração do corante que evidenciou a presença de matriz osteogênica foi determinada pela mensuração da absorbância a 562nm, usando espectrofotômetro (SpectraMax M2, 
Molecular Devices, USA), comparando os resultados com concentrações conhecidas de vermelho de Alizarina (SpectraMax M2, Molecular Devices,USA). Os resultados foram expressos em porcentagem dos respectivos controles e foram normalizados a $100 \%(123)$.

A atividade da enzima fosfatase alcalina (ALP) foi mensurada pelo método colorimétrico do paranitrofenol, usando o kit Sigmafast $p$-nitrophenyl phosphate (Sigma-Aldrich). Para o ensaio de fosfatase alcalina (ALP), as células foram lavadas com PBS e incubadas em $0,05 \%$ Triton X-100 por 20 minutos à temperatura ambiente, sob agitação. As células foram transferidas para ependorfs de $1,5 \mathrm{ml}$, homogeneizadas em vórtex por 20 segundos, centrifugadas por 15 minutos a $4^{\circ} \mathrm{C} \mathrm{e}$ 2500 RPM e mantidas em gelo por 20 minutos. Alíquotas do lisado celular foram incubadas com substrato de $\mathrm{p}$-Nitrofenol fosfato ( $\mathrm{p}-\mathrm{NF}$ ) a $37^{\circ} \mathrm{C}$ por 30 minutos. A reação foi parada pela adição de $5 \mu \mathrm{l} 1 \mathrm{~N} \mathrm{NaOH}$ e a absorbância foi mensurada a 405 nm usando o espectrofotômetro (SpectraMax M2, Molecular Devices, USA) $(124,125)$. Uma curva padrão de p-NF foi estabelecida para determinar a atividade enzimática. As amostras foram normalizadas e a quantificação de proteínas foi determinada pelo método de Lowry (126).

Também foi feita a análise quantitativa do nível de cálcio nas amostras celulares para evidenciar a diferenciação das células tratadas e não tratadas com os indutores osteogênicos. A concentração de cálcio foi determinada pelo método colorimétrico ortho-cresolftaleínacomplexona (o-CPC) (127). As células foram tripsinizadas, ressuspensas em PBS e expostas à presença do reagente de cálcio contendo: 0,69 mol/l tampão de etanolamina; $0,2 \%$ azida sódio; 0,338 mmol/l 0 cresolftaleína complexona; e $78 \mathrm{mmol} / /$ 8-hidroxinquinolina-13. Os resultados da reação celular foram adquiridos pelo espectrofotômetro (Advia 2400, Siemens) (Laboratório Sabin-DF).

\subsubsection{Diferenciação adipogênica}

Para a indução adipogênica, as células foram plaqueadas em placa de 24 poços à densidade de $5 \times 10^{4}$ cells $/ \mathrm{cm}^{2}$. Ao atingir a confluência de 80 a $90 \%$, as células foram tratadas com meio completo (DMEM-LG-Sigma-Aldrich, suplementado com 
10\% de SFB-Gibco, antibiótico-antimicótico: $100 \mu \mathrm{g} / \mathrm{ml}$ de penicilina e estreptomicina e $25 \mu \mathrm{g} / \mathrm{ml}$ de anfotericina B-Gibco e L-glutamina:10 $\mu \mathrm{l} / \mathrm{ml}$-Gibco), contendo indutores adipogênicos: $5 \mathrm{mg} / \mathrm{ml}$ insulina; $5 \mathrm{mmol}$ indometacina; $1 \mathrm{mmol}$ dexametazona e $0.5 \mathrm{mmol} / \mathrm{l}$ isobutil-1-metil xantina (todos da Sigma-Aldrich) por 21 dias. A metade dos poços de cada placa foi mantida como controle negativo e recebeu apenas meio de cultivo celular sem indutores. Após o período de indução, as células foram fixadas com solução de paraformaldeído 4\% (Vetec) durante 15 minutos, lavadas 2 vezes com água destilada, coradas com solução de óleo vermelho O (Sigma-Aldrich) em etanol a $0,5 \%$ (massa/volume) durante 30 minutos e lavadas para remoção do corante. A formação adipogênica foi monitorada pela marcação citoquímica do óleo vermelho $O$ (Sigma), evidenciando o acúmulo intracelular de lipídeos, visualizados pelo microscópio invertido Axiovert (Zeiss, Alemanha) com objetiva de 20x e sistema de captura digital.

\subsection{ANÁLISE ESTATÍSTICA}

A análise estatística foi realizada usando o programa GraphPad. Para comparar a produção de matriz osteogênica e adipogênica nas diferentes amostras de células (DPSC, AF-MSC e ADSC), os dados quantitativos foram submetidos à análise estatística de variância (ANOVA). Para a análise da quantificação do corante vermelho de Alizarina e quantificação de cálcio foi utilizado o pós-teste de múltipla comparação de Sldak's, com única variância agrupada e com $p<0.05$ considerado estatisticamente significativo. Já para a análise da quantificação de fosfatase alcalina, quantificação do óleo vermelho $\mathrm{O}$ e a quantificação da intensidade de fluorescência advinda da citometria de fluxo, o pós-teste utilizado foi o teste de múltipla comparação de Tukey's, com única variância agrupada e com $p<0.05$ considerado estatisticamente significativo. 
4 RESULTADOS 


\section{RESULTADOS}

\subsection{ANÁLISE DA EFICIÊNCIA DA TRANSDUÇÃO E REDUÇÃO DA EXPRESSÃO DE CD90 EM MSC}

Os vetores lentivirais foram capazes de transduzir as MSCs com eficiência, já que a proteína GFP foi incorporada no material genético da MSC (Figura 8). A transdução foi realizada para reduzir a expressão de CD90 por meio de vetores lentivirais específicos que expressavam três construtos de shRNA CD90. Após a transdução, linhagens celulares estáveis de MSCs expressando shRNA CD90 e shRNA Controle foram obtidas após seleção com antibiótico Puromicina.

Para confirmar a redução da expressão de CD90, MSCs não transduzidas, shRNA CD90 e shRNA Controle foram analisadas pela citometria de fluxo (Figura 9 e 10) e PCR em tempo real (PCR) (Figura 11). Os resultados da citometria de fluxo demonstraram que MSCs não transduzidas e shRNA Controle MSCs apresentaram o mesmo nível de expressão de CD90 (98\%), enquanto shRNA CD90 MSCs apresentaram significativa redução da expressão de CD90 (23\%) (Figura 9 e 10). A PCR confirmou que shRNA CD90 MSCs tiveram efetivamente a redução dos níveis de transcrição de CD90 (Figura 11). Os resultados foram obtidos em triplicata e os níveis reduzidos da expressão de CD90 foram similares para as DPSCs, AF-MSCs e ADSCs.
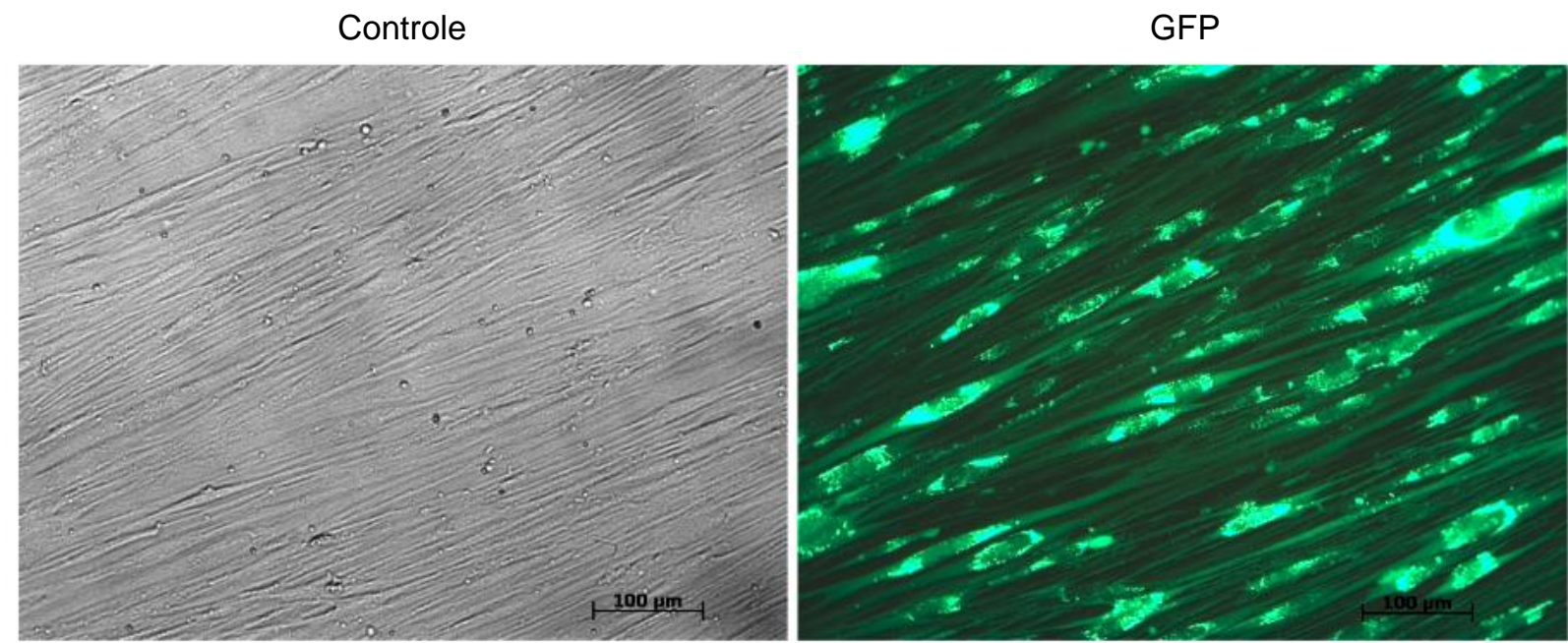

Figura 8 - Eficiência de transdução de MSCs por partículas lentivirais. Expressão de GFP por MSCs 10 dias após a transdução. Microscopia de fluorescência aumento de 200X. * (3 experimentos independentes) $n=3$. 


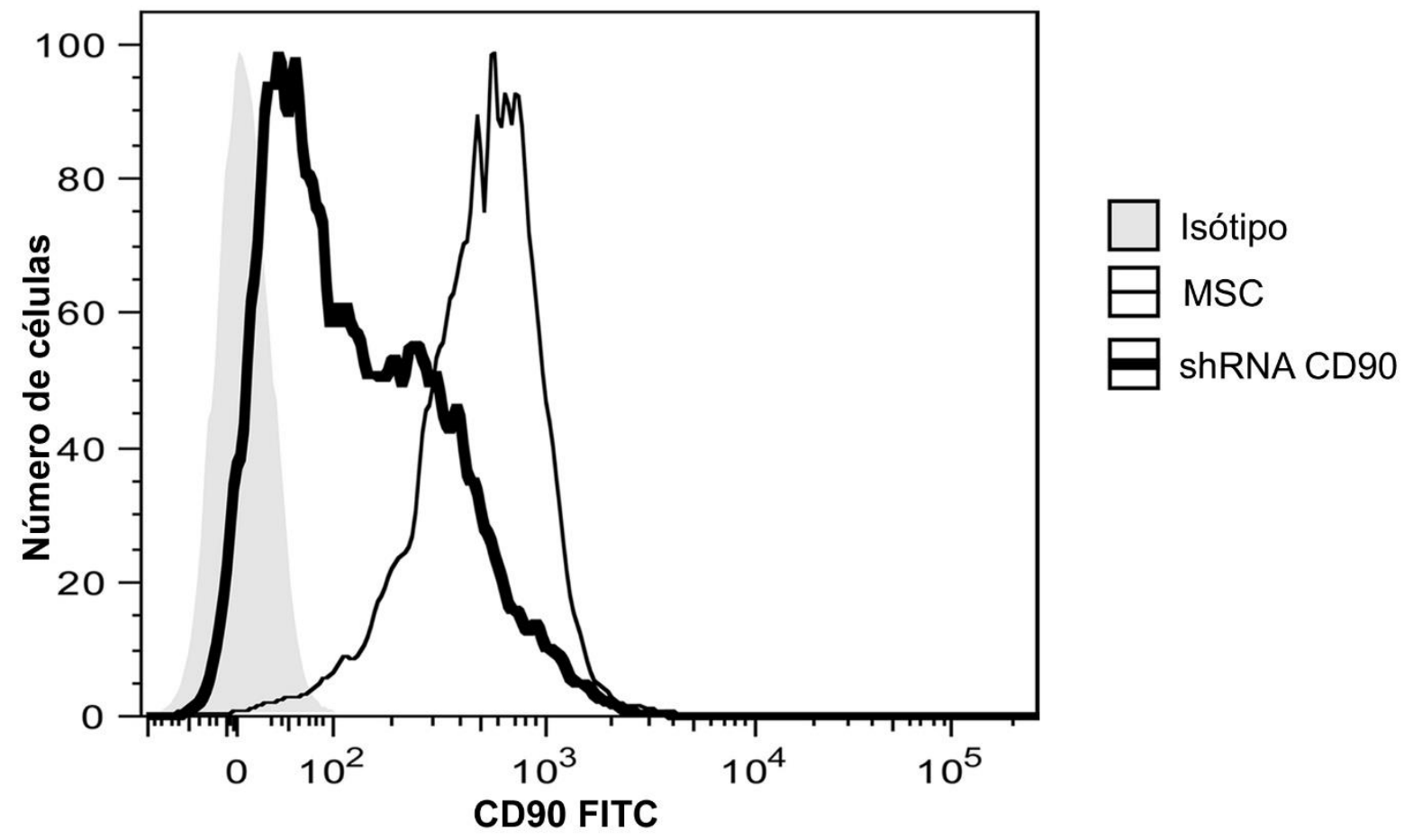

Figura 9 - Análise da expressão de CD90 em MSC e shRNA CD90 MSC por citometria de fluxo. Acentuado decréscimo da expressão de CD90 observado em shRNA CD90 MSC (linha mais espessa), enquanto MSCs não transduzidas (linha mais fina) expressam elevados níveis de CD90. O histograma cinza representa o isótipo controle. Histograma representativo de DPSCs.

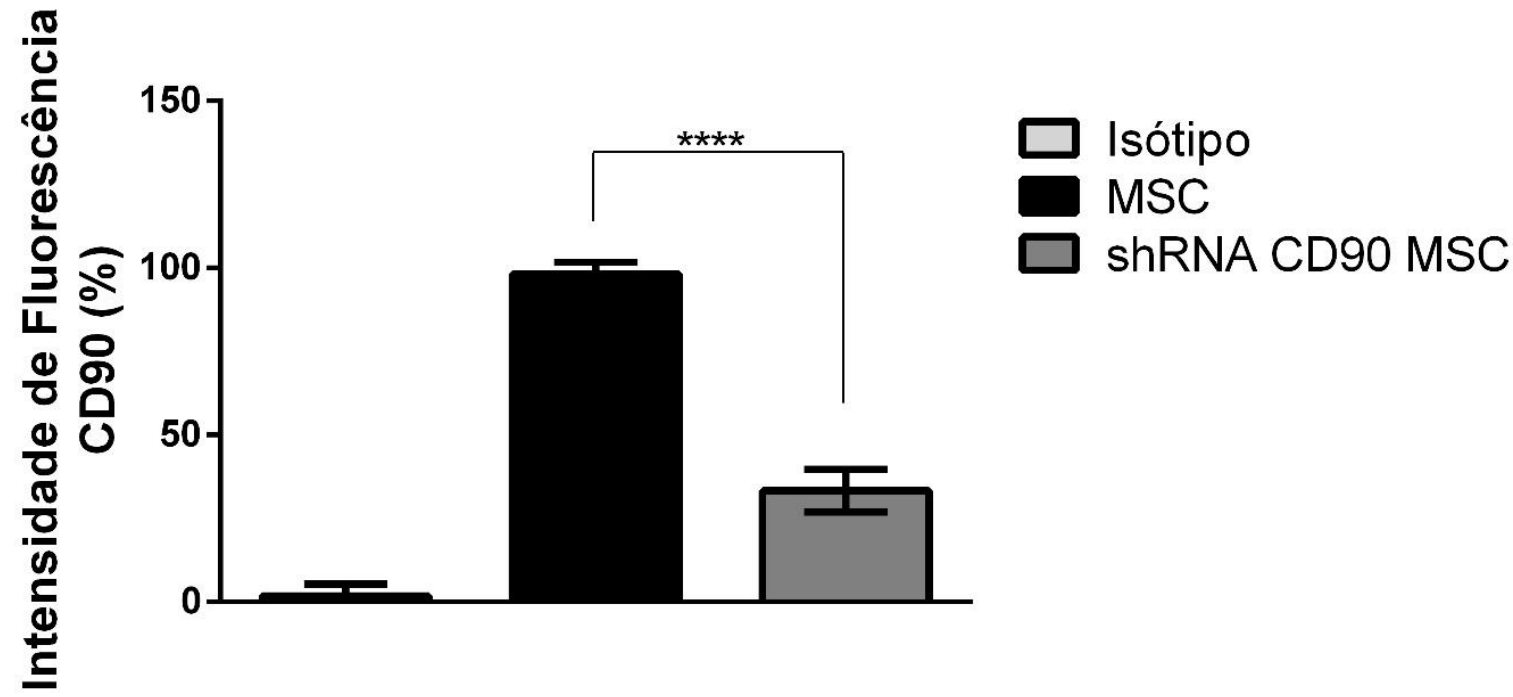

Figura 10 - Análise da intensidade de fluorescência de CD90 em MSC e shRNA CD90. $\left(^{* * \star}\right)$ Houve diferença estatística significativa no decréscimo da intensidade de fluorescência de CD90 (MFI) em shRNA CD90 quando comparada com MSCs não transduzidas (MFI=MFI do marcador - MFI do isótipo). Gráfico de barras representa média de intensidade de fluorescência de CD90-FITC nas linhagens celulares utilizadas nesse trabalho. $n=7 .{ }^{* * * *} p<0.001$. Gráfico representativo de média de fluorescência de DPSC, AF-MSC, ADSC. 


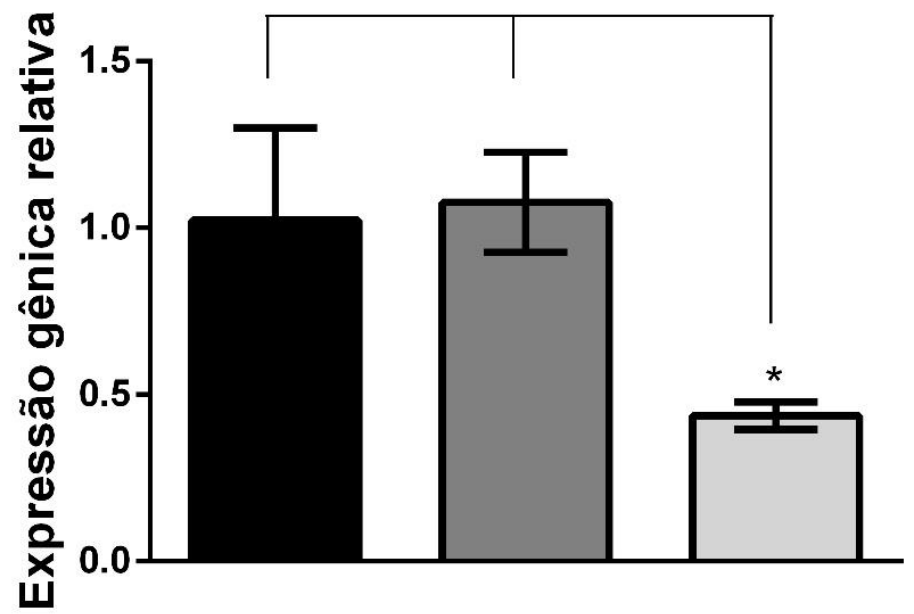

MSC

shRNA Controle MSC shRNA CD90 MSC

Figura 11 - Nível de expressão relativa de mRNA em MSC, shRNA Controle MSC e shRNA CD90 MSC. Linhagens celulares de shRNA CD90 apresentou de forma consistente baixa expressão de CD90. $\left({ }^{*}\right)$ Houve diferença estatística significativa entre as médias dos grupos MSC e shRNA Controle MSC em comparação às do grupo shRNA CD90 MSC. Os experimentos foram realizados em triplicata. ${ }^{*} p<0.05$.

\subsection{SELEÇÃO NEGATIVA PARA CD90 NAS SHRNA CD90 MSCS}

Após a transdução celular foi observado que a expressão de CD90 reduziu significativamente, mas não totalmente. Dessa forma, as amostras de células shRNA CD90 MSCs foram submetidas à separação magnética, coletando em seguida a fração mais negativa para CD90 (CD90-negativo MSCs). As amostras de CD90negativo MSCs foram caracterizadas pela citometria de fluxo para evidenciar o sucesso da purificação, confirmando que CD90-negativo MSCs passaram a expressar níveis extremamente baixos de CD90 quando comparados com shRNA CD90 MSCs (Figura 12 e 13). 


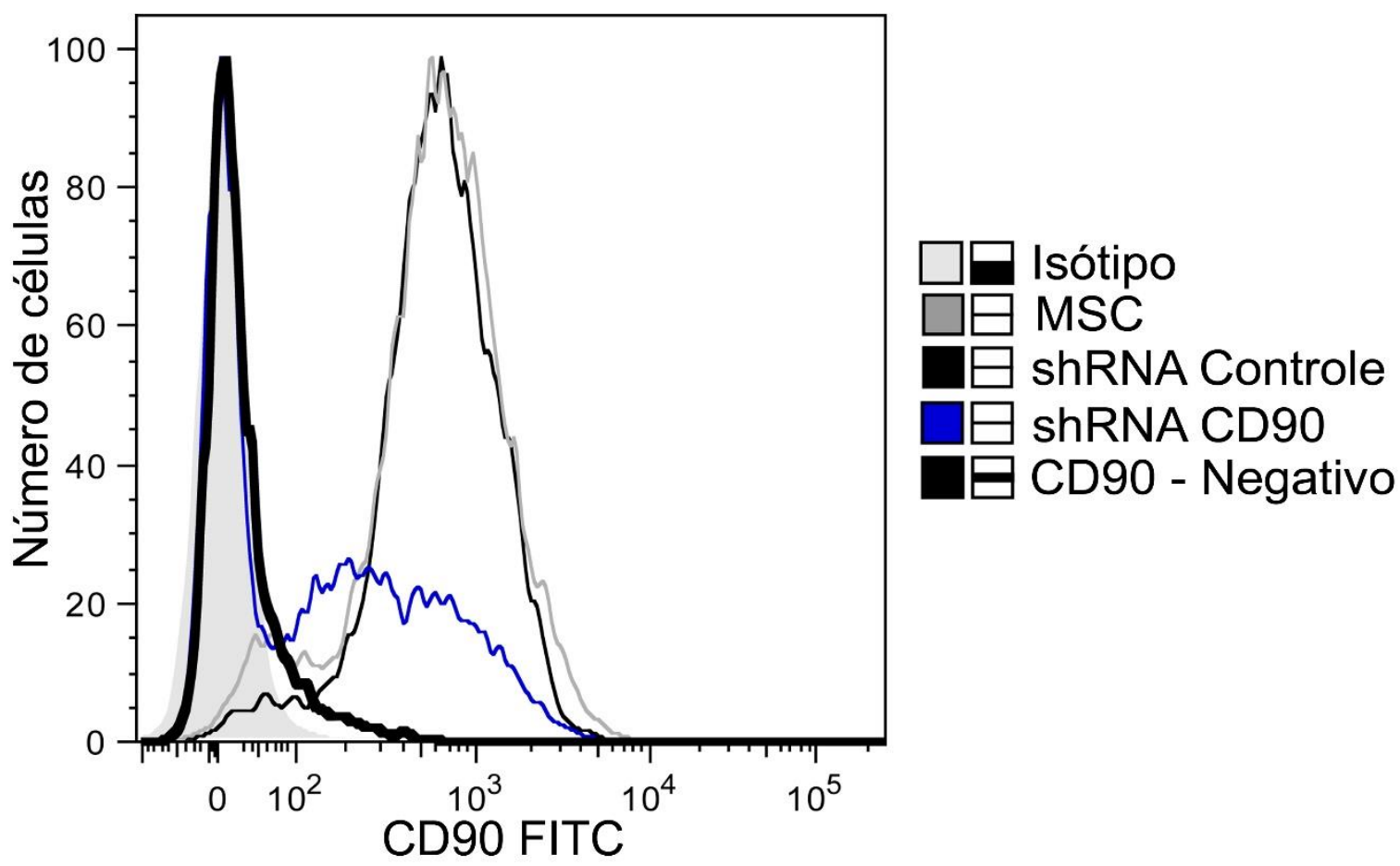

Figura 12 - Seleção negativa de shRNA CD90 MSCs. População de MSCs com expressão negativa para CD90 (CD90-negativo MSCs), evidenciando um nível reduzido de expressão de CD90.
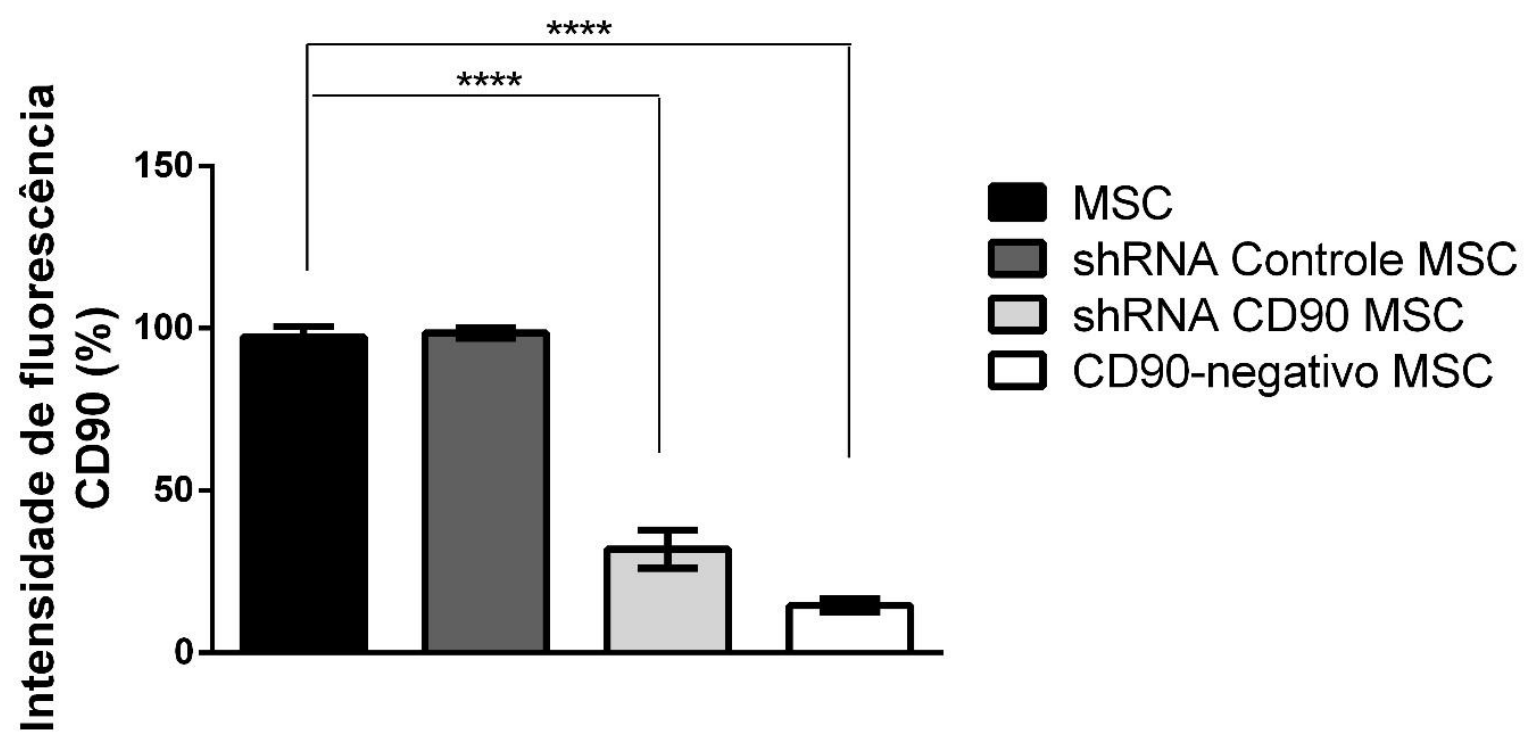

Figura 13 - Análise da intensidade de fluorescência (MFI) do marcador CD90 (MFI=MFI do marcador-MFI do isótipo) nas células. ${ }^{* * * *}$ ) Houve diferença estatística significativa na média de intensidade de fluorescência entre MSC e shRNA Controle MSC quando comparado com shRNA CD90 MSC e CD90-negativo MSC. ${ }^{* \star \star *} p<0.001(n=7$, experimentos independentes com MSCs derivadas de 7 doadores: ) 


\subsection{ENSAIO DE MORFOLOGIA E PROLIFERAÇÃO}

$\mathrm{Na}$ análise de morfologia celular, observamos que não existem diferenças entre a shRNA Controle MSCs, shRNA CD90 MSCs e MSCs não transduzidas (Figura 14). As células shRNA CD90 MSCs apresentaram características de morfologia semelhante a fibroblasto, sem alterar suas características após a transdução. Nós também observamos que shRNA CD90 MSCs mantiveram sua capacidade de formar colônias acima de 10 passagens, sugerindo que CD90 não é envolvido na manutenção da morfologia e capacidade de formação de colônias das MSCs.

Para evidenciar se CD90 exercia alguma função na taxa de proliferação de MSCs, uma curva de crescimento para MSCs não transduzidas, shRNA Controle e shRNA CD90 foi realizada, com as células na passagem 5 . A análise da área sob a curva de proliferação não evidenciou diferença significativa entre a taxa de proliferação das células (Figura 15). A viabilidade celular (preservação de estruturas/propriedades celulares) foi avaliada pelo ensaio de Azul de Tripan, sem apresentar diferenças entre as células transduzidas e não transduzidas. 
MSC

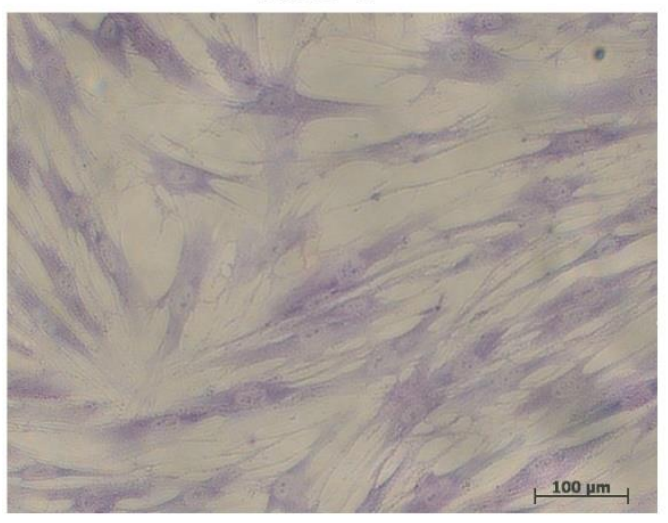

shRNA CD90

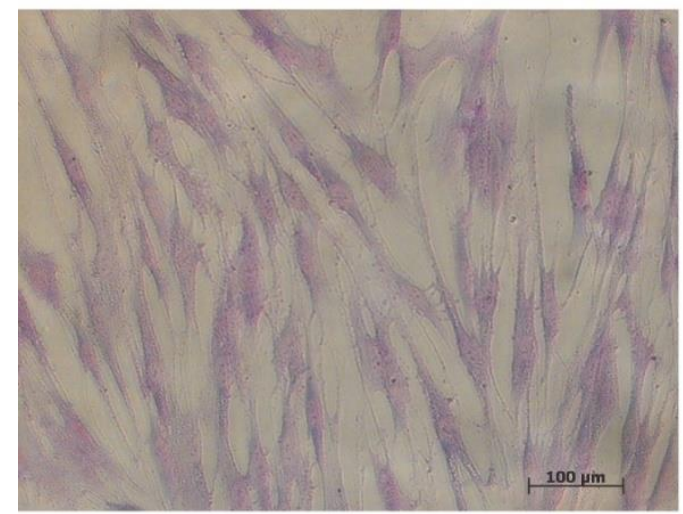

shRNA Controle

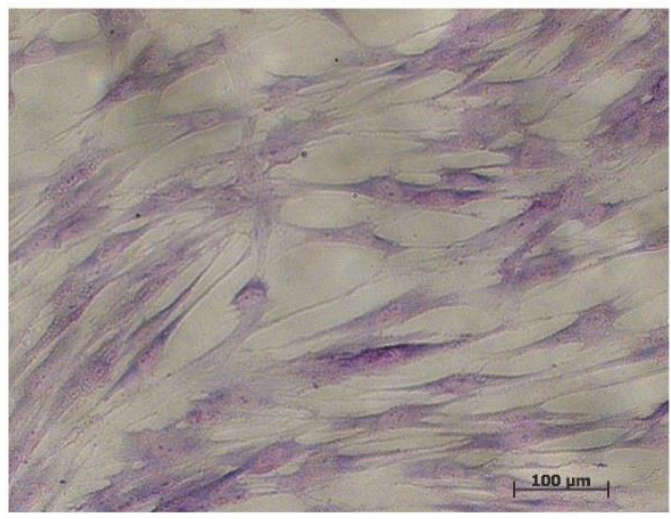

CD90-Negativo

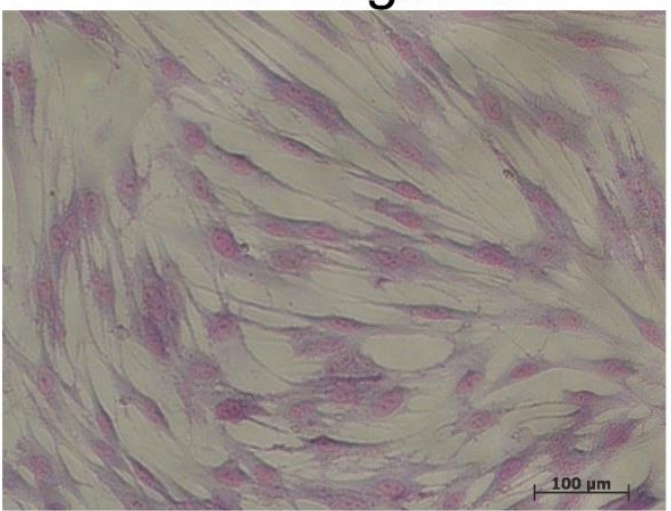

Figura 14 DPSCs coradas com corante panóptico. Imagens representativas das MSCs por microscopia de contraste de fases. As imagens apresentadas foram realizadas em 3 experimentos independentes para DPSC, AF-MSC e ADSC. MSCs, shControle MSCs, shRNA CD90 MSCs e CD90negativo MSCs apresentaram morfologia fibroblastóide similar. (100X) $(n=7)$.

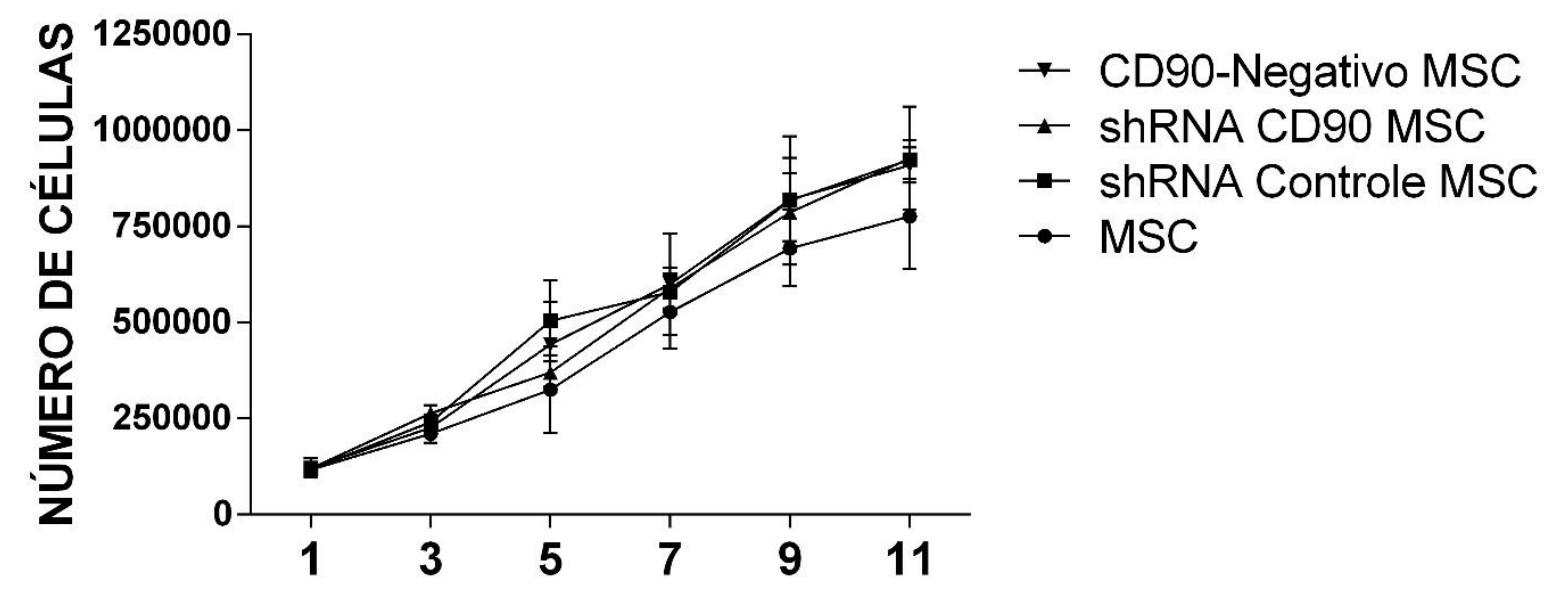

Figura 15 - Proliferação de DPSCs. Curva de proliferação de MSCs não-transduzidas, shRNA Control MSCs e shRNA CD90 MSCs, apresentando similaridade na proliferação, sem diferenças estatísticas. O ensaio foi realizado em triplicata, com dois experimentos independentes. Barra de escala $-100 \mu m(p \geq 0.05)$. 


\subsection{ANÁLISE DE PROLIFERAÇÃO DE LINFÓCITOS}

Nós investigamos se a expressão de CD90 em MSCs pode afetar o efeito inibitório de MSCs em linfócitos estimulados nas células MSCs, shRNA Controle MSC, shRNA CD90 MSC e CD90-negativo MSC (Figura 16). Os resultados mostraram que os linfócitos marcados com CFSE (marcador citoplasmático) apresentaram uma "diluição" desse marcador e consequente redução da intensidade de fluorescência (linha preta espessa). Já os linfócitos marcados e não ativados (linha cinza) representam o controle negativo. Os grupos experimentais referem-se aos linfócitos ativados, co-cultivados com células não-tranduzidas (MSC), shRNA Controle MSC, shRNA CD90 MSC e CD90-negativo MSC. Os linfócitos não marcados com CFSE foram utilizados para controle do experimento (histograma cinza). As células CD90negativo MSC e shRNA CD90 MSC suprimiram a proliferação de linfócitos $T$, da mesma forma que as células shRNA Controle MSC e MSC não transduzida (Figura 16 e 17), indicando que a redução da expressão de CD90 não afetou a característica imunossupressiva de MSCs na proliferação de linfócitos. As análises também evidenciaram que a ablação de CD90 em MSCs não afetou a porcentagem de célulasT CD8+ (Figura 18).

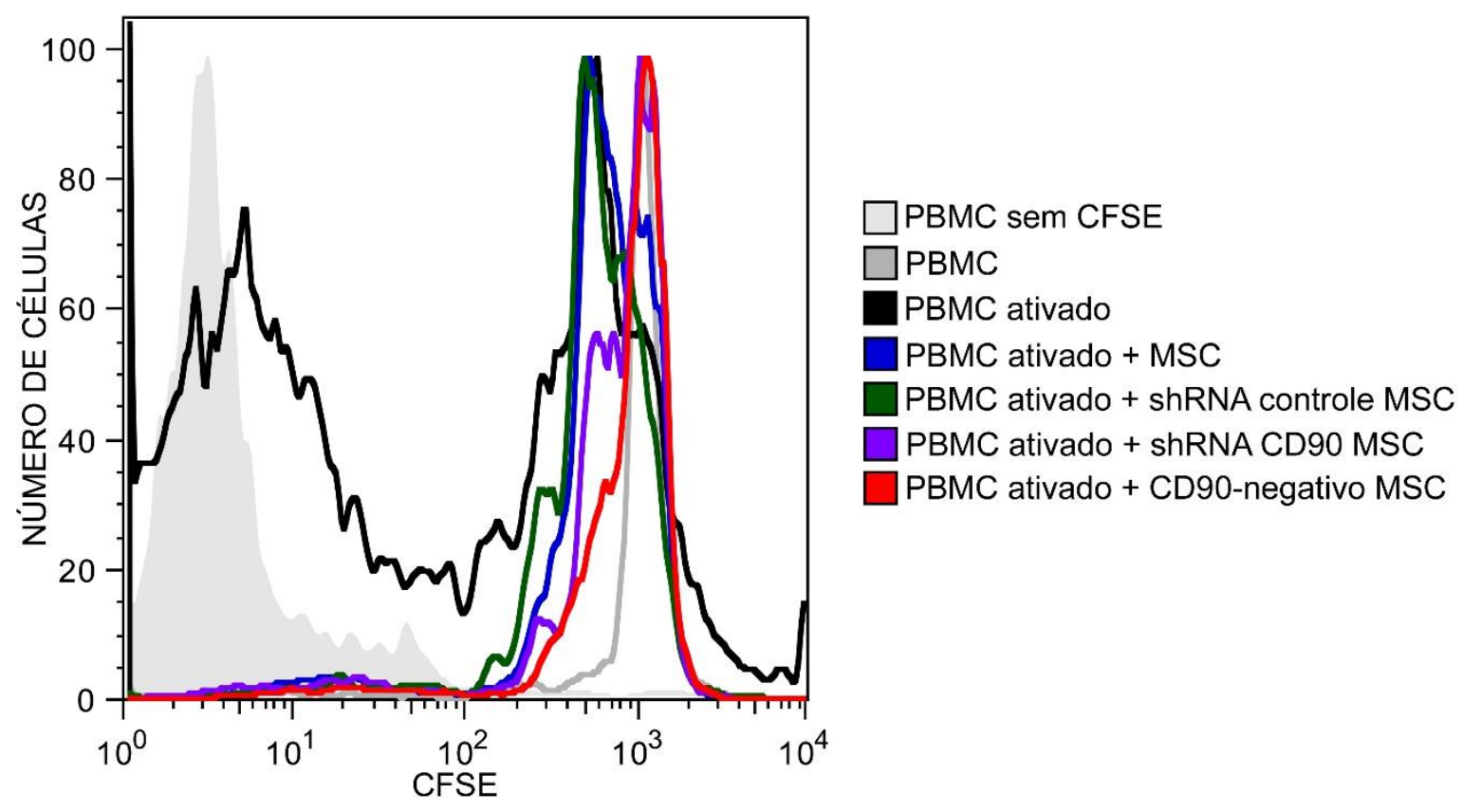

Figura 16 - Ensaio de proliferação de células T.O ensaio foi realizado usando células mononucleares de sangue periférico humano marcadas com CFSE, ativadas com fitohemaglutinina e cocultivadas com ou sem DPSCs e AF-MSCs humanas por 5 dias. Histograma representativo da análise de citometria de fluxo de DPSCs (ensaio realizado em triplicata) das células mononucleares marcadas com CFSE, ativadas com fitohemaglutinina e cocultivadas com ou sem DPSCs. 


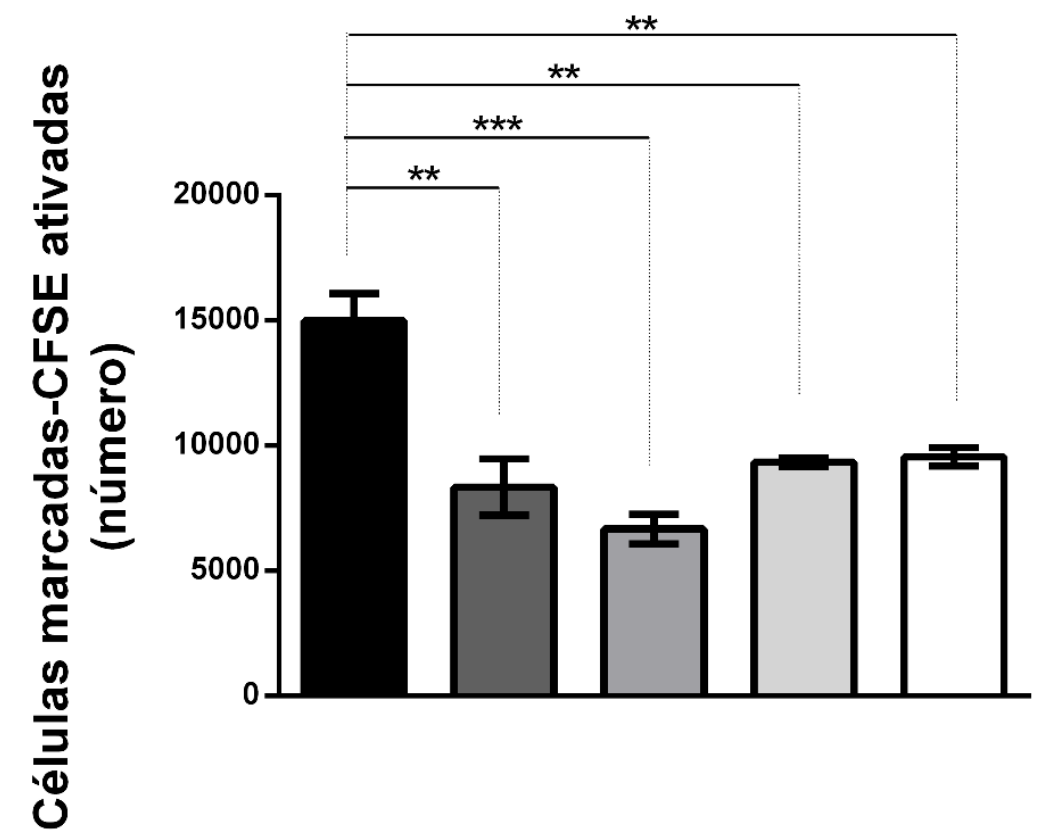

Figura 17 Número de PBMCs ativados com CFSE. Histograma evidenciando a similaridade de proliferação de PBMCs ativadas e coradas com CFSE cocultivadas ou não com MSCs, shRNA Controle, shRNA CD90 e CD90-negativo MSCs. Não há diferença estatística entre as médias das amostras analisadas $p \geq 0.05$.

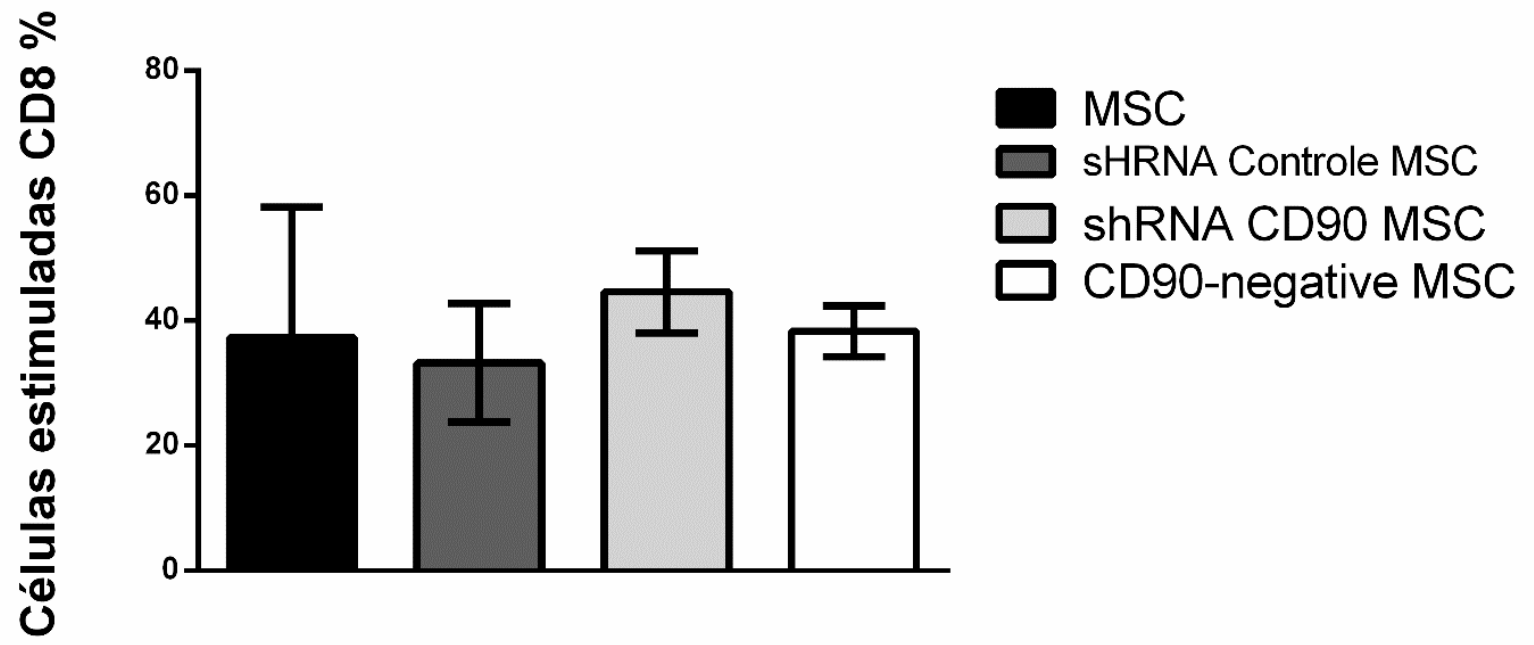

Figura 18 - Porcentagem de proliferação de células T expressando CD8. Gráfico represenativo de porcentagem de proliferação de célulasT CD8+, marcadas com CFSE cocultivadas ou não com MSCs, shRNA Controle, shRNA CD90 e CD90-negativo MSCs. Não há diferença estatística entre as médias $p \geq 0.05$. 


\subsection{CARACTERIZAÇÃO IMUNOFENOTÍPICA POR CITOMETRIA DE FLUXO}

As células não transduzidas (MSCs), as shRNA Controle MSCs e as shRNA CD90 MSCs foram analisadas quanto à expressão de marcadores imunofenotípicos para MSCs (Figura 19). Como esperado, tanto as MSCs, quanto as shRNA Controle MSCs e shRNA CD90 MSCs foram negativas para a expressão dos seguintes marcadores: CD14, CD31, CD34, CD45, CD106 e HLA-DR; e positivas para a expressão de CD29, CD73 e CD105. Ao observar a expressão de CD44 e CD166, o resultado evidenciou de forma inesperada a redução da expressão desses marcadores, sugerindo que a redução da expressão de CD90 levou a redução da expressão de CD44 e CD166 (Figura 20, 21 e 22) em MSCs do tecido pulpar, do tecido gorduroso e do líquido amniótico. Foi realizada também a análise da média de intensidade de fluorescência de amostras de DPSC, AF-MSC e ADSC dos marcadores expressos e não expressos em MSCs (Tabela 1). 

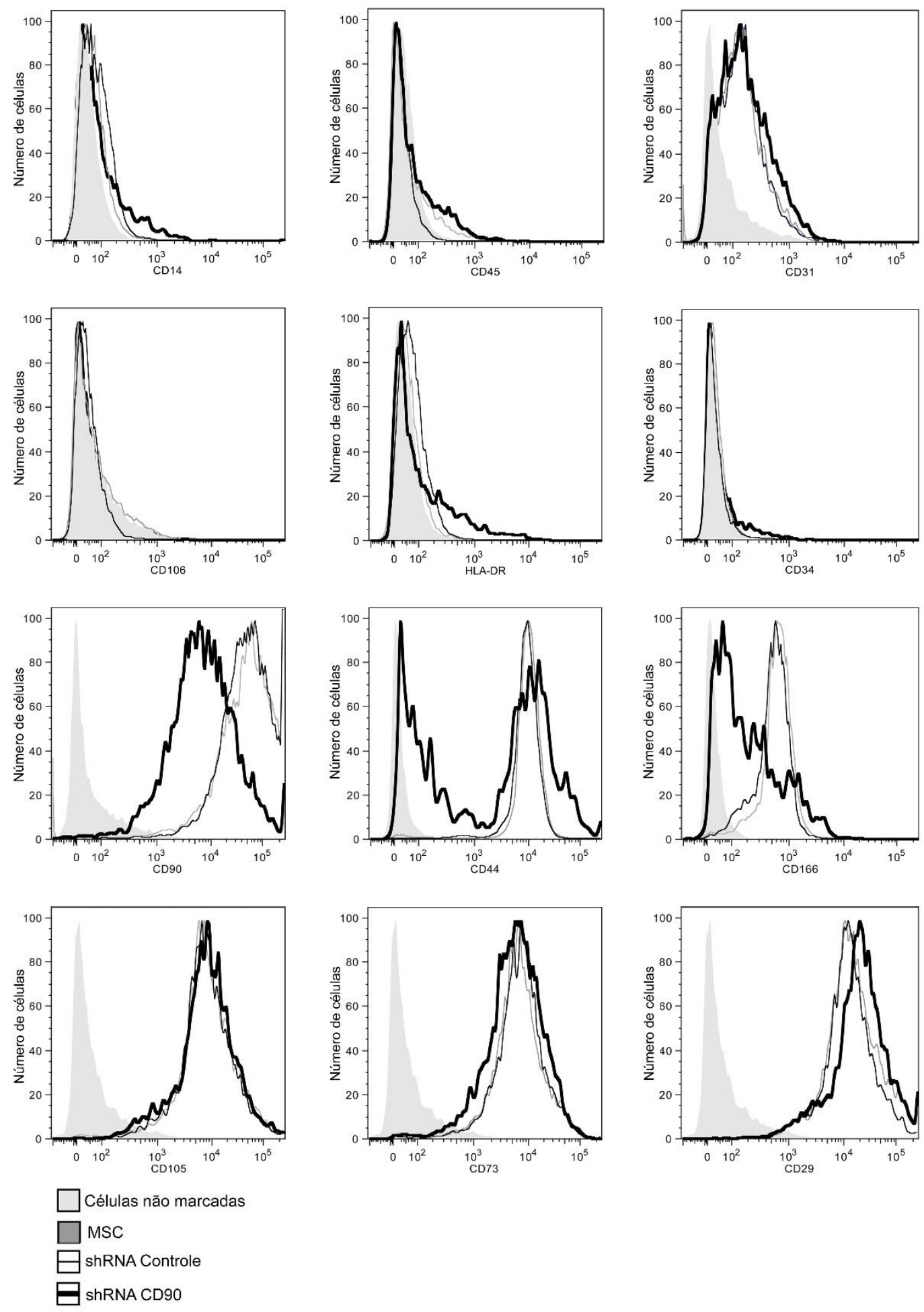

Figura 19 - Imunofenotipagem de DPSC, AF-MSC e ADSC por citometria de fluxo. As MSCs e shRNA Controle MSC das três fontes predominantemente expressavam CD90, CD44, CD166, CD105, CD73 e CD29 e quase não expressavam CD14, CD45, CD31, CD106, HLA-DR e CD34. Histograma representativo de DPSC. As shRNA CD90 MSCs das três fontes apresentaram redução da expressão de CD90, CD44 e CD166. 


\begin{tabular}{ccccc}
\hline MSC (\%) & $\begin{array}{c}\text { shRNA Control } \\
\text { MSC (\%) }\end{array}$ & $\begin{array}{c}\text { shRNA CD90 } \\
\text { MSC (\%) }\end{array}$ & $\begin{array}{c}\text { CD90-Negative } \\
\text { MSC (\%) }\end{array}$ \\
CD14 & $3,30 \pm 0,85$ & $3,8 \pm 1,27$ & $4,20 \pm 2,9$ & $3,11 \pm 1,74$ \\
CD45 & $1,10 \pm 1,05$ & $0,5 \pm 0,43$ & $0,26 \pm 0,46$ & $0,21 \pm 0,21$ \\
CD31 & $5,93 \pm 3,57$ & $4,8 \pm 5,18$ & $4,00 \pm 3,12$ & $4,43 \pm 2,12$ \\
CD106 & $1,66 \pm 2,88$ & $0 \pm 0$ & $0 \pm 0$ & $0 \pm 0$ \\
HLA-DR & $0 \pm 0$ & $3,53 \pm 3,06$ & $3,7 \pm 3,43$ & $0 \pm 0$ \\
CD34 & $1,58 \pm 2,74$ & $3,70 \pm 3,21$ & $2,76 \pm 1,69$ & $1,76 \pm 0,91$ \\
CD90 & $99,49 \pm 0,61$ & $98,87 \pm 0,36$ & $27,66 \pm 2,6$ & $10,08 \pm 1,57$ \\
CD44 & $99,76 \pm 0,11$ & $99,28 \pm 0,6$ & $67,98 \pm 2,4$ & $60,90 \pm 0,021$ \\
CD166 & $95,48 \pm 2,98$ & $94,35 \pm 1,11$ & $49,67 \pm 1,93$ & $56,87 \pm 2,98$ \\
CD105 & $96,78 \pm 1,86$ & $96,71 \pm 1,86$ & $97,12 \pm 1,12$ & $98,46 \pm 0,65$ \\
CD73 & $98,60 \pm 0,48$ & $98,62 \pm 0,30$ & $98,46 \pm 0,65$ & $98,56 \pm 0,61$ \\
CD29 & $98,97 \pm 0,34$ & $99,26 \pm 0,30$ & $99,40 \pm 0,32$ & $99,35 \pm 0,42$ \\
\hline
\end{tabular}

Tabela 1 Média de intensidade de fluorescência de DPSC, AF-MSC e ADSC para os marcadores positivos para MSC: CD90, CD44, CD166, CD105, CD73, CD29 e para os marcadores negativos para MSC: CD14, CD45, CD31, CD106, HLA-DR e CD34. ( $\mathrm{n}=7)$.
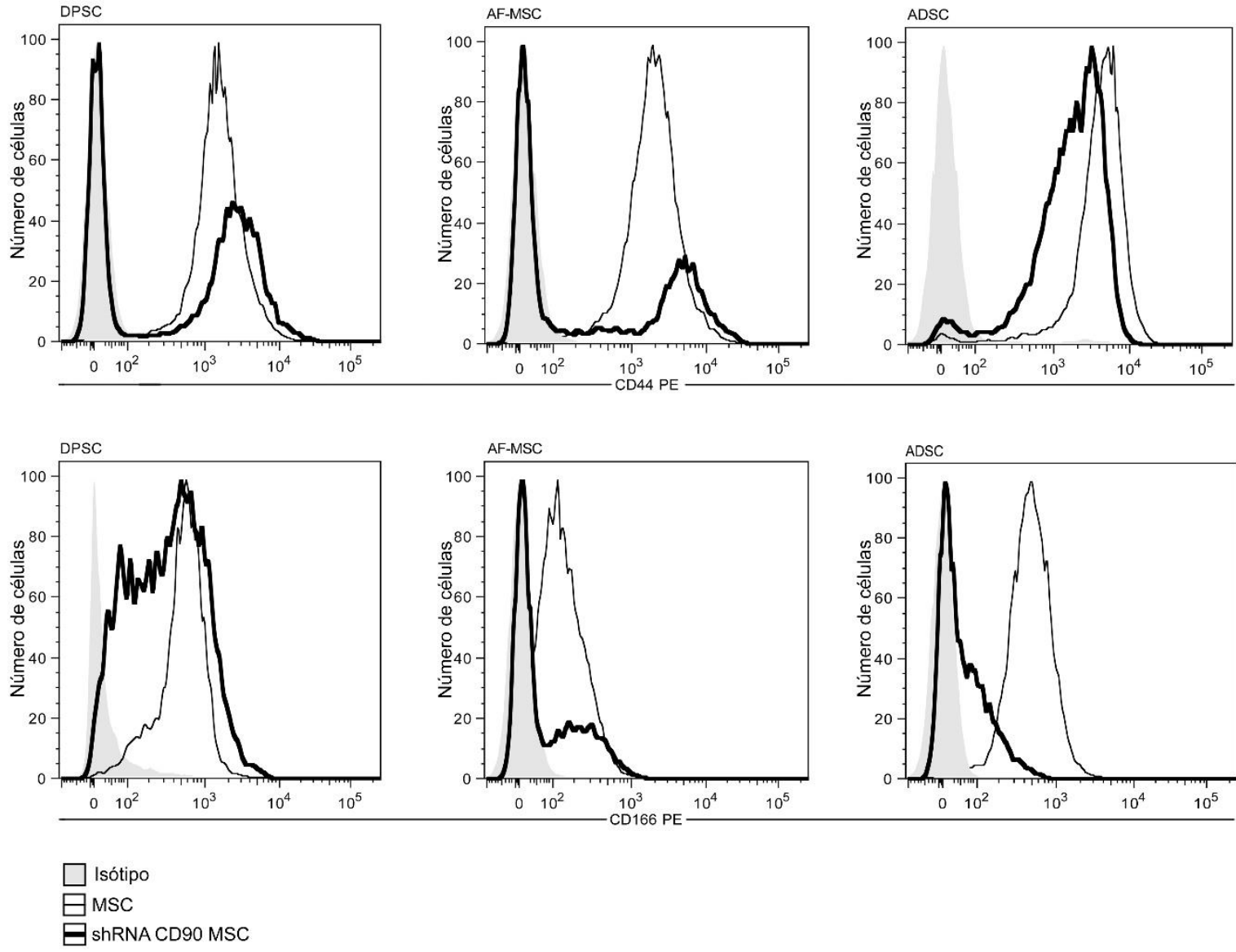

Figura 20 - Expressão de CD44 e CD166 em DPSC, AF-MSC e ADSC. A redução da expressão de CD90 nas células shRNA CD90 MSCs levou a redução da expressão de CD44 e CD166 em MSCs. Um controle isótipo (histograma cinza) foi usado como controle das regiões de fluorescência. As análises representativas foram realizadas em triplicata. 


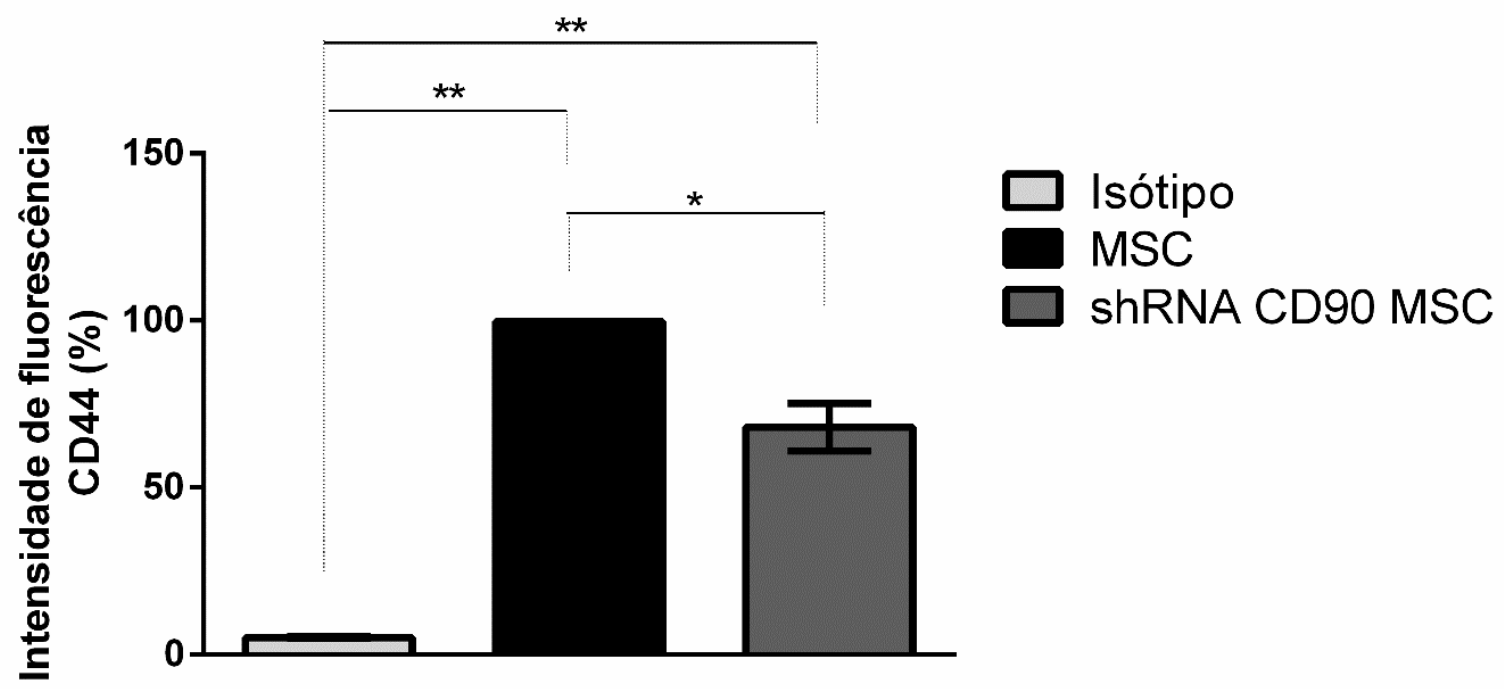

Figura 21 - Análise da média de intensidade de fluorescência de CD44.

$\left({ }^{\star}\right)$ Houve diferença estatística entre as células MSCs e shRNA CD90 MSCs ${ }^{*} p<0.05 ;{ }^{* *} p<0.01$.

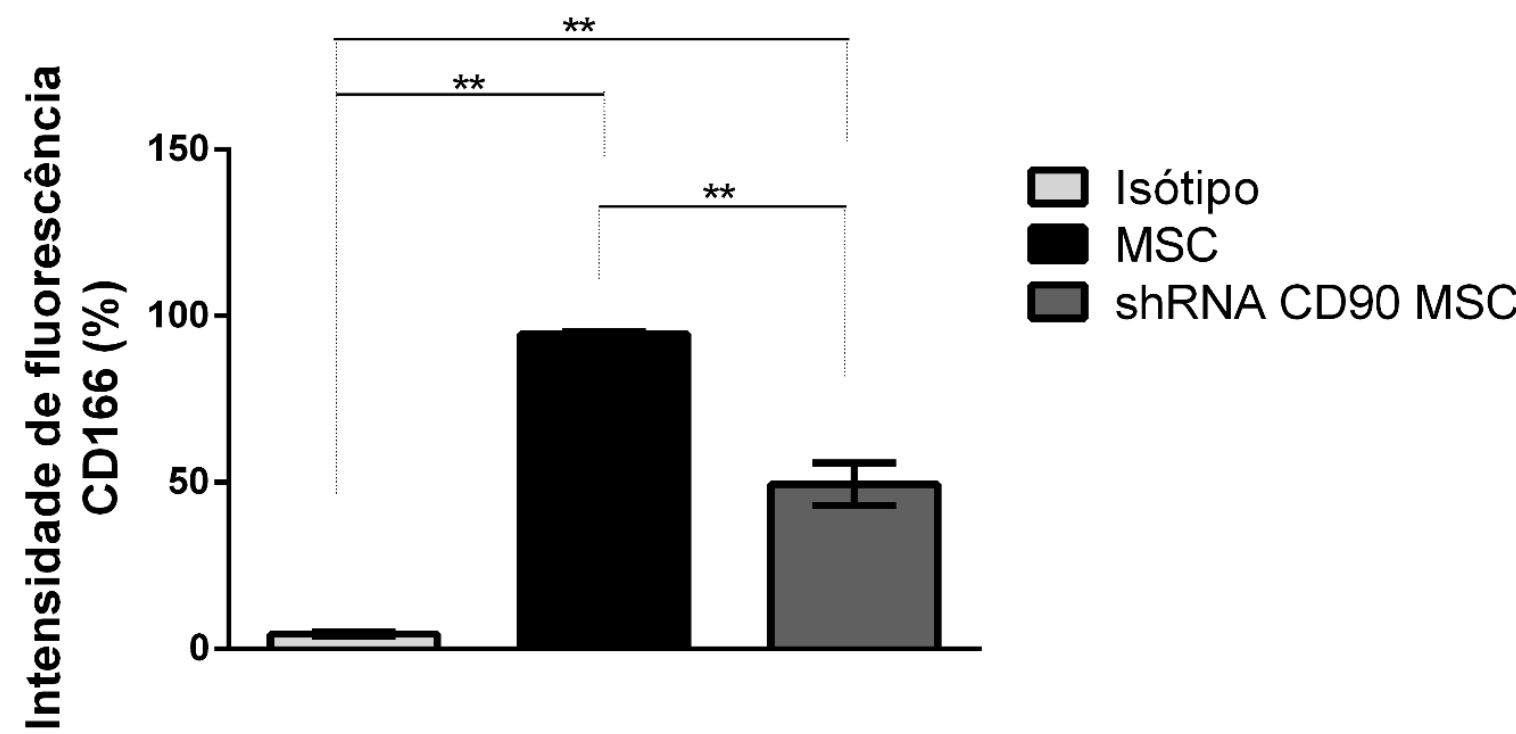

Figura 22 - Análise da média de intensidade de fluorescência de CD166. $\left(^{*}\right)$ Houve diferença estatística entre as células MSCs e shRNA CD90 MSCs ${ }^{* *} p<0.01$. 


\subsection{CD90 E DIFERENCIAÇÃO DE MSC}

O potencial de diferenciação de MSCs não transduzidas, shRNA Controle MSCs, shRNA CD90 MSCs e CD90-negativo MSCs foi analisado quanto ao potencial de diferenciação osteogênica e adipogênica.

Como esperado, a indução osteogênica (OS) resultou na ocorrência de deposição de matriz mineralizada, que foi detectada 21 dias após o início da indução à diferenciação. A matriz mineralizada foi avaliada por: a) Concentração de vermelho de Alizarina (AR); b) determinação da concentração de cálcio; e c) atividade de fosfatase alcalina. De acordo com dados prévios de outros pesquisadores $(32,148)$, a deposição mineral foi maior em células isoladas da polpa dental quando comparadas com células do líquido amniótico. A concentração de vermelho de Alizarina foi analisada em relação aos níveis de expressão de CD90. As células shRNA CD90 MSCs apresentaram um significativo aumento da produção de matriz osteogênica, com a visualização de uma maior concentração de corante de Alizarina (AR) nas amostras em comparação com ambas: MSCs não transduzidas e shRNA Controle MSCs, tanto na análise qualitativa (Figura 23), quanto na quantitativa (Figura 24). Elevada mineralização também foi observada nas células CD90-negativo MSC. $O$ efeito da redução da expressão de CD90 na diferenciação osteogênica de MSCs foi acessada pela atividade de fosfatase alcalina (Figura 25). Os resultados evidenciaram melhora na produção da enzima fosfatase alcalina nas células com expressão de CD90 reduzida (Figura 25). A avaliação quantitativa da produção de cálcio nas células shRNA CD90 MSCs foi $57 \%$ maior quando comparada com as MSCs não transduzidas (Figura 26).

A capacidade de diferenciação adipogênica das MSCs também foi analisada (Figura 27) usando MSCs isoladas da polpa dental, tecido adiposo e líquido amniótico. Todas as populações celulares apresentaram mudanças morfológicas significativas quando comparadas com MSCs não induzidas à adipogênese. As células apresentaram vacúolos de lipídios no citoplasma e várias gotículas, evidenciados pelo corante óleo vermelho $\mathrm{O}$ (Figura 27). Foi observado um aumento no número de células adipocíticas nas amostras de shRNA CD90 MSCs quando comparadas com shRNA Controle MSCs e um aumento maior nas células CD90-negativo MSCs. Independente da expressão de CD90, foi evidenciado que as MSCs da polpa dental apresentaram menor produção de matriz adipogênica quando comparadas com as células do líquido 
amniótico e tecido gorduroso (Figura 28). A formação de adipócitos mais proeminente foi observada em CD90-negativo MSCs isoladas do tecido gorduroso.

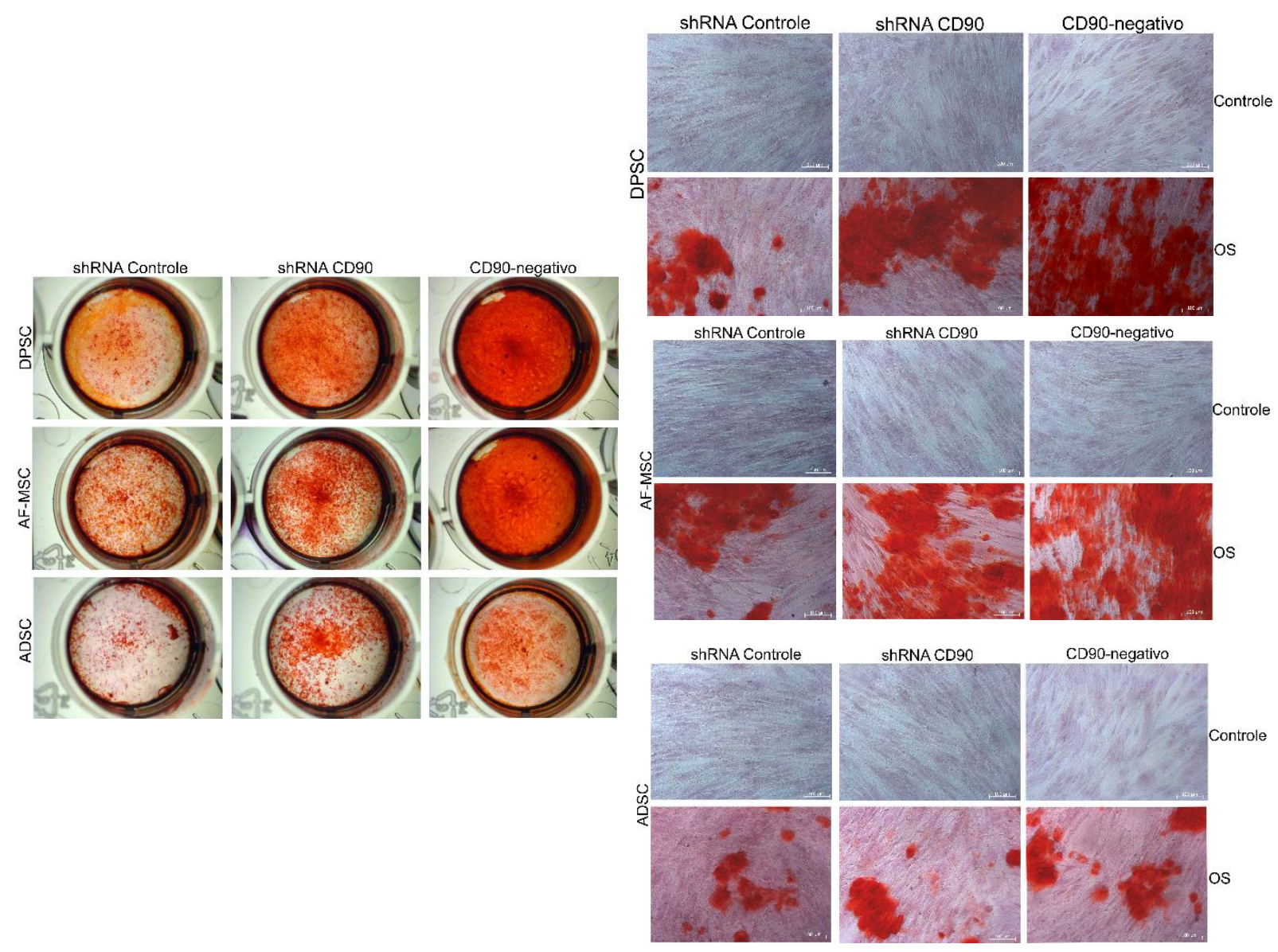

Figura 23 - Ensaio de diferenciação osteogênica-análise qualitativa. DPSC, AF-MSC e ADSC (MSCs, shRNA Control MSCs, shRNA CD90 MSCs e CD90-negative MSCs) foram testadas quanto à habilidade de diferenciação in vitro em linhagem osteogênica. Depósitos calcificados foram identificados pelo corante Alizarina Red (AR) em células após 21 dias de crescimento em meio de indução osteogênico. A calcificação foi acessada pela microscopia de luz. Barra de escala representa100 $\mu \mathrm{m}$. 


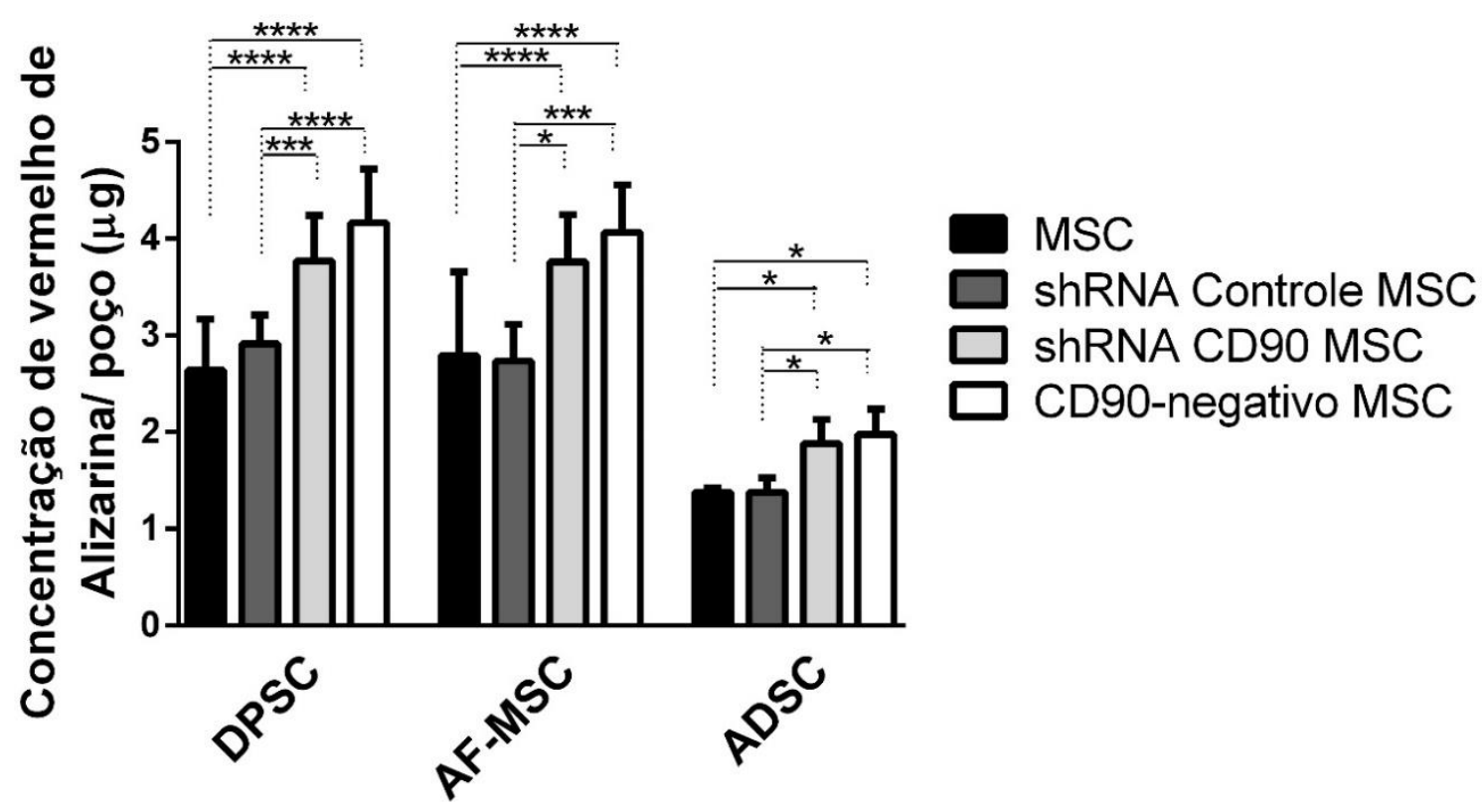

Figura 24 - Ensaio de diferenciação osteogênica-análise quantitativa do tecido mineralizado. Os dados expressam a média e o desvio-padrão da concentração de corante vermelho de Alizarina absorvido pelo tecido mineralizado em microgramas produzido por DPSC, AF-MSC e ADSC. Houve diferença estatística significativa entre as MSCs e shRNA Controle MSCs quando comparada com as shRNA CD90 MSCs e CD90-negativo MSCs para as DPSCs, AF-MSCs e ADSCs. ${ }^{*} p<0.05$; ${ }^{* *} p<$ $0.01 ;{ }^{* * *} p<0.001$. Foram realizados sete ensaios independentes $(n=7)$.

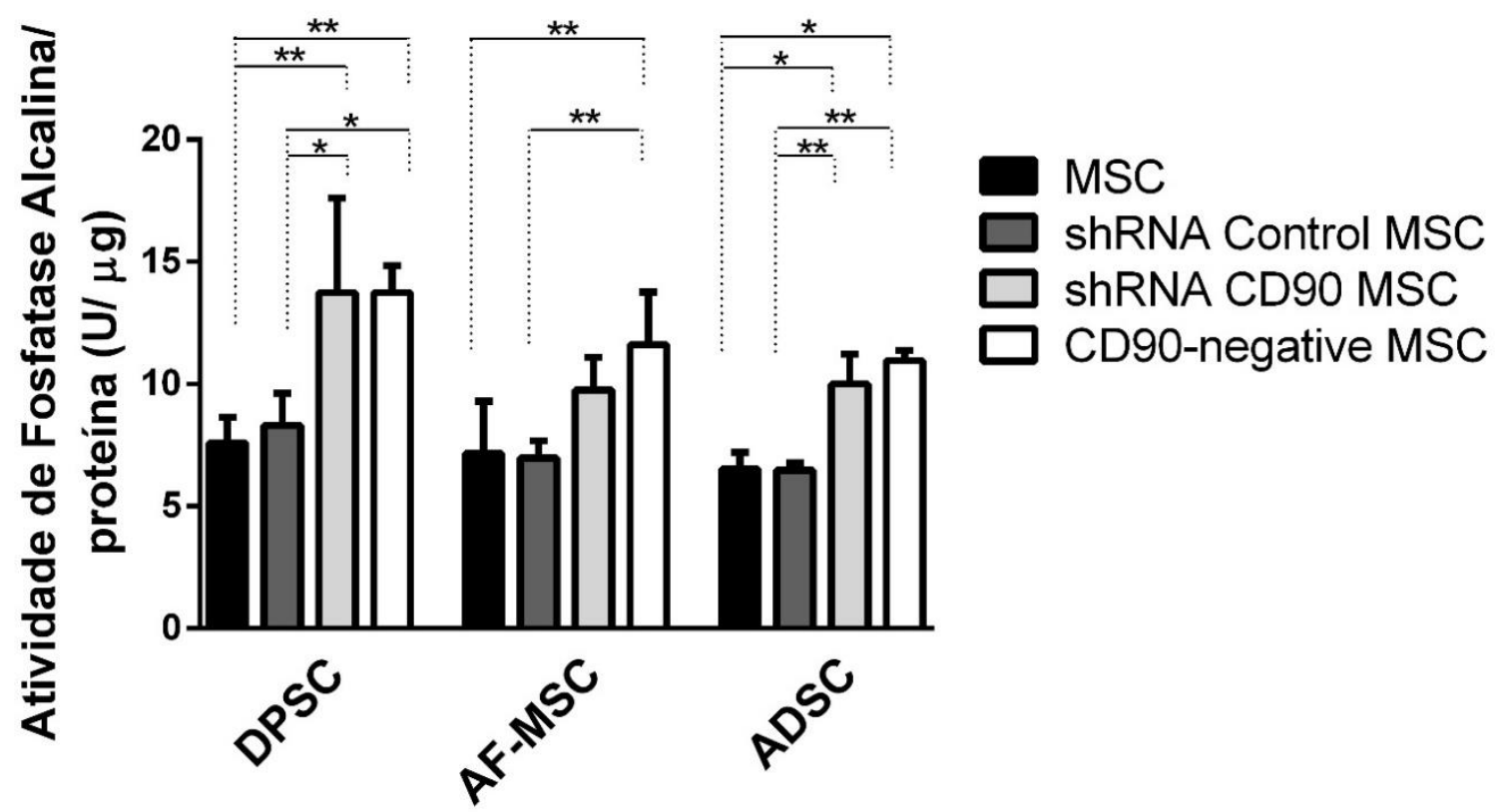

Figura 25 - Ensaio de diferenciação osteogênica-análise da atividade de fosfatase alcalina. Os dados expressam a média da relação entre a atividade de fosfatase alcalina normalizado pelo conteúdo de proteína total, com os respectivos desvio-padrão, evidenciando diferença estatística significativa entre as MSC e shRNA Controle em relação às shRNA CD90 MSCs e CD90-negativo MSCs ${ }^{*} p<0.05$; ${ }^{* *} p<0.01$. 


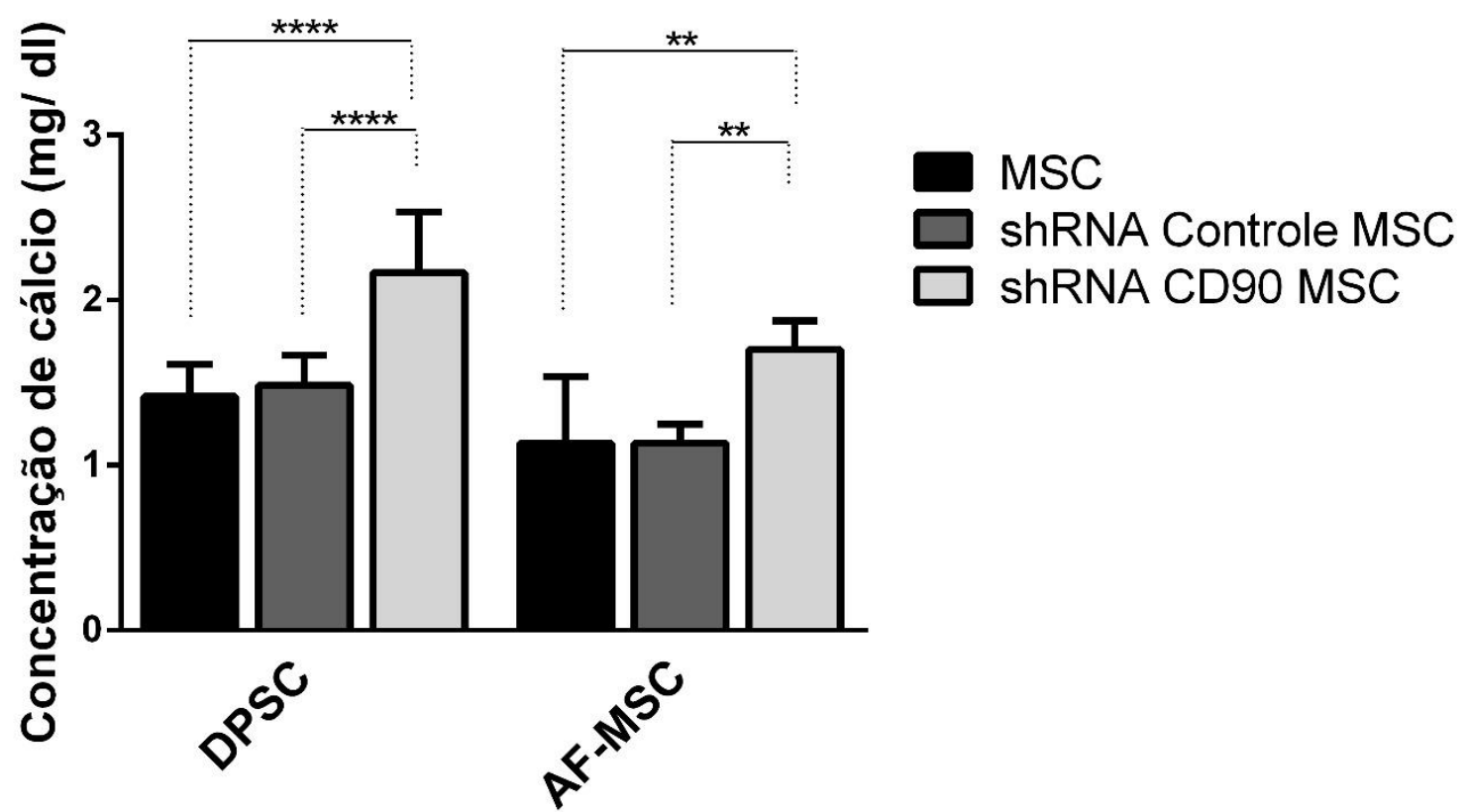

Figura 26 - Ensaio de diferenciação osteogênica-análise da concentração de cácio. Os dados expressam a média e desvio-padrão da concentração de cálcio, em miligramas por decilitro, presentes nos poços de DPSCs e AF-MSCs induzidos à diferenciação osteogênica. As ADSCs não apresentaram produção de cálcio significativa ${ }^{*} p<0.05 ;{ }^{* *} p<0.01 ;{ }^{* * *} p<0.001$. 

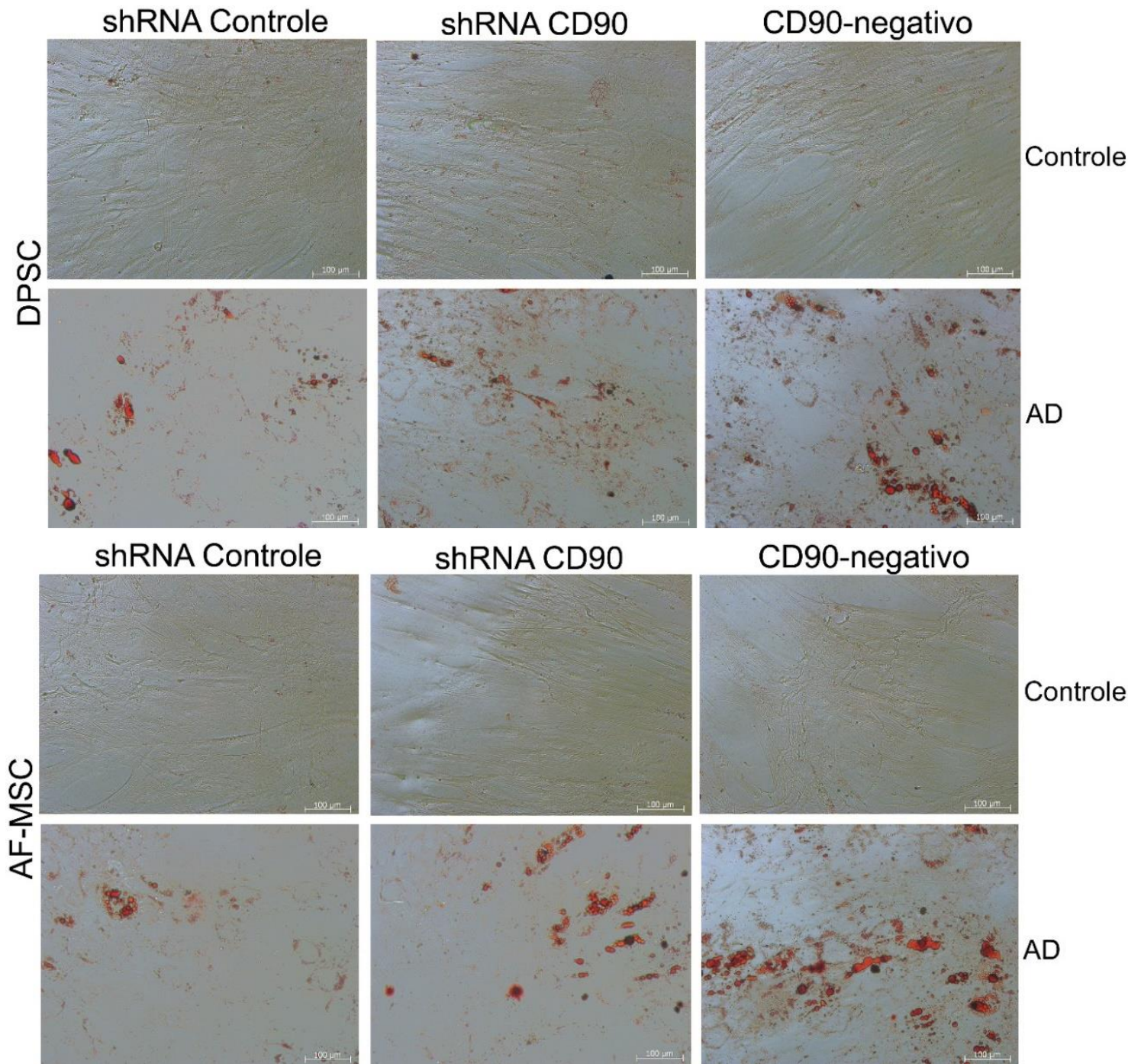

CD90-negativo
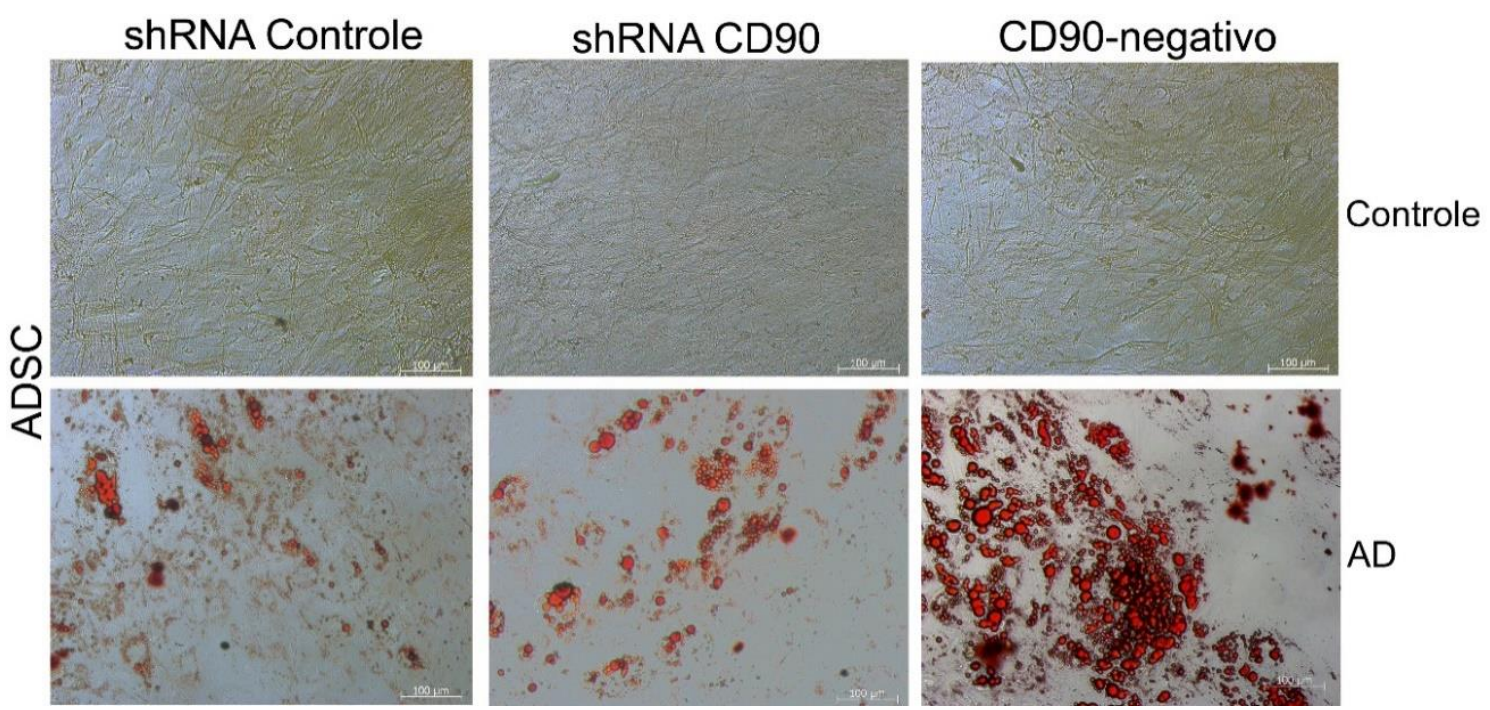

Figura 27 - Ensaio de diferenciação adipogênica-análise qualitativa. Análise em microscopia de luz de DPSC, AF-MSC e ADSC induzidas à doferencição adipogênica, coradas com óleo vermelho $O$. Foi evidenciado a formação de vesículas lipídicas intracelulares presentes nas DPSCs, AF-MSCs e ADSCs, apresentando maior diferenciação adipogênica nas shRNA CD90 MSCs e CD90-negativo MSCs. Imagens representativas de experimentos realizados em triplicata. 


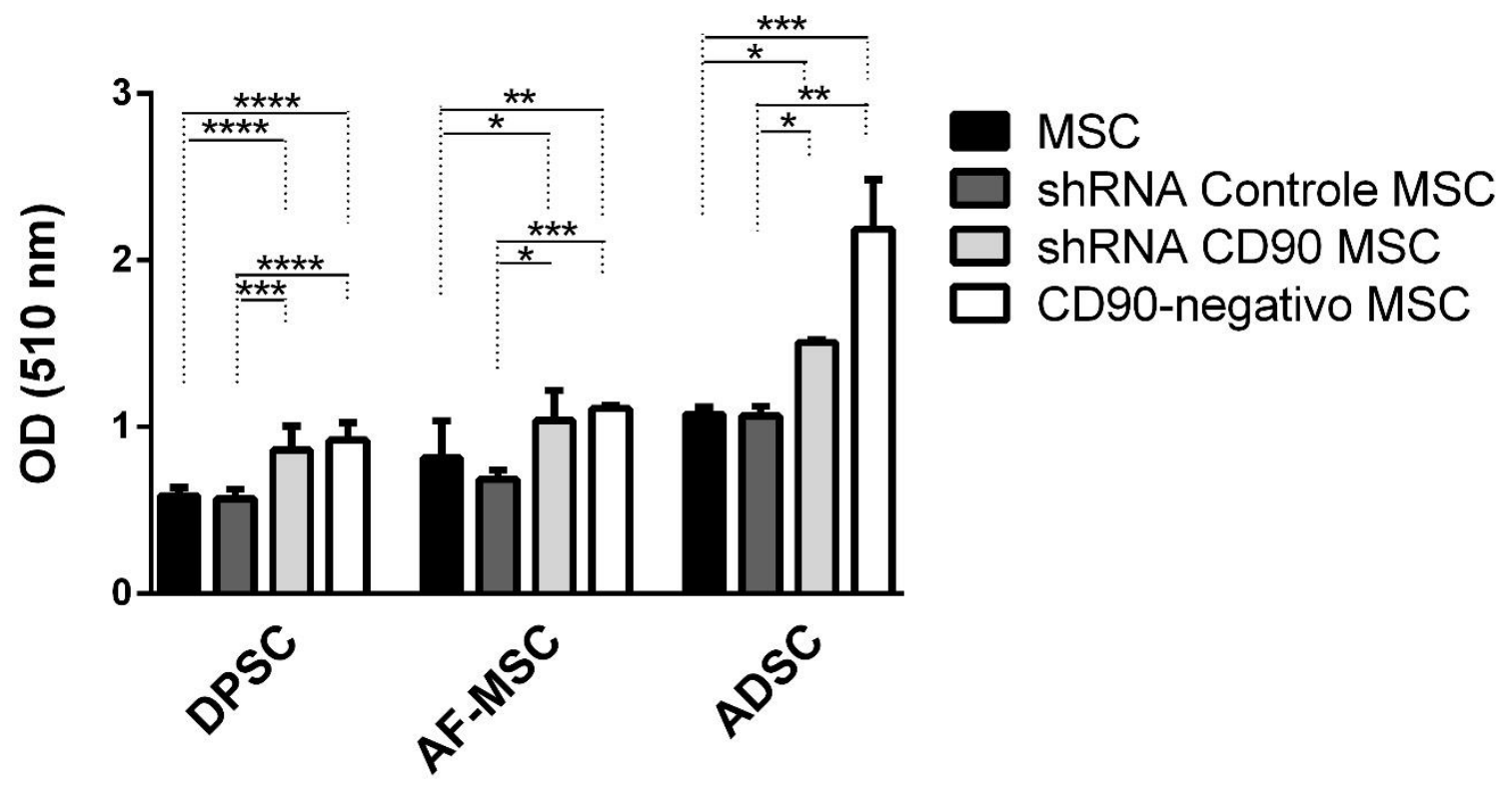

Figura 28 - Ensaio de diferenciação adipogênica-análise quantitativa. $O$ óleo vermelho $O$ retido nos vacúolos lipídicos foi mensurado pela determinação da densidade óptica a $510 \mathrm{~nm}$. ${ }^{*} p<0.05$; ${ }^{* *} p<$ $0.01 ;{ }^{* * *} p<0.001$. 
5 DISCUSSÃO 


\section{DISCUSSÃO}

A biologia de MSCs tem sido objeto de estudo de vários pesquisadores $(10,12,17,41,62,128)$ devido ao seu potencial terapêutico e o presente estudo buscou elucidar a função de CD90, um marcador imunofenotípico essencial para a caracterização de MSCs, em relação à morfologia, proliferação e diferenciação de MSCs. Foram usadas MSCs isoladas de três fontes (polpa dental, líquido amniótico e tecido gorduroso) para verificar se os efeitos causados pela ablação de CD90 estão relacionados à uma fonte específica.

Para avaliar a função de CD90, foi realizada a transdução de MSCs com vetores lentivirais que carreavam small hairpins (shRNA) contra o marcador CD90 das MSCs, acarretando em diminuição da expressão de CD90 pelo mecanismo de RNA interferência. Após a transdução de MSCs, a redução da expressão de CD90 em mais de $70 \%$ das shRNA CD90 MSCs foi confirmada pela análise imunofenotípica usando citometria de fluxo (Figura 9 e 10) e PCR em tempo real (Figura 11). Posteriormente, buscou-se reduzir de forma mais significativa a expressão de CD90, utilizando a purificação celular. O resultado demonstrou uma redução maior na expressão de CD90 para as shRNA CD90 MSCs purificadas (Figura 12 e 13).

Outro importante dado avaliado foi o perfil imunofenotípico das MSCs modificadas (shRNA CD90 MSCs). Como esperado, o resultado demonstrou a expressão positiva para os marcadores de MSCs: CD29, CD73, CD105; e negativa para os marcadores: CD14, CD31, CD34, CD45, CD106, e HLA-DR (Figura 19). Mas os resultados evidenciaram que a redução da expressão de CD90 em todas as linhagens de shRNA CD90 MSCs levaram à redução dos marcadores CD44 e CD166 (Figure 20, 21 e 22).

A função de CD166 em MSCs ainda não foi esclarecida até o momento. Mas CD44 (hyaluronan receptor) (129) é expresso por um vasto número de células e é envolvido em adesão, migração e sítios de MSCs (130-132). CD44 também tem sido reconhecido como um marcador de células-tronco para vários tipos de câncer e é fortemente relacionado à metástase. Outro estudo evidenciou que a redução de CD44 em células-tronco do câncer provocou sua diferenciação em células normais (133). Já o receptor CD166 (activated leukocytes cell adhesion molecule, ALCAM) é um 
membro da superfamília de imunoglobulinas das moléculas de adesão celular $(134,135)$ e está presente em MSCs indiferenciadas e outros tipos celulares (136). Assim como CD44, CD166 também foi reconhecido por participar na invasão de tumor (137-139). Um estudo recente usando linhagens de células do câncer de fígado evidenciou uma relação próxima entre CD44 e CD166. Os autores mostraram que o nocaute de CD166 inibiu a expressão de CD44 através da via de sinalização NFKB (140). Apesar das evidências científicas da relação entre CD44 e CD166 em células tumorais, ainda não houve um estudo que associasse a relação em a expressão de CD44 e CD166 em MSCs, sugerindo novos estudos para esclarecer essa relação.

Assim como CD44 e CD166, CD90 foi identificado como um marcador de células-tronco tumorais. O aumento da expressão de CD90 foi observada em CSC de câncer de fígado (92-94), mucosa gástrica (95), câncer de colo (96), células do estroma do câncer de próstata (97), glioma (99) e adenocarcinoma pancreático (100). Foi demonstrado que a manipulação de CD90 é uma ferramenta terapêutica promissora contra vários CSCs. Para ilustrar, pesquisadores evidenciaram que o anticorpo CD90 inibiu de forma específica e eficiente a proliferação de células B do linfoma (102). Alguns estudos apresentaram a relação funcional da associação entre CD90 e CD44 ou CD166. Concomitantemente, outros estudos associaram CD90, CD44 e CD166 como marcadores de células-tronco de câncer $(92,136,137,141)$. Mas os resultados do presente estudo apresentaram que CD90 levou ao decréscimo da expressão de CD44 e CD166, que poderia indicar o estado de indiferenciação celular.

Em relação ao aspecto morfológico das MSCs que expressam CD90, o foi demonstrado que a linhagem celular shRNA CD90 MSCs e CD90-negativo MSCs não apresentaram alterações nem na morfologia, nem na taxa de proliferação, quando comparados com as células controle (Figura 14 e 15). Nosso resultado foi diferente de Phipps et al (1989), que associaram CD90 ao aspecto fusiforme de fibroblastos de pulmão. Os autores selecionaram fibroblastos de pulmão pela expressão de CD90 e descreveram que a subpopulação de fibroblastos com CD90- apresentou um formato mais poligonal em relação aos fibroblastos com $\mathrm{CD} 90_{+}$, que por sua vez tinham aspecto fusiforme (142).

Outro resultado apontado foi que a redução da expressão de CD90 não afetou a atividade imunossupressiva de MSCs na proliferação de linfócitos in vitro (Figura 16). A característica imunossupressiva é uma importante propriedade terapêutica de 
MSCs, e já que foi mantida nas células com a expressão de CD90 reduzida, poderá ter a ampliação do uso dessas células modificadas em futuras terapias celulares in vivo.

Uma importante característica das MSCs que foi investigada nesse estudo foi a relação de CD90 e a diferenciação de MSCs. Para isso, as MSCs com expressão de CD90 reduzida foram diferenciadas em linhagens osteogênica e adipogênica. Nos ensaios de diferenciação, as linhagens de shRNA CD90 MSCs e CD90-negativo MSCs apresentaram maior taxa de diferenciação adipogênica, quando comparada com os controles (Figura 27 e 28). Do mesmo modo, um aumento de diferencição osteogênica foi observada nas amostras de shRNACD90 MSCs e CD90-negativo MSCs. O corante vermelho de Alizarina evidenciou que as amostras CD90-negativo MSCs, ou seja, as frações celulares purificadas de shRNA CD90 MSCs, com expressão de CD90 negativa acumularam mais matriz mineralizada que shRNA CD90 MSCs. De acordo com nossos resultados, a redução da expressão de CD90 facilitou a diferenciação adipogênica e osteogênica.

Recentemente, Woeller et al (2015) elucidaram que CD90 controlou a adipogênese. Eles observaram que ratos com expressão de CD90 negativa aumentaram a adipogênese, enquanto na overexpressão de CD90, ocorreu o bloqueio da adipogênese (143). Eles também descreveram que embora fibroblastos préadipócitos expressavam CD90, adipócitos do tecido gorduroso apresentaram níveis indetectáveis de CD90. Em concordância com esses resultados, nós observamos que a perda da expressão de CD90 em MSCs aumentou a produção de matriz adipogênica in vitro. Baseados nas observações de seu estudo, Woeller et al (2015) sugeriram que CD90 poderá ser um novo marcador terapêutico em obesidade. Entretanto, nossos resultados indicaram que o decréscimo da expressão de CD90 facilitou não apenas a diferenciação adipogênica, mas também a diferenciação osteogênica, indicando que a redução da expressão de CD90 evidenciou a uma perda do estado indiferenciado (stemness) de MSCs, assim, quando manipulado, poderá ser capaz de melhorar a diferenciação na presença de estímulos específicos.

Numerosas vias de sinais de transdução induzem a diferenciação adipogênica e/ou osteogênica de MSCs. A maioria dos sinais culminam na ativação da expressão ou de PPARy (adipogenesis master regulator) ou Runx2 (osteogenesis master regulator). Foi demonstrado que CD90 foi associado não-covalentemente com Fyn, 
Scr family tyrosine kinase. Recentemente, foi apresentado que CD90 inibiu Fyn para dificultar a adipogênese (143). Consistentemente, ratos com a expressão de Fyn negativa tem reduzido a massa de gordura. Além disso, o Fyn inhibitor SU6656 causou a redução do acúmulo de tecido adiposo em ratos e inibição da adipogênese em fibroblastos humanos $(143,144)$. No presente experimento, usamos MSCs de três fontes diferentes de tecidos humanos para evidenciar que a expressão reduzida de CD90 não induziria, mas facilitaria a adipogênese. Entretanto, observamos que a perda de CD90 aumentou a adipogênese. A evidência de que o nível de CD90 regulou a adipogênese e a osteogênese foi muito interessante, porque é correntemente aceito que o estímulo de diferenciação usualmente causa uma relação inversa entre diferenciação adipogênica e osteogênica (145), todavia, os sinais moleculares que convergem em adipogênese e osteogênese não foram completamente elucidados. Nesse estudo nós demonstramos que a produção de matriz mineralizada é diretamente correlacionada com o nível de ablação de CD90, apresentando-se maior nas amostras CD90-negativo MSCs que nas amostras shRNA CD90 MSCs. Ainda não está claro como CD90 pode afetar a adipogênese. Mas foi bem demonstrado que CD90 pode regular a atividade de RhoGTPase em fibroblastos. Expressão exógena em fibroblastos que não expressavam CD90 resultou na ativação de Rho GTPase (84). Rho GTPase é um modulador essencial de sinais de IGF-1 que afeta a diferenciação adipogênica. A inibição da atividade de Rho GTPase parece ser necessária para a diferenciação adipogênica (146). Estudos demonstram que CD90 participa de várias outras vias de sinalização e embora CD90 tem sido reconhecido como marcador celular, é também um importante regulador de sinalização de MSCs (147). Novos estudos são necessários para entender os efeitos de CD90 nas possíveis sinalizações cis e trans e como CD90 atua, bem como o entendimento desse mecanismo no processo de "stemness" e diferenciação de MSCs.

Várias pesquisas têm apresentado que MSCs de diferentes fontes acarretam diversas propriedades a características que podem ter impacto em aplicações terapêuticas futuras. A capacidade de diferenciação varia de acordo com a fonte de célula $(32,33,46)$. Devido a disponibilidade e facilidade de cultivo de MSCs de polpa dental humana, nós iniciamos o estudo usando as células do tecido pulpar e adicionalmente buscamos comprovar as conclusões concernentes ao CD90 a partir de células de outras fontes. Desse modo, fizemos ensaios de diferenciação usando 
MSCs de líquido amniótico e tecido gorduroso (lipoaspirado). Como discutido em estudos prévios $(32,148-150)$, nós observamos que as DPSCs produziram uma maior quantidade de matriz osteogênica, quando comparadas com ADSCs. Mas não houve muita diferença na produção de matriz osteogênica entre as DPSCs e AF-MSCs. Mesmo diante dessa variação das MSCs de diferentes fontes quanto ao potencial de diferenciação, o presente estudo confirmou que a redução da expressão de CD90 levou a uma maior e mais eficiente diferenciação nas MSCs das diferentes fontes avaliadas $(151,152)$.

CD90 é uma glicoproteína de superfície expressa em vários tipos celulares. Em geral, influencia na proliferação, diferenciação, migração e sobrevivência das células. As funções de CD90 são específicas para cada célula em que é expressa e nos tecidos e nesse presente estudo, nós evidenciamos que a redução da expressão de CD90 em MSCs humanas aumentou a eficiência da diferenciação dessas células. Outros estudos apontaram que a expressão de CD90 poderia ser usada como um indicador de diferenciação de MSCs, já que imediatamente após a indução de diferenciação, houve um progressivo decréscimo do nível de mRNA CD90 correlacionado ao grau de diferenciação observado (66). É importante reiterar que a ablação de CD90 não resultou em diferenciação espontânea de MSCs. Contudo, as linhagens de MSCs com expressão reduzida de CD90 na presença de indutores, evidenciaram que CD90 possui uma função importante na manutenção do estado indiferenciado de MSCs, podendo agir como obstáculo durante as etapas iniciais de diferenciação celular. A ablação de CD90 mostrou ser uma eficiente ferramenta para aumentar a eficiência de diferenciação de MSCs in vitro e pode ser usada no futuro em diferentes campos de terapias celulares in vitro e in vivo. 
6 CONCLUSÕES 


\section{CONCLUSÕES}

Os dados apresentados indicam que a ablação de CD90 representa uma estratégia promissora e para aumentar a eficiência de diferenciação das MSCs in vitro, podendo ser usada futuramente para terapias celulares. Dessa forma, os resultados apontaram que CD90 está relacionado ao estado indiferenciado de MSCs, podendo ser um obstáculo para as etapas iniciais da diferenciação de MSCs.

A ablação de CD90 levou a redução da expressão de CD44 e CD166, relacionando esses resultados ao estado indiferenciado de MSCs e maior susceptibilidade à diferenciação. 
REFERÊNCIAS BIBLIOGRÁFICAS 


\section{REFERÊNCIAS BIBLIOGRÁFICAS}

1. Gronthos S, Brahim J, Li W, Fisher LW, Cherman N, Boyde a, et al. Stem cell properties of human dental pulp stem cells. J Dent Res. 2002;81(8):531-5.

2. Potten C, Wilson J. Essentials stem cell biology. Acad Press. 2009;17-27.

3. Zomer HD, Vidane AS, Gonçalves NN, Ambrosio CE. Mesenchymal and induced pluripotent stem cells: general insights and clinical perspectives. Stem Cells Cloning Adv Appl. 2015;8:125-34.

4. Weissman IL. Translating Stem and Progenitor Cell Biology to the clinic: Barriers and Opportunities. Science. 2000;80(287):1442-46.

5. Wagers AJ and Weissman IL. Plasticity of adult stem cells. Cell. 2004;116: 639-48.

6. Cowan CA, Ph D, Klimanskaya I, Ph D, Mcmahon J, Atienza J, et al. Derivation of Embryonic Stem-Cell Lines from Human Blastocysts. New Engl Jounal Med. 2004;350(13):1353-6.

7. Thomson JA, Itskovitz-Eldor J, Shapiro SS, Waknitz MA, Swiergiel JJ, Marshall VS, et al. Embryonic Stem Cell Lines Derived from Human Blastocysts. Sci STKE. 1998;282:1145-8.

8. Odorico JS, Kaufman DS, Thomson JA. Multilineage Differentiation from Human Embryonic Stem Cell Lines. Stem Cells. 2001;19:193-204.

9. Farag MMS, Sobh MA, Shalaby AAA, Ewais EEA. Isolation, characterization, and in vitro differentiation of osteogenic human amniotic fluid- derived stem cells. Int J Adv Res. 2015;3(12):1475-82.

10. Caplan AI, Dennis JE. Mesenchymal Stem Cells as Trophic Mediators. Jounal Cell Biochem. 2006;98:1076-84.

11. Eaves CJ. Hematopoietic stem cells: concepts, definitions, and the new reality. Hematop stem cells. 2016;125(17):2605-14.

12. Pittenger MF, Mackay AM, Beck SC, Jaiswal RK, Douglas R, Mosca JD, et al. Multilineage Potential of Adult Human Mesenchymal Stem Cells. Science . 1999;284:143-7.

13. Friedestein A, Deriglasosa U, Kulagina N, Panasuk A, Rudakowa S, Lurià E, et al. Precursors of fibroblasts in different populations of hematopoietic cells as detectes by the in vitro colony assay method. Exp Hematol. 1974;2:140819.

14. Owen M, Friedestein AJ. Stromal stem cells: marrow-derived osteogenic precursors. Ciba Found Symp, 1988;136:42-60. 
15. Caplan A. Mesenchymal stem cells. J Orthop Res. 1991;9(5):641-50. Available from: http://www.ncbi.nlm.nih.gov/pubmed/1870029.

16. Prockop, DJ. Marrow Stromal Cells as Stem Cells for Nonhematopoietic Tissues. Science 1997;276:71-74. DOI: 10.1126/science.276.5309.71.

17. Krampera M, Pasini A, Rigo A, Scupoli MT, Tecchio C, Malpeli G, et al. HBEGF/HER-1 signaling in bone marrow mesenchymal stem cells: Inducing cell expansion and reversibly preventing multilineage differentiation. Blood. 2005;106(1):59-66.

18. Dezawa M. Bone Marrow Stromal Cells Generate Muscle Cells and Repair Muscle Degeneration. Science 2005;309(5732):314-7. Available from: http://www.sciencemag.org/cgi/doi/10.1126/science.1110364

19. Fu Y-S, Cheng Y-C, Lin M-YA, H C, Chu P-M, Chou S-C, et al. Conversion of human umbilical cord mesenchymal stem cells in warton's jelly to dopaminergic neurons in vitro: Potential Therapeutic Application for Parkinsonism. Stem Cells. 2006;24:115-24.

20. Luk JM, Wang PP, Lee CK, Wang JH, Fan ST. Hepatic potential of bone marrow stromal cells: Development of in vitro co-culture and intra-portal transplantation models. J Immun Met. 2005;305:39-47.

21. Horwitz EM, Le Blanc K, Dominici M, Mueller I, Slaper-Cortenbach I, Marini FC, et al. Clarification of the nomenclature for MSC: The International Society for Cellular Therapy position statement. Cytotherapy. 2005;7(5):393-5.

22. Dominici M, Blanc K Le, Mueller I, Marini FC, Krause DS, Deans RJ, et al. Minimal criteria for defining multipotent mesenchymal stromal cells. The International Society for Cellular Therapy position statement. Cytotherapy. $2006 ; 8(4): 315-7$.

23. Minguell, J. J., Conget, P., \& Erices, A. (2000). Biology and clinical utilization of mesenchymal progenitor cells. Brazilian Journal of Medical and Biological Research, 33(8), 881-7. Retrieved from http://www.ncbi.nlm.nih.gov/pubmed/10920429.

24. Koç ON, Peters C, Aubourg P, Raghavan S, Dyhouse S, DeGasperi R, et al. Bone marrow-derived mesenchymal stem cells remain host-derived despite successful hematopoietic engraftment after allogeneic transplantation in patients with lysosomal and peroxisomal storage diseases. Experimental Hematology; 1999;27:1675-81.

25. Panepucci RA, Siufi JLC, Silva Jr WA, Proto-Siquiera R, Neder L, Orellana M, et al. Comparison of gene expression of umbilical cord vein and bone marrowderived mesenchymal stem cells. Stem Cells. 2004;22(7):1263-78.

26. Roobrouck VD, Ulloa-Montoya F, Verfaillie CM. Self-renewal and differentiation capacity of young and sged stem cells. Exp cell Res; 2008; 314:1937-44. Doi 10.1016/j.yexcr2008.03.006. 
27. Soukup T, Mokrý J, Karbanová J, Pytlík R, Suchomal P, Kucerová L. Mesenchymal stem cells isolated from the muman bone marrow: cultivation, phenotypic analysis and changes in proliferation kinetics. Acta Medica Cordoba. 2006;49(1):27-33.

28. Giordano A, Galderisi U, Marino IR. From the Laboratory Bench to the Patient's Bedside : An Update on Clinical Trials With Mesenchymal Stem Cells. J Cell Physiol. 2007;211:27-35.

29. Kadivar M, Khatami S, Mortazavi Y, Taghikhani M, Shokrgozar MA. Multilineage differentiation activity by the human umbilical vein-derived mesenchymal stem cells. Iran Biomed J. 2006;10(4):175-84.

30. Struys T, Moreels M, Martens W, Donders R, Worfs E, Lambrichts I. Ultrastructural and Immunocytochemical Analysis of Multilineage Differentiated Human Dental Pulp- and Umbilical Cord-Derived Mesenchymal Stem Cells. Cells Tissues Organs. 2011;193:366-78.

31. Rao MS, Mattson MP. Stem cells and aging: expanding the possibilities. Mech Ageing Dev. 2001;122:713-34.

32. Davies OG, Cooper PR, Shelton RM, Smith a J, Scheven B a. A comparison of the in vitro mineralisation and dentinogenic potential of mesenchymal stem cells derived from adipose tissue, bone marrow and dental pulp. J Bone Miner Metab; 2014;33:371-82.

33. Gronthos S, Mankani M, Brahim J, Robey PG, Shi S. Postnatal human dental pulp stem cells (DPSCs) in vitro and in vivo. Proc Natl Acad Sci U S A. 2000;97(25):13625-30.

34. Bi Y, Ehirchiou D, Kilts TM, Inkson CA, Embree MC, Sonoyama W, et al. Identification of tendon stem / progenitor cells and the role of the extracellular matrix in their niche. Nat Med. 2007;13(10):1219-27.

35. Shih DT, Lee D, Chen S, Tsai R, Huang C. Isolation and characterization of neurogenic mesenchymal stem cells in human scalp tissue. Stem Cells. $2005 ; 23: 1012-20$.

36. Zuk PA, Zhu M, Ashjian P, Ugarte DA De, Huang JI, Mizuno $\mathrm{H}$, et al. Human Adipose Tissue Is a Source of Multipotent Stem Cells. Mol Biol Cell. 2002;13:4279-95.

37. Bari C De, Accio FD, Tylzanowski P, Luyten FP. Multipotent Mesenchymal Stem Cells From Adult Human Synovial Membrane. Arthritis Rheum. 2001;44(8):1928-42.

38. Patki S, Kadam S, Chandra V, Bhonde R. Human breast milk is a rich source of multipotent mesenchymal stem cells. Hum Cell. 2010;23:35-40.

39. Igura K, Zhang X, Takahashi K, Mitsuru A, Yamaguchi S, Takahashi TA. Isolation and characterization of mesenchymal progenitor cells from chorionic 
villi of human placenta. Cytotherapy. 2004;6(6):543-53.

40. Erices $\mathrm{A}$, Conget $\mathrm{P}$, Minguell J. Mesenchymal progenitor cells in human umbilical cord blood. Br J Haematol. 2000;109:235-42.

41. Sarugaser R, Lickorish D, Baksh D, Hosseini MM, Davies JE. Human Umbilical Cord Perivascular (HUCPV) Cells: A source of mesenchymal progenitors. Stem Cells. 2005;23:220-9.

42. Wang $\mathrm{H}$, Hung S, Peng S, Huang $\mathrm{C}$, Wei H, Guo Y, et al. Mesenchymal stem cells in the Wharton's jelly of the human umbilical cord. Stem Cells. 2004;22:1330-7.

43. Tsai $M$, Lee J, Chang $\mathrm{Y}$, Hwang $\mathrm{S}$. Isolation of human multipotent mesenchymal stem cells from second-trimester amniotic fluid using a novel two-stage culture protocol. Hum Reprod. 2004;19(6):1450-6.

44. Bernardo ME,Emons JA, Karperien M,Nauta AJ, Willemze R, Roelofs $\mathrm{H}$, el al. Human mesenchymal stem cells derived from bone marrow display a better chondrogenic differentiation compared with other sources. Connective tissue research. 2007;48(3):132-40. PubMed PMID: 17522996.

45. Divya MS, Roshin GE, Divya TS, Rasheed VA, Santhoshkumar TR, Elizabeth $\mathrm{KE}$, et al. Umbilical cord blood-derived mesenchymal stem cells consist of a unique population of progenitors co-expressing mesenchymal stem cell and neuronal markers capable of instantaneous neuronal differentiation. Stem Cell Research \& Therapy. 2012;3:1-16. doi:10.1186/scrt148.

46. Noel D, Djouad F, Bouffi C,Mrugala D, Jorgensen C. Multipotent mesenchymal stromal cells and immune tolerance. Leukemia \& lymphoma. 2007;48(7):12839. PubMed PMID: 17613755.

47. De Miguel MP, Fuentes Julian S, Blazquez Martinez A, Pascual CY, Aller MA, Arias $\mathrm{J}$, et al. Immunosuppressive properties of mesenchymal stem cells: advances and applications. Current molecular medicine. 2012;12(5):574-91. PubMed PMID: 22515979.

48. Reese JS, Koç ON, Gerson SL. Human Mesenchymal Stem Cells Provide Stromal Support for Efficient CD34+ Transduction. Jounal hematotherapy stem cell Res. 1999;8:515-23.

49. Koç O, Day J, Nieder M, Gerson S, Lasarus G, Krivit W. Allogeneic mesenchymal stem cell infusion for treatment of metachromatic leukodystrophy (MLD) and Hurler syndrome (MPS- IH). Bone Marrow Transplant. 2002;30:215-22.

50. Uccelli A, Pistoia V, Moretta L. Mesenchymal stem cells: a new strategy for immunosuppression ? ScienceDirect. 2007;28:219-26.

51. Klingemann H, Matzilevich D, Marchand J. Mesenchymal Stem Cells Sources and clinical application. Transfus Med hemotherapy. 2008;35:272-7. 
52. TOLEDO OA. Crescimento e desenvolvimento. Em: Odontopediatria. Fundamentos para a prática clínica. 2005. 3-25 p.

53. Sloan AJ \& Smith AJ. Stem cells and the dental pulp: Potential roles in dentine regeneration and repair. Oral Diseases. 2007;13(2):151-7. http://doi.org/10.1111/j.1601-0825.2006.01346.x

54. Zhang W, Walboomers XF, Shi S, Fan M, Jansen JA. Multilineage differentiation potential of stem cells derived from human dental pulp after cryopreservation. Tissue Engineering. 2006;12(10):2813-23. http://doi.org/10.1089/ten.2006.12.ft-220

55. Sessarego N, Parodi A, Podestà M, Benvenuto F, Mogni M, Raviolo V, et al. Multipotent mesenchymal stromal cells from amniotic fluid : solid perspectives for clinical application. Haematologica. 2008;93(3):339-46.

56. Schaffler A, Buchler C. Adipose Tissue-Derived Stromal Cells - Basic and Clinical Implications for Novel Cell-Based Therapies. Stem Cells. 2007;25:818-27.

57. Conget PA. Phenotypical and Functional Properties of human bone marrow mesenchymal progenitor cells. J Cell Physiol. 1999;181:67-73.

58. Russel K, Phinney D, Lacey M, Barrilleaux B, KE M, KC O. In Vitro HighCapacity Assay to Quantify the Clonal Heterogeneity in Trilineage Potential of Mesenchymal Stem Cells Reveals a Complex Hierarchy of Lineage Commitment. Stem Cells. 2010;28:788-98.

59. Lv F-J, Tuan R, Cheung K, Leung V. Concise Review: The Surface Markers and Identity of Human Mesenchymal Stem Cells. Stem Cells. 2014;32:140819.

60. Miura M, Gronthos S, Zhao M, Lu B, Fisher LW, Robey PG, et al. SHED: stem cells from human exfoliated deciduous teeth. Proc. Natl. Acad. Sci. U. S. A. 2003;100:5807-12.

61. Huang G, Gronthos S, Shi S. Mesenchymal Stem Cells Derived from Dental Tissues vs. Those from Other Sources: Their Biology and Role in Regenerative Medicine. J. Dent. Res. 2009;88:792-806.

62. Kolf CM, Cho E, Tuan RS. Review Mesenchymal stromal cells Biology of adult mesenchymal stem cells : regulation of niche, self-renewal and differentiation MSC markers. Arthritis Res. Ther. 2007;9:1-10.

63. Sarugaser R, Lickorish D, Baksh D, Hosseini MM, Davies JE. Human Umbilical Cord Perivascular (HUCPV) Cells: A source of mesenchymal progenitors. Stem Cells. 2005;23:220-9.

64. Hiwase SD, Dyson PG, To LB, Lewis ID. Cotransplantation of placental mesenchymal stromal cells enhances single and double cord blood engraftment in nonobese diabetic/severe combined immune deficient mice. 
Stem Cells. 2009;27:2293-300.

65. Delorme B, Ringe J, Gallay N, Le Vern Y, Kerboeuf D, Jorgensen C, et al. Specific plasma membrane protein phenotype of culture-amplified and native human bone marrow mesenchymal stem cells. Hematop. Stem Cells. 2008;111:2631-5. Available from: http://bloodjournal.hematologylibrary.org/content/111/5/2631.short

66. Sibov TT, Severino P, Marti LC, Pavon LF, Oliveira DM, Tobo PR, et al. Mesenchymal stem cells from umbilical cord blood: Parameters for isolation, characterization and adipogenic differentiation. Cytotechnology. 2012;64:51121.

67. Raff M. Surface antigenic markers for distinguishing $T$ and $B$ lymphocytes in mice.Transplant Rev.1971;6:52-80.

68. Rege TA, Hagood JS. Thy-1, a versatile modulator of signaling affecting cellular adhesion, proliferation, survival, and cytokine/growth factor responses. Biochim. Biophys. Acta - Mol. Cell Res. 2006;1763:991-9.

69. Bradley JE, Ramirez G, Hagood JS. Roles and regulation of Thy-1, a contextdependent modulator of cell phenotype. BioFactors. 2009;35:258-65.

70. Williams AF, Gagnon J. Neuronal Cell Thy-1 Glycoprotein: Homology with Immunoglobulin. Science. 1982;216:696-703.

71. Seki T, Spurr N, Obata F, Goyert S, Goodfellow P, Silver J. The human Thy-i gene: Structure and chromosomal location. Proc. Natl. Acad. Sci. USA. 1985;82:6657-61.

72. Bae SH, Choi JY, Yoon SK, Oh I-H, Yoon KH, Park ST, et al. Thy1-positive bone marrow stem cells express liver-specific genes in vitro and can mature into hepatocytes in vivo. Hepatol Int. 2008;2:63-71.

73. Barboni E, Gormley AM, Rivero FBP, Vidal M, Morris R. Activation of T lymphocytes by cross-linking of glycophospholipid-anchored Thy-1 mobilizes separate pools of intracellular second messengers to those induced by the antigen-receptor/CD3 complex. Immunology. 1991;72:457-63.

74. Haeryfar SMM, Conrad DM, Musgrave BL, Hoskin D. Antibody blockade of Thy-1 ( CD90 ) impairs mouse cytotoxic T lymphocyte induction by anti-CD3 monoclonal antibody. Immunol. Cell Biol. 2005;83:352-63.

75. Hueber A-O, Raposo G, Pierres M, He H-T. Thy-1 Triggers Mouse Thymocyte Apoptosis Through a bcl-2-resistant Mechanism. J Exp Med. 1994;179:78596.

76. Fujita N, Kato $\mathrm{Y}$, Naito M, Tsuruo T. A novel anti-Thy-1 (CD90) monoclonal antibody induces apoptosis in mouse malignant T-lymphoma cells in spite of inducing bcl-2 expression. International journal of cancer Journal international du cancer. 1996;66(4):544-50. PubMed PMID: 8635872. 
77. Fujita N, Kodama N, Kato $\mathrm{Y}$, Lee SH, Tsuruo T. Aggregation of Thy-1 glycoprotein induces thymocyte apoptosis through activation of CPP32-like proteases. Experimental cell research.1997;232(2):400-6.

PubMed PMID:9168818.

78. Abeysinghe HR, Pollock SJ, Guckert NL, Veyberman Y, Keng P, Halterman $\mathrm{M}$, et al. The role of the THY1 gene in human ovarian cancer suppression based on transfection studies. Cancer Genet. Cytogenet. 2004;149:1-10.

79. Lung HL, Bangarusamy DK, Xie D, Cheung AKL, Cheng Y, Kumaran MK, et al. THY1 is a candidate tumour suppressor gene with decreased expression in metastatic nasopharyngeal carcinoma. Oncogene. 2005;24:6525-32.

80. Saalbach A, Haustein UF, Anderegg U. A Ligand of Human Thy-1 is Localized on Polymorphonuclear Leukocytes and Monocytes and Mediates the Binding to Activated Thy-1-Positive Microvascular Endothelial Cells and Fibroblasts. Soc. Investig. Dermatology. 2000;115:882-8.

81. Saalbach A, Hildebrandt G, Haustein U-F, Anderegg U. The Thy-1 / Thy-1 Ligand Interaction Is Involved in Binding of Melanoma Cells to Activated Thy1- Positive Microvascular Endothelial Cells. Microvasc Res. 2002;64:86-93.

82. Saalbach A, Anderegg U, Bruns M, Schnabel E, Hermann K, Haustein U. Novel fibroblast-specific monoclonal antibodies: properties and specificities. Soc. Investig. Dermatology. 1996;106:1314-9.

83. Saalbach A, Wetzel A, Haustein U-F, Sticherling M, Simon JC, Anderegg U. Interaction of human Thy-1 (CD90) with the integrin alphavbeta3 (CD51/CD61): an important mechanism mediating melanoma cell adhesion to activated endothelium. Oncogene. 2005;24:4710-20.

84. Barker TH, Grenett HE, MacEwen MW, Tilden SG, Fuller GM, Settleman J, et al. Thy-1 regulates fibroblast focal adhesions, cytoskeletal organization and migration through modulation of p190 RhoGAP and Rho GTPase activity. Exp. Cell Res. 2004;295:488-96.

85. Jósvay K, Winter Z, Katona RL, Pecze L, Marton A, Buhala A, et al. Besides neuro-imaging, the Thy1-YFP mouse could serve for visualizing experimental tumours, inflammation and wound-healing. Sci. Rep. 2014;4:1-7.

86. Schubert K, Polte T, Bönisch U, Schader S, Holtappels R, Hildebrandt G, et al. Thy-1 (CD90) regulates the extravasation of leukocytes during inflammation. Eur. J. Immunol. 2011;41:645-56.

87. Wetzel A, Chavakis T, Preissner KT, Sticherling M, Haustein U-F, Anderegg $U$, et al. Human Thy-1 (CD90) on activated endothelial cells is a counterreceptor for the leukocyte integrin Mac-1 (CD11b/CD18). J. Immunol. 2004;172:3850-9.

88. Zhou Y, Hagood JS, Murphy-ullrich JE. Thy-1 Expression Regulates the Ability of Rat Lung Fibroblasts to Activate Transforming Growth Factor- $\beta$ in Response 
to Fibrogenic Stimuli. Am. Jounal Pathol. 2004;165:659-69.

89. Hagood JS, Prabhakaran P, Kumbla P, Salazar L, Macewen MW, Barker TH, et al. Loss of Fibroblast Thy-1 Expression Correlates with Lung Fibrogenesis. Am. Jounal Pathol. 2005;167:365-79.

90. Leis $\mathrm{M}$, Marschall M, Stamminger T. Downregulation of the cellular adhesion molecule Thy-1 (CD90) by cytomegalovirus infection of human fibroblasts. J. Gen. Virol. 2004;85:1995-2000.

91. Li Q, Wilkie AR, Weller M, Liu X, Cohen Jl. THY-1 Cell Surface Antigen (CD90) Has an Important Role in the Initial Stage of Human Cytomegalovirus Infection. PLOS Pathog. 2015;11:e1004999. Available from: http://dx.plos.org/10.1371/journal.ppat.1004999

92. Yang ZF, Ho DW, Ng MN, Lau CK, Yu WC, Ngai P, et al. Significance of CD90 + Cancer Stem Cells in Human Liver Cancer. Cancer Cell. 2008;13:153-66.

93. Lu J-W, Chang J-G, Yeh K-T, Chen R-M, Tsai JJP, Hu R-M. Overexpression of Thy1/CD90 in human hepatocellular carcinoma is associated with HBV infection and poor prognosis. Acta Histochem. Elsevier. 2011;113:833-8. Available from: http://dx.doi.org/10.1016/j.acthis.2011.01.001.

94. Sukowati CHC, Anfuso B, Torre G, Francalanci P, Crocè LS, Tiribelli C. The Expression of CD90/Thy-1 in Hepatocellular Carcinoma: An In Vivo and In Vitro Study. PLoS One. 2013;8:1-11.

95. Jiang J, Zhang Y, Chuai S. Transtuzumab (Herceptin) targets gastric cancer stem cells characterized by CD90 phenotype. Oncogene. 2012;31:671-82.

96. Gisina AM, Lupatov AY, Karalkir PA, Maionovskaya OA, Petrov LO, Sidorov DV, et al. Oncology. 2011;152:684-7.

97. Pascal LE, Goo YA, Vêncio RZ, Page LS, Chambers AA, Liebeskind ES, et al. Gene expression down-regulation in CD90+ prostate tumor-associated stromal cells involves potential organ-specific genes. BMC Cancer. 2009;9:112.

98. True LD, Zhang H, Ye M, Huang C-Y, Nelson PS, von Haller PD, et al. CD90/THY1 is overexpressed in prostate cancer-associated fibroblasts and could serve as a cancer biomarker. Mod. Pathol. Nature Publishing Group; 2010;23:1346-56. Available from: http://dx.doi.org/10.1038/modpathol.2010.122

99. He J, Liu Y, Zhu T, Zhu J, DiMeco F, Vescovi AL, et al. CD90 is Identified as a Candidate Marker for Cancer Stem Cells in Primary High-Grade Gliomas Using Tissue Microarrays. Mol. Cell. Proteomics. 2012;11:M111.010744M111.010744.

100. Zhu J, Thakolwiboon S, Liu X, Zhang M, Lubman DM. Overexpression of CD90 (Thy-1) in Pancreatic Adenocarcinoma Present in the Tumor 
Microenvironment. PLoS One. 2014;9:1-20. Available from: http://dx.plos.org/10.1371/journal.pone.0115507.

101. Jurisic G, lolyeva M, Proulx ST, Halin C, Detmar M. Thymus cell antigen 1 (Thy1, CD90) is expressed by lymphatic vessels and mediates cell adhesion to lymphatic endothelium. Exp. Cell Res. Elsevier Inc.; 2010;316:2982-92. Available from: http://dx.doi.org/10.1016/i.yexcr.2010.06.013.

102. Ishiura $\mathrm{Y}$, Kotani N, Yamashita R, Yamamoto $\mathrm{H}$, Kozutsumi $\mathrm{Y}$, Honke K. Anomalous expression of Thy1 (CD90) in B-cell lymphoma cells and proliferation inhibition by anti-Thy1 antibody treatment. Biochem. Biophys. Res. Commun. Elsevier Inc.; 2010;396:329-34. Available from: http://dx.doi.org/10.1016/j.bbrc.2010.04.092.

103. Morris R, Tiveron $\mathrm{M}$, Xue $\mathrm{G}$. The relation of the expression and function of the neuronal glycoprotein Thy-1 to axonal growth. Biochem. Soc. Trans. $1991 ; 20: 401-5$.

104. Jeng CJ, McCarroll SA, Martin TFJ, Floor E, Adams J, Krantz D, et al. Thy-1 is a component common to multiple populations of synaptic vesicles. J. Cell Biol. 1998;140:685-98.

105. Leyton L, Schneider P, Labra C V, Ruegg C, Hetz CA, Quest AFG, et al. Thy1 binds to integrin $\beta 3$ on astrocytes and triggers formation of focal contact sites. Curr. Biol. 2001;11:1028-38.

106. Nostern Bertrand M, Errington ML, Murphy KP, Tokugawa Y, Barboni E, Kozlova E, et al. Normal spatial learning despite regional inhibition of LTP in mice lacking Thy-1. Nature. 1996; 379:826-9

107. Campioni D, Lanza F, Moretti S, Ferrari L, Cuneo A. Loss of Thy-1 (CD90) antigen expression on mesenchymal stromal cells from hematologic malignancies is induced by in vitro angiogenic stimuli and is associated with peculiar functional and phenotypic characteristics. Cytotherapy. Elsevier; 2008;10(1):69-82. Available from: http://dx.doi.org/10.1080/14653240701762364

108. Campioni D, Rizzo R, Stignani M, Melchiorri L, Ferrari L, Moretti S, et al. A decreased positivity for CD90 on human mesenchymal stromal cells (MSCs) is associated with a loss of immunosuppressive activity by MSCs. Cytom. Part B - Clin. Cytom. 2009;76:225-30.

109. Maleki M, Ghanbarvand F, Behvarz MR, Ejtemaei M, Ghadirkhomi E. Comparison of Mesenchymal Stem Cell Markers in Multiple Human Adult Stem Cells. Int. Jounal Stem Cells. 2014;7:118-26.

110. Durai S, Mani M, Kandavelou K, Wu J, Porteus MH, Chandrasegaran S. Zinc finger nucleases: Custom-designed molecular scissors for genome engineering of plant and mammalian cells. Nucleic Acids Res. 2005;33:597890 . 
111. Gardlík R, Pálffy R, Hodosy J, Lukács J, Turna J, Celec P. Vectors and delivery systems in gene therapy. Med Sci Monit. 2005;11(4):RA110-A121.

112. Miyoshi H, Blömer U, Takahashi M, Gage FH, Verma IM. Development of a self-inactivating lentivirus vector. J Virol. 1998;72(10):8150-7.

113. McGinley L, McMahon J, Strappe P, Barry F, Murphy M, O'Toole D, et al. Lentiviral vector mediated modification of mesenchymal stem cells \& enhanced survival in an in vitro model of ischaemia. Stem Cell Res Ther. BioMed Central; 2011;2(12):1-18. Available from: http://stemcellres.com/content/2/2/12

114. Lin P, Lin Y, Lennon DP, Correa D, Schluchter M, Caplan A. Efficient Lentiviral Transduction of Human Mesenchymal Stem Cells That Preserves Proliferation and Differentiation Capabilities. Stem Cells Transl Med. 2012;1:886-97.

115. Horn P a, Morris JC, Neff T, Kiem HP. Stem cell gene transfer-efficacy and safety in large animal studies. Mol Ther. 2004;10(3):417-31.

116. Kallifatidis G, Beckermann BM, Groth A, Schubert M, Apel A, Khamidjanov A, et al. Improved lentiviral transduction of human mesenchymal stem cells for therapeutic intervention in pancreatic cancer. Cancer Gene Ther. 2008;15(4):231-40.

117. Grinev V V, Severin IN, Posrednik D V, Kosmacheva SM, Potapnev MP. Highly efficient transfer and stable expression of two genes upon lentivirus transduction of mesenchymal stem cells from human bone marrow. Russ $\mathrm{J}$ Genet. 2012;48(3):336-46. Available from: http://www.ncbi.nlm.nih.gov/entrez/query.fcgi?cmd=Retrieve\&db=PubMed\&d opt=Citation\&list uids $=22679786$

118. Stewart SA, Dykxhoorn DM, Palliser D, Mizuno H, Yu EY, An DS, et al. Lentivirus-delivered stable gene silencing by RNAi in primary cells. RNA. 2003;9(4):493-501.

119. Rubinson DA, Dillon CP, Kwiatkowski AV, Sievers C, Yang L, Kopinja J, et al. A lentivirus-based system to functionally silence genes in primary mammalian cells, stem cells and transgenic mice by RNA interference. Nat Genet. 2003;33(3):401-6.

120. Scherr M, Venturini L, Battmer K, Schaller-Schoenitz M, Schaefer D, Dallmann I, et al. Lentivirus-mediated antagomir expression for specific inhibition of miRNA function. Nucleic Acids Res. 2007;35(22):1-9.

121. Barros SA, Gollob JA. Safety profile of RNAi nanomedicines. Adv Drug Deliv Rev. 2012;64:1730-7.

122. Saldanha-Araújo F, Ferreira FIS, Palma PV, Araujo AG, Queiroz RHC, Covas DT, et al. Mesenchymal stromal cells up-regulate CD39 and increase adenosine production to suppress activated T-lymphocytes. Stem Cell Res. $\begin{array}{llll}\text { Elsevier } & \text { B.V.; } & \text { 2011;7(1):66-74. } & \text { Available from: }\end{array}$ 


\section{http://dx.doi.org/10.1016/j.scr.2011.04.001}

123. Gregory CA, Gunn WG, Peister A, Prockop DJ. An Alizarin red-based assay of mineralization by adherent cells in culture: comparison with cetylpyridinium chloride extraction. Anal Biochem. 2004;329(1):77-84. Available from: http://www.ncbi.nlm.nih.gov/pubmed/15136169.

124. Conconi MT, Tommasini M, Muratori E, Parnigotto PP. Essential amino acids increase the growth and alkaline phosphatase activity in osteoblasts cultured in vitro. II Farm. 2001;56:755-61.

125. Silva LHA. Marcação de células-tronco mesenquimais com nanopartículas metálicas funcionalizadas com ácido 2,3-dimercaptosuccínico (DMSA). 2014.

126. Lowry $\mathrm{OH}$, Rosebrough NJ, Farr AL, Randall RJ. Protein measurement with the folin phenol reagent. J Biol Chem.1951;193:265-75.

127. Gitelman J. An Improved Automated Procedure of Calcium in Biological for the Determination Specimens. Anal Biochem. 1967;18:521-31.

128. Feng J, Mantesso A, De Bari C, Nishiyama A, Sharpe PT. Dual origin of mesenchymal stem cells contributing to organ growth and repair. Proc Natl Acad Sci USA. 2011;108(16):6503-8.

129. Lesley J, Hascall VC, Tammi M, Hyman R. Hyaluronan Binding by Cell Surface CD44. J Biol Chem. 2000;35:26967-75.

130. Zhu H, Mitsuhashi N, Klein A, Barsky LW, Weinberg K, Barr ML, et al. The role of the hyaluronan receptor CD44 in mesenchymal stem cell migration in the extracellular matrix. Stem Cells. 2006;24:928-35. doi:10.1634/stemcells.2005-0186.

131. Puré E, Cuff CA. A crucial role for CD44 in inflammation. TRENDS in Molecular Medicine. 2001;7:213-21.

132. Sapaeth EL, Labaff AM, Toole BP, Klopp A, Andreeff M and Marini FC. Mesenchymal CD44 expression contributes to the acquisition of an activated fibroblast phenotype via TWIST activation in the tumor microenvironment. Cancer Res 2013; 73(17). doi: 101158/0008-5472.

133. Pham PV, Phan NL, Nguyen NT, Truong NH, Duong TT, Le D V, et al. Differentiation of breast cancer stem cells by knockdown of CD44: promising differentiation therapy. Journal of Translational Medicine. 2011;9:209. doi:10.1186/1479-5876-9-209.

134. Bowen MA, Patel DD, Li X, Modrell B, Malacko AR, Wang W, et al. Cloning, mapping and characterization of activated leukocyte-cell adhesion molecule (ALCAM) a CD6 ligant. J Exp Med. 1995;181:2213-20.

135. Swart GW, Lunter PC, Kilsdonk JW van, Kempen LC van. Activated Leukocyte Cell Adhesion Molecule ( ALCAM / CD166 ): Signaling at the Divide of Melanoma Cell Clustering and Cell Migration. Cancer and Metastasis. 
2005;24:223-36. doi:10.1007/s10555-005-1573-0.

136. Bruder SP, Jaiswal N, Haynesworth SE. Growth Kinetics, Self-Renewal and the Osteogenic Potential of Purified Human Mesenchymal Stem Cells During Extensive Subcultivation and Following Cryopreservation. Jounal of Cellular Biochemistry. 1997;64:278-94.

137. Lugli A, lezzi G, Hostettler I, Muraro MG, Mele V, Tornillo L, et al. Prognostic impact of the expression of putative cancer stem cell colorectal cancer. British Journal of Cancer. 2010;103:382-90. doi:10.1038/sj.bjc.6605762.

138. Piscuoglio S, Lehmann FS, Zlobec I, Tornillo L, Dietmaier W, Hartmann A, et al. Effect of EpCAM , CD44 , CD133 and CD166 expression on patient survival in tumours of the ampulla of Vater. $J$ Clin Pathol. 2011:1-6. doi:10.1136/jclinpath-2011-200043.

139. Fujiwara K, Ohuchida K, Sada M, Horioka K, lii CDU, Shindo K, et al. CD166/ ALCAM Expression Is Characteristic of Tumorigenicity and Invasive and Migratory Activities of Pancreatic Cancer Cells. PLoS ONE. 2014;9:1-11. doi:10.1371/journal.pone.0107247.

140. Ma L, Pan Q, Sun F, Yu Y, Wang J. Cluster of differentiation 166 ( CD166 ) regulates cluster of differentiation ( CD44 ) via NF- kB in liver cancer cell line Bel-7402. Biochemical and Biophysical Research Communications. 2014;451:334-8. doi:10.1016/j.bbrc.2014.07.128.

141. Donnenberg VS, Donnenberg AD, Zimmerlin L, Landreneau RJ, Bhargava R, Wetzel RA, et al. Localization of CD44 and CD90 positive cells to the invasive front of breast tumors. Cytometry Part B - Clinical Cytometry. 2010;78B:287301. doi:10.1002/cyto.b.20530.

142. Phipps RP, Penney DP, Keng P. Characterization of two major populations of lung fibroblasts: distinguishing morphology and discordant display of Thy-1 and class II MHC. Am J Respir Cell Mol Biol.1989;1:65-74.

143. Woeller CF, O'Loughlin CW, Pollock SJ, Thatcher TH, Feldon SE, Phipps RP. Thy1 ( CD90 ) controls adipogenesis by regulating activity of the Src family kinase , Fyn. FASEB. 2015;29:920-31. doi:10.1096/fj.14-257121.

144. Shukla MN, Rose JL, Ray R, Lathrop KL, Ray A, Ray P. Hepatocyte growth factor inhibits epithelial to myofibroblast transition in lung cells via Smad7. American Journal of Respiratory Cell and Molecular Biology. 2009;40:643-53. doi:10.1165/rcmb.2008-02170C.

145. James AW. Review of Signaling Pathways Governing MSC Osteogenic and Adipogenic Differentiation. Scientifica. 2013;2013:1-17. doi:10.1155/2013/684736.

146. Sordella R, Jiang W, Chen GC, Curto M, Settleman J. Modulation of Rho GTPase signaling regulates a switch between adipogenesis and myogenesis. Cell. 2003;113:147-58. doi:10.1016/S0092-8674(03)00271-X. 
147. Barker TH, Hagood JS. Getting a grip on Thy-1 signaling. Biochim Biophys Acta. 2008;1793(5):921-3.

148. Ito K, Yamada Y, Nakamura S, Ueda M. Osteogenic potential of effective bone engineering using dental pulp stem cells, bone marrow stem cells and periosteal cells for osseointegration of dental implants. Int $\mathrm{J}$ Oral Maxillofac Implants.2011;26:947-54.

149. Yu J, Wang Y, Deng Z, Tang L, Li Y, Shi J, et al. Odontogenic capability: bone marrow stromal stem cells versus dental pulp stem cells. Biol Cell. 2007;99:465-74.

150. Alge DL, Zhou D, Adams LL, Wiss BK, Shadday MD, Woods EJ, et al. Donormatched comparision of dental pulp stem cells and bone marrow-derived mesenchymal stem cells in a rat model. J Tissue Eng Regen Med. 2010;4:7381.

151. Chen XD, Qian HY, Neff L, Satomura K, Horowitz MC. Thy-1 antigen expression by cells in the osteoblast lineage. Journal of Bone and Mineral Research. 1999;14:362-75. doi:10.1359/jbmr.1999.14.3.362.

152. Wiesmann A, Bühring H-J, Mentrup C, Wiesmann H-P. Decreased CD90 expression in human mesenchymal stem cells by applying mechanical stimulation. Head \& Face Medicine. 2006;2:1-6. doi:10.1186/1746-160X-2-8. 


\section{APÊNDICE A- Termo de Consentimento Livre e Esclarecido}

TERMO DE CONSENTIMENTO LIVRE E ESCLARECIDO

Universidade de Brasilia-UnB

Título do Projeto: ESTUDO DA FUNÇÃO DE CD90 NA PROLIFERAÇÃO E DIFERENCIAÇÃO DE CÉLULAS-TRONCO MESENQUIMAIS HUMANAS.

Pesquisadora responsável: Daniela Abreu de Moraes

Telefones: (61) 9-81856577 (61) 3335-0770

e-mail: daniela.di.moraes@gmail.com

Nome do paciente:

Idade: Telefone: R.G.:

R.G. do responsável legal:

O (A) Sr.(a) está convidado (a) a participar do projeto de pesquisa com o título acima, que tem o objetivo de estudar células que estão dentro do dente (na polpa dental). Essas células são chamadas de células-tronco mesenquimais e pretendemos estudá-la para entendermos seu funcionamento.

Os dentes que serão extraídos por indicação do ortodontista serão doados para a pesquisa. As células presentes no interior desses dentes serão estudadas no Laboratório de Morfologia e Morfogênese da Universidade de Brasília.

Não haverá desconfortos ou riscos para o paciente, se realizar ou não a doação e se concordar ou não em participar da pesquisa.

Caso haja qualquer dúvida, entre em contato pelo telefone ou e-mail da pesquisadora que está nesse termo.

A confidencialidade das informações geradas, bem como a privacidade dos participantes será garantida pela pesquisadora.

Eu, RG

Declaro ter sido informado e concordo em doar o(s) dente(s) extraídos para o projeto de pesquisa descrito acima.

Brasília, de de 
APÊNDICE B- Artigo 1 


\title{
A reduction in CD90 (THY-1) expression results in increased differentiation of mesenchymal stromal cells
}

Daniela A. Moraes ${ }^{1,6}$, Tatiana T. Sibov ${ }^{3}$, Lorena F. Pavon ${ }^{3}$, Paula Q. Alvim', Raphael S. Bonadio', Jaqueline R. Da Silva', Aline Pic-Taylor', Orlando A. Toledo², Luciana C. Marti', Ricardo B. Azevedo and Daniela M. Oliveira ${ }^{1,5^{*}}$

\begin{abstract}
Background: Mesenchymal stromal cells (MSCs) are multipotent progenitor cells used in several cell therapies. MSCs are characterized by the expression of CD73, CD90, and CD105 cell markers, and the absence of CD34, CD45, CD11a, CD19, and HLA-DR cell markers. CD90 is a glycoprotein present in the MSC membranes and also in adult cells and cancer stem cells. The role of CD90 in MSCs remains unknown. Here, we sought to analyse the role that CD90 plays in the characteristic properties of in vitro expanded human MSCs.

Methods: We investigated the function of CD90 with regard to morphology, proliferation rate, suppression of T-cell proliferation, and osteogenic/adipogenic differentiation of MSCs by reducing the expression of this marker using CD90-target small hairpin RNA lentiviral vectors.

Results: The present study shows that a reduction in CD90 expression enhances the osteogenic and adipogenic differentiation of MSCs in vitro and, unexpectedly, causes a decrease in CD44 and CD166 expression.

Conclusion: Our study suggests that CD90 controls the differentiation of MSCs by acting as an obstacle in the pathway of differentiation commitment. This may be overcome in the presence of the correct differentiation stimuli, supporting the idea that CD90 level manipulation may lead to more efficient differentiation rates in vitro.

Keywords: Mesenchymal stem cells, Mesenchymal stromal cells, CD90, Thy-1, Fibroblast, Differentiation
\end{abstract}

\section{Background}

Mesenchymal stromal cells (MSCs) are multipotent progenitor cells identified by their plastic-adherence when maintained under standard culture conditions, selfrenewability, and differentiation into several mesodermal lineages [1-3]. MSCs are classically able to differentiate into osteoblasts, adipocytes, and chondroblasts in vitro [4]. Since their initial description as colony-forming cell units present in the bone marrow [5], MSCs have been isolated from many tissue sources such as placenta [6], dental pulp [7], tendons [8], scalp tissue [9], adipose tissue [10], umbilical cord blood [11], umbilical cord perivascular

\section{* Correspondence: dmoliveira@unb.br}

'Departamento de Genética e Morfologia, Universidade de Brasilia, Brasilia, DF, Brazil

IIB-Departamento de Genética e Morfologia, Universidade de Brasília - UNB, Campus Universitário Darcy Ribeiro, Asa Norte, Brasilia CEP 70910-970, Brazil Full list of author information is available at the end of the article cells [12], umbilical cord Wharton's jelly [13], synovia membrane [2], amniotic fluid [14], and breast milk [15] Due to their relatively easy isolation, multi-differentiation potential, low antigenicity, and good proliferation/expansion in cell culture, MSCs are considered ideal candidates for cell-based regenerative therapies [16]. Based on the minimal criteria established by the International Society for Cellular Therapy (ISCT), human MSCs are identified by a combination of high CD105, CD73, and CD90 expression, and very low/no CD34, CD45, CD11a, CD19, and HLA-DR expression [4, 17]. Currently, there is no unique cell marker capable of solely isolating and defining MSCs. The observation that only a subpopulation of plastic-adherence isolated MSCs show multipotency [18] has led to a search for an ideal and definitive single MSC marker that would not only be specific to MSC, but would allow direct correlation with stemness [19].

\section{BioMed Central}

O 2016 The Author(s). Open Access This article is distributed under the terms of the Creative Commons Attribution 4.0 International license (http//creativecommons.org/licenses/by/4.0N, which permits unrestricted use, distribution, and reproduction in any medium, provided you give appropriate credit to the original author(s) and the source, provide a link to the Creative Commons license, and indicate if changes were made. The Creative Commons Public Domain Dedication waiver (http//creativecommons.org/publicdomain/zero/1.0n applies to the data made available in this article, unless otherwise stated 
Although CD90 and STRO-1 are broadly used to identify MSCs, neither of them is specific to MSCs [20-22]. STRO-1 is only expressed in a low percentage of MSCs. Some authors also discuss the absence of this marker in MSCs from all tissue sources [12, 19, 23], and it remains unclear, in the current literature, whether STRO-1 expression correlates to MSC stemness. On the other hand, CD90 is highly expressed in all MSCs, irrespective of the source, and it is a good marker for CFU-F enrichment [24]. High CD90 expression has also been related to the undifferentiated status of MSCs, since a decrease in CD90 level can be correlated with the temporal lineage commitment in vitro [25].

CD90, or Thy-1, is a 25-37 KDa glycosylphosphatidylinositol (GPI)-anchored glycoprotein [26]. CD90 was first detected in mice $T$ cells [27] and later found to be expressed in thymocytes, $\mathrm{T}$ cells, neurons, hematopoietic stem cells, cancer stem cells, endothelial cells, and fibroblasts [28]. Although it has been shown that CD90 is conserved among different species, its function seems to vary according to cell type [29]. CD90 has been reported to participate in T-cell activation [30], neuritis outgrowth modulation [31], vesicular release of neurotransmitter at the synapse [32], astrocyte adhesion [33], apoptosis in carcinoma cells [34], tumour suppression [35-37], wound healing [38], fibrosis [39, 40], and fibrogenesis [41]. Furthermore, it regulates fibroblast focal adhesion, cytoskeleton organization, and cell migration [42]. In mouse models, activation of CD90 expression can be observed in inflammation, wound healing, and tumour development [43]. Recent studies suggest that CD90 has a role in oncogenesis, and it has also been proposed as a marker for cancer stem cells (CSCs) in various malignancies [44-51].

Despite an increasing number of studies suggesting CD90 participation in MSC self-renewal and differentiation [52], its function in MSC biology remains unknown. The unveiling of the function of CD90 in MSCs may further facilitate the in vitro manipulation of MSCs and consequently MSC-based therapies for regenerative medicine. In this study, we investigated the function of CD90 in MSC biology. To achieve this objective, we analysed the effect of CD90 knockdown on proliferation, morphology, and differentiation of human MSCs.

\section{Methods}

\section{Subjects and cell culture}

The cells were obtained with the approval of the Ethics Committee of the Faculty of Health Sciences at the University of Brasilia (Brazil) and University of São Paulo (Brazil). MSCs were isolated from healthy human tissues and cultured as previously reported. In the present study, we obtained MSCs from three different tissue sources: dental pulp [7] (three donors), adipose tissue [10] (two donors), and amniotic fluid [14] (two donors).
After isolation, cells were cryopreserved and stored in liquid nitrogen. For the assays we used cells that were stored for no longer than 1 year. Briefly, cells were thawed and expanded in a regular medium of Dulbecco's modified Eagle's medium (DMEM-LG; Sigma Chemical), supplemented with $10 \%$ fetal bovine serum (FBS; Gibco), 100 units $/ \mathrm{ml}$ penicillin, $100 \mathrm{mg} / \mathrm{ml}$ streptomycin (Gibco), and $10 \mu \mathrm{l} / \mathrm{ml} \mathrm{L-glutamine} \mathrm{(Gibco)} \mathrm{at} 37{ }^{\circ} \mathrm{C}, 5 \%$ $\mathrm{CO}_{2}[1]$. The medium was changed every $48 \mathrm{~h}$.

\section{Lentiviral transduction for CD90 depletion}

For lentiviral transduction, MSC isolates (a total of seven samples at cell passage 2) were cultured in a $75-\mathrm{cm}^{2}$ flask in medium containing $10 \%$ FBS (Gibco), 100 units $/ \mathrm{ml}$ penicillin, $100 \mathrm{mg} / \mathrm{ml}$ streptomycin (Gibco), $10 \mu \mathrm{l} / \mathrm{ml} \mathrm{L}$-glutamin (Gibco) at $37{ }^{\circ} \mathrm{C}, 5 \% \mathrm{CO}_{2}$. When cells reached a confluence of $60 \%$, transduction was performed in the presence of $8 \mu \mathrm{g} / \mathrm{ml}$ Polybrene (SigmaAldrich) according to the manufacturer's instructions (Santa Cruz Biotechnology). CD90 small hairpin (sh)RNA-expressing lentivirus (shRNA CD90) or nontargeting shRNA-expressing scramble sequences of RNA (shRNA control) were then added to the cells at a multiplicity of infection (MOI) of 10. The medium was changed after $24 \mathrm{~h}$. Three days after transduction, stable clones of MSCs expressing CD90-shRNA (shRNA CD90 MSC) and control shRNA (shRNA control MSC) were selected using $5 \mu \mathrm{g} / \mathrm{ml}$ Puromycin (Sigma-Aldrich) for 10 days. The medium was changed every $48 \mathrm{~h}$.

\section{Real-time quantitative PCR}

Total RNA was extracted from MSCs using Illustra RNAspin Mini (GE Healthcare), according to the manufacturer's guidelines. cDNA was prepared with High-Capacity cDNA Reverse Transcription (Applied Biosystems) and used as templates for polymerase chain reaction (PCR). The Kit Power Up SYBR Green Master Mix (Applied Biosystems) was used to quantify CD90 gene expression by quantitative real-time (qRT)-PCR under conditions recommended by the manufacturer and using the following primers: CACCCTCTCCGCACACCT (forward) and CCCCACCATCCCACTACC (reverse). For normalization of the data, the housekeeping gene glyceraldehyde 3phosphate dehydrogenase (GAPDH) mRNA was used (forward primer: AGAAGGCTGGGGCTCATTTG; reverse primer: AGGGGCCATCCACAGTCTTC). qRTPCR was performed with the StepOne Plus Real-Time PCR System. A standard curve was generated for each primer pair, and genes of interest were assigned a relative expression value interpolated from the standard curve using the threshold cycle. All expression values were normalized against GAPDH. All amplifications were done in triplicate. 
Magnetic separation of the MSCs for negative selection of CD90

Cell purification was performed according to the manufacturer's instructions (MiltenyiBiotec). To isolate the CD90-negative MSC population, shRNA CD90 MSCs were incubated with anti-CD90-coupled magnetic beads (MiltenyiBiotec, Germany) for $15 \mathrm{~min}$ at $4{ }^{\circ} \mathrm{C}$, rinsed, and placed in a column. The negative fraction (CD90-negative MSCs) was collected, and cell purity checked by flow cytometry (FACSVERSE-BD Biosciences, San Jose, CA, USA) and FlowJo analysis software (TreeStar, Ashland, OR, USA).

\section{Flow-cytometric analysis}

Commercially available monoclonal antibodies were used for MSC immunophenotyping following the manufacturer's instructions. Subcultures at passage 3 were used for the flow-cytometric analysis. MSCs were lifted using TrypLE (Invitrogen, Carlsbad, CA, USA) and centrifuged for $5 \mathrm{~min}$ at $1000 \mathrm{rpm}$. The supernatant was discarded by aspiration and the cells incubated for $30 \mathrm{~min}$ in a dark environment in a flow cytometry buffer (phosphate-buffered saline (PBS), 2 \% FBS) containing monoclonal antibodies against cell surface molecules and their respective isotype controls. The following antibodies were used: CD14-FITC; CD29-PE; CD31-PE; CD34-PE; CD44-PE; CD73-PE; CD90-APC; CD90-FITC; CD106-FITC; CD166-PE and CD166-PerPC-Cy5.5; CD45-PerCP-Cy5.5; HLA-DRPerCP-Cy5.5 (Biosciences); and CD105-PE (clone 8E11; Chemicon, Temecula, CA, USA). Mouse IgG1-FITC, IgG1-PE, IgG1 PerCP-Cy5.5, IgG1-APC (Biosciences), and IgG2A-FITC (AbDSerotec, UK) were used as isotype controls. Cells were analysed using a fluorescence-activated cell sorter (CyFlowSpace-Partec, Germany; FACSVERSE$\mathrm{BD}$ or FACSARIA-BD, both from BD Biosciences) and the data analysed using FlowJo analysis software (TreeStar).

\section{MSC morphology analysis}

Transduced and non-transduced MSCs at passage 3 were placed, in triplicate, in 24-well culture plates $\left(5 \times 10^{4}\right.$ cells/ well). After cell concentration reached a confluence of $70 \%$, media were removed and the cells were washed with PBS and fixed with a $4 \%$ paraformaldehyde solution for $15 \mathrm{~min}$ at room temperature. Cells were then washed with PBS, stained with Kit Instant Prov (NewProv, Brazil) and rewashed with PBS. Cell morphology (shape and size) was then analysed under an Axiovert inverted microscope (Zeiss, Germany) and EVOS FL cell imaging system (Life Technologies, Eugene, OR, USA).

\section{Growth assay}

For the assessment of growth characteristics, MSCs (1 $10^{5}$ cells, at passage 3 after transduction, passage 5 after isolation) were seeded in $75-\mathrm{cm}^{2}$ culture flasks in MSC culture medium. Every 48 h, three replicate flasks were trypsinised and viable cells counted with a haemocytometer. MSC viability was evaluated by Trypan blue exclusion assay.

\section{Lymphocyte proliferation assay}

Peripheral blood mononuclear cells were isolated from peripheral blood and separated using the standard method with Ficoll-Paque PLUS (Amersham Biosciences, Uppsala, Sweden). The mononuclear cells were washed twice with PBS buffer. Cells were then counted in an automated cell counter (2.0 Scepter, Millipore), resuspended to a final concentration of $10^{4}$ cells $/ \mathrm{ml}$ and labelled with CFSE (Sigma-Aldrich). The CFSE was adjusted to a final concentration of $5 \mu \mathrm{M}$ and incubated for $10 \mathrm{~min}$ at $37{ }^{\circ} \mathrm{C}$. The reaction was stopped by adding RPMI with $10 \%$ FBS. In immediate succession, $2 \times 10^{4}$ lymphocytes were cultured with or without $5 \times 10^{4}$ MSCs previously adhered to the bottom of a 24-well plate in a total volume of $1 \mathrm{ml}$ per well of RPMI with $10 \%$ FBS medium. To evaluate the lymphocyte proliferation rate in the presence of MSCs, cell suspensions were activated with a phytohaemagglutinin (PHA; Sigma, USA) stimulus at a final concentration of $1 \mu \mathrm{g} /$ $\mathrm{ml}$ in cell culture and maintained at $37{ }^{\circ} \mathrm{C}$ with $5 \% \mathrm{CO}_{2}$ for 5 days for subsequent assessment by flow cytometry (CyFlowSpace-Partec, Germany) and the FlowJo analysis software (TreeStar) [53]. Suspension cells were stained with CD8-PE antibody (Biosciences), and lymphocyte proliferation was measured according to CFSE staining on gated population.

\section{In vitro differentiation assays}

To evaluate the differentiation potential of MSCs, cells were subjected to in vitro osteogenic and adipogenic differentiation according to the established protocols [1] Transduced and non-transduced MSCs at passage 4 (passage 2 after transduction) were seeded in 24-well plates at a density of $5 \times 10^{4}$ cells/well. When a confluence of $80 \%$ was achieved, the regular medium was replaced with an induction medium, which was refreshed every $72 \mathrm{~h}$ for 21 days. Cells cultured in regular medium were used as controls.

\section{Osteogenic differentiation}

MSCs were placed in 24-well plates at a density of $5 \times$ $10^{4} \mathrm{cells} / \mathrm{cm}^{2}$ the previous day and then treated with osteogenic supplements as previously described [1] for 21 days. The osteogenic medium contained $100 \mathrm{nM}$ dexamethasone (Sigma-Aldrich), $10 \mathrm{mM}$ 2- $\beta$-glycero-phosphate (Sigma-Aldrich), and $50 \mu \mathrm{M}$ of L-ascorbic acid-2phosphate (Sigma-Aldrich). Osteogenic differentiation was evaluated by alkaline phosphatase (ALP) activity, calcium concentration determination, and colorimetric Alizarin red 
staining. Mineralized matrix formation after osteogenic differentiation was detected as previously described [1]. Samples were fixed with $4 \%$ paraformaldehyde for $15 \mathrm{~min}$, rinsed in PBS, and dyed for $20 \mathrm{~min}$ with $40 \mathrm{mM}$ Alizarin Red solution (Sigma-Aldrich) at $\mathrm{pH} 4.2$ and room temperature. Cells were washed five times with distilled water, followed by an immediate 15-min rinse with PBS to reduce non-specific dying. The resulting samples were analysed and photographed under an Axiovert inverted microscope (Zeiss, Germany). To determine alizarin red concentration, the samples were exposed to $10 \mathrm{mM}$ sodium phosphate containing $10 \%$ cetylpyridinium chloride (Sigma-Aldrich) at $\mathrm{pH}$ of 7.0 for $15 \mathrm{~min}$ at room temperature. The Alizarin Red concentration was determined by measuring absorption at $562 \mathrm{~nm}$ using a spectrophotometer (SpectraMax M2, Molecular Devices, USA). Results were expressed as a percentage of the respective controls, which were normalized to $100 \%$ [54]. Lysate alkaline phosphatase activity was measured spectrophotometrically using a Sigmafast p-nitrophenyl phosphate kit (Sigma-Aldrich). For ALP assays, cells were washed with PBS and lysed in $0.05 \%$ Triton X-100 through three cycles of freezing and thawing. A lysate aliquot was incubated with p-nitrophenyl phosphate substrate (p-NF) at $37{ }^{\circ} \mathrm{C}$ for $30 \mathrm{~min}$. The reactions were stopped by adding $5 \mu \mathrm{l} 1 \mathrm{~N}$ $\mathrm{NaOH}$ and absorbance measured at $405 \mathrm{~nm}$ using a spectrophotometer (SpectraMax M2, Molecular Devices) [55]. A pattern curve of p-NF was established in order to determine the enzymatic activity. Samples were normalized and total protein quantification determined by the Lowry method [56].

The quantitative levels of calcium in cell samples were determined for both osteogenic differentiation-induced and non-induced cells. Supernatant calcium concentration was determined by colorimetry using the ortho-cresolphthalein complexone (o-CPC) method [57]. Cells were trypsinised, resuspended in $\mathrm{PBS}$, and then reacted with a calcium reagent containing $0.69 \mathrm{~mol} / \mathrm{l}$ ethanolamine buffer, $0.2 \%$ sodium azide, $0.338 \mathrm{mmol} / \mathrm{l}$ 0-cresolphthalein complexone, and $78 \mathrm{mmol} / \mathrm{l}$ 8-hydroxynquinoline-13. Cell reactions were read by a spectrophotometer (Advia2400, Siemens)

\section{Adipogenic differentiation}

For adipogenic induction, cells were seeded in 24-well plates at a density of $5 \times 10^{4}$ cells $/ \mathrm{cm}^{2}$. When the cells reached confluence, they were treated with an adipogenic induction medium containing $5 \mathrm{mg} / \mathrm{ml}$ insulin, $5 \mathrm{mmol}$ indomethacin, $1 \mathrm{mmol}$ dexamethasone, and $0.5 \mathrm{mmol} / \mathrm{l}$ isobutyl-1-methylxanthine (all from SigmaAldrich) in regular medium. Adipocyte formation was monitored by the appearance of lipid droplets under a microscope. After the induction period, cytochemical analysis of the differentiated and control cells was performed by conventional optical microscopy. The cells were fixed in $4 \%$ formaldehyde for $15 \mathrm{~min}$, rinsed in PBS, and dyed for 30 min with $0.5 \%$ Oil Red O (SigmaAldrich) in ethanol. Cells were subsequently washed five times with distilled water to remove any excess dye. Quantification of lipid accumulation was achieved by extracting Oil Red-O from stained cells with isopropanol and measuring the OD of the extract at $510 \mathrm{~nm}$ using a Spectramax M2 spectrophotometer (Molecular Devices) [58]

\section{Statistical analysis}

Statistical analysis was performed using the software GraphPad $^{\text {*x }}$ (San Diego, CA, USA). Quantitative data were expressed as mean \pm standard deviations (SD) and statistical analyses of variance (ANOVA). Multiple comparisons were performed with Tukey's HSD test when appropriate. Findings with $p<0.05$ were considered statistically significant.

\section{Results}

\section{MSC isolates and purity}

MSCs were obtained from dental pulp (DPSC; three donors), amniotic fluid (AF-MSC; two donors), and adipose tissue (ADSC; two donors). The success rate of isolating MSCs from all tissues was $100 \%$. Cells from all three sources (a total of seven isolates) contained a high number of adherent MSC-like cells which proliferated rapidly in number. Analysis of positive and negative characteristics for human MSC surface antigens by flow cytometry for cultured MSCs showed a high purity ( $\geq 97 \%$ ) of the cells (Additional file 1: Table S1).

\section{Analysis of the CD90 downregulated expression effect in} MSCs

To initiate our study, we reduced CD90 expression in MSCs (DPSC, AF-MSC, and ADSC) by transducing commercially available lentiviruses expressing three CD90 shRNAs. After transduction, the MSC lines stably expressing shRNA CD90 and shRNA control were established by antibiotic selection. To confirm CD90 reduc tion, unmodified/non-transduced MSCs, shRNA CD90 MSCs, and shRNA control MSCs were analysed by flow cytometry (Fig. 1a and b) and qRT- PCR (Fig. 1c). Nontransduced MSCs and shRNA control MSCs showed the same level of CD90 expression (mean $98 \%$ ), whereas shRNA CD90 MSCs presented reduced CD90 expression (mean 23.9 \%) (Fig. 1b). Transduction and establishment of shRNAs (CD90 and control) expressing MSCs were performed using samples from all tissues, with similar levels of reduction in CD90 expression observed in all samples (Additional file 1: Table S1). qRT- PCR confirmed that shRNA CD90 used here effectively reduced transcript levels of CD90 (Fig. 1c). 


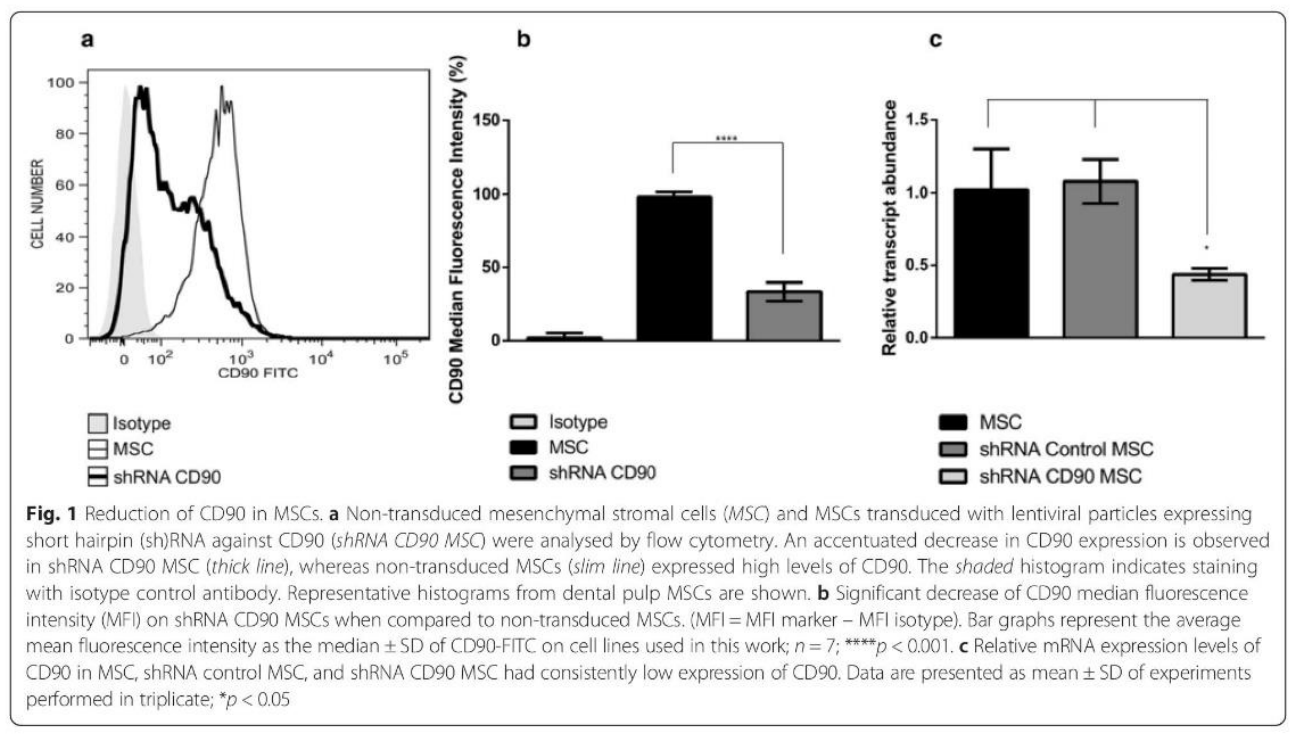

Since CD90 expression was not completely ablated in shRNA CD90 MSCs, we submitted shRNA CD90 MSC samples to magnetic-activated cell sorting and collected the post-separation CD90-negative fraction (subsequently termed CD90-negative MSCs). CD90-negative MSCs were characterized by flow cytometry to verify purification success. Flow cytometry analysis confirmed that the CD90-negative MSCs samples expressed lower levels of CD90 than shRNA CD90 MSCs (Fig. 2).

\section{Morphology and growth kinetics}

In our cellular morphology analysis of the cells used in this study, we observed no differences in the shape and size of MSCs, shRNA control MSCs, shRNA CD90 MSCs, CD90-negative MSCs, and non-transduced MSCs (Fig. 3a). The shRNA CD90 MSCs and CD90-negative MSCs derived from all three sources displayed characteristic MSC/fibroblast-like morphology. We also observed that shRNA CD90 MSCs and CD90-negative MSCs maintained their capacity to form colonies for up to 10 passages, suggesting that CD90 is not involved in the maintenance of MSC cell morphology and colony-forming ability.

In order to assess the role of CD90 in MSC proliferation rate, cell growth curves for MSCs, shRNA control MSCs, shRNA CD90 MSCs, CD90-negative MSCs, and nontransduced MSCs at the same corresponding cell passage (cell passage 5) were conducted in parallel (Fig. 3b). Analysis of the area under the curve showed no significant difference in proliferation rates. The trypan blue exclusion assay also showed no difference in cell viability.

\section{Lymphocyte proliferation analysis}

We also investigated whether CD90 expression in MSCs would affect the inhibitory effect of MSCs on nonspecific mitogen-stimulated lymphocytes in an in vitro assay. The assay showed that shRNA CD90 MSCs and CD90-negative MSCs suppressed peripheral blood mononuclear cell proliferation to the same extent as MSCs and shRNA control MSCs and non-transduced MSCs (Fig. 4a and b), indicating that a reduction in the expression of CD90 does not affect the characteristic immunosuppressive effect of MSCs on lymphocyte proliferation. Further analysis shows that ablation of CD90 on MSCs also does not affect the percentage of proliferated CD8+ T cells (Fig. 4c)

\section{Flow cytometry immunophenotyping}

We further analysed the cell expression of the MSC marker panel. As expected, and as for non-transduced MSCs, shRNA control MSCs, shRNA CD90 MSCs, and CD90-negative MSCs were negative for the expression of the following markers: CD14, CD31, CD34, CD45, CD106, and HLA-DR, but they were positive for CD29, CD73, and CD105 (Additional file 1: Table S1 and Additional file 2: Figure S1). Surprisingly, we found a reduction in the expression of the CD44 and CD166 markers in shRNA CD90 MSCs, suggesting that the CD90 reduction is linked to the decrease in CD166 and CD44 expression (Fig. $5 \mathrm{a}$ and $\mathrm{b}$ ). These reductions were observed in MSCs from all three sources (Fig. 5a). 

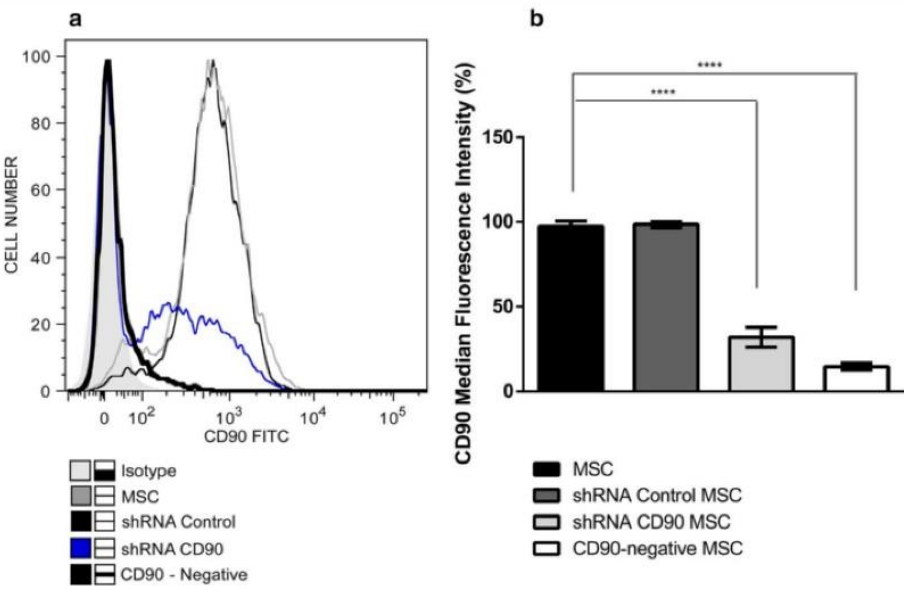

Fig. 2 CD90-negative selection of shRNA CD90 MSCs by magnetic-activated cell sorting. Mesenchymal stromal cells (MSCs) expressing short hairpin (sh)RNA CD90 (shRNA CD90 MSO were magnetically labelled with CD90 microbeads, and MSC populations negatively selected for CD90 (CD90-negative MSCS). a Histogram superposition: isotype control (shaded histogram grey), non-transduced MSCs (black slim line), shRNA control MSCs (grey line), shRNA CD90 MSCs (blue line), and CD90-negative MSCs (black thick line).Representative histograms from a dental pulp MSC group are shown, $\mathbf{b}$ Graph showing mean fluorescence intensity (MFI) of CD90 marker (MFI = MFI marker - MFI isotype) on cells; $n=7$, independent experiments with MSCS derived from 7 tissue donors; $* * * p<0.001$

CD90 and MSC differentiation

The differentiation potentials of non-transduced MSCs, shRNA control MSCs, shRNA CD90 MSCs, and CD90negative MSCs were analysed in parallel in multilineage (osteogenic and adipogenic) differentiation assays. MSCs isolated from dental pulp, amniotic fluid, and adipose tis sue were submitted to osteogenic differentiation assays. As expected, osteogenic induction (OS) resulted in the occurrence of a mineralized matrix deposition which was detected 21 days after the initiation of differentiation

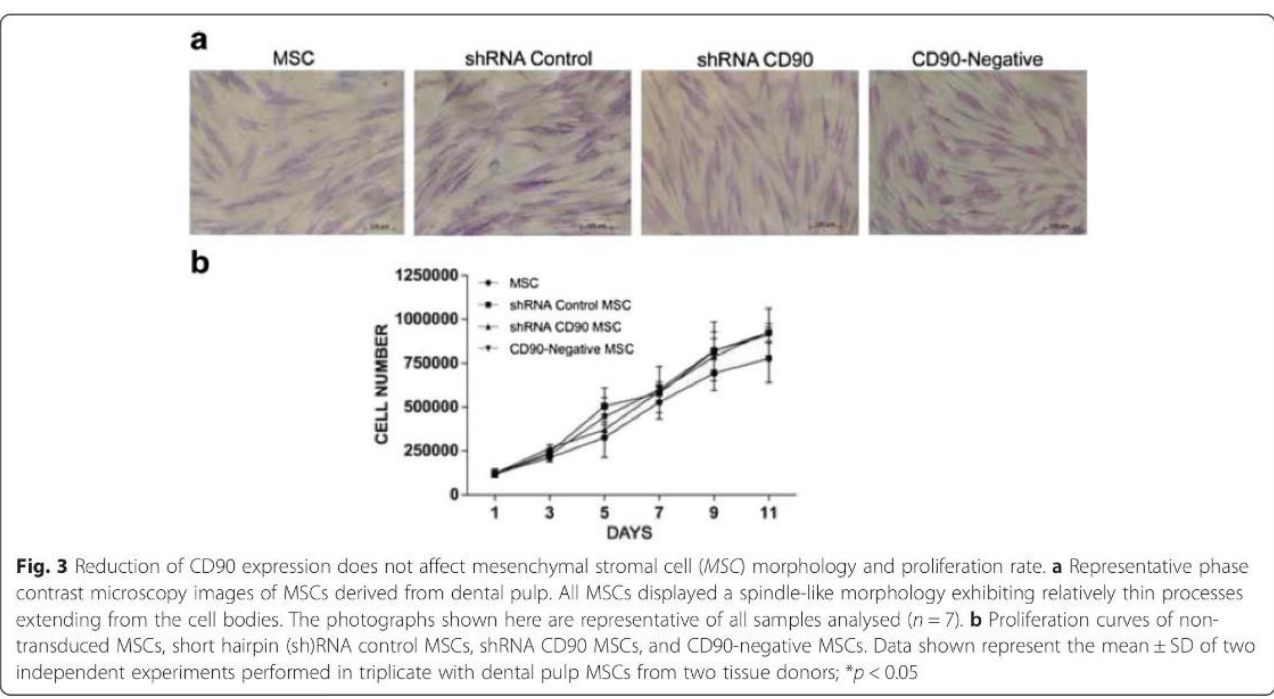




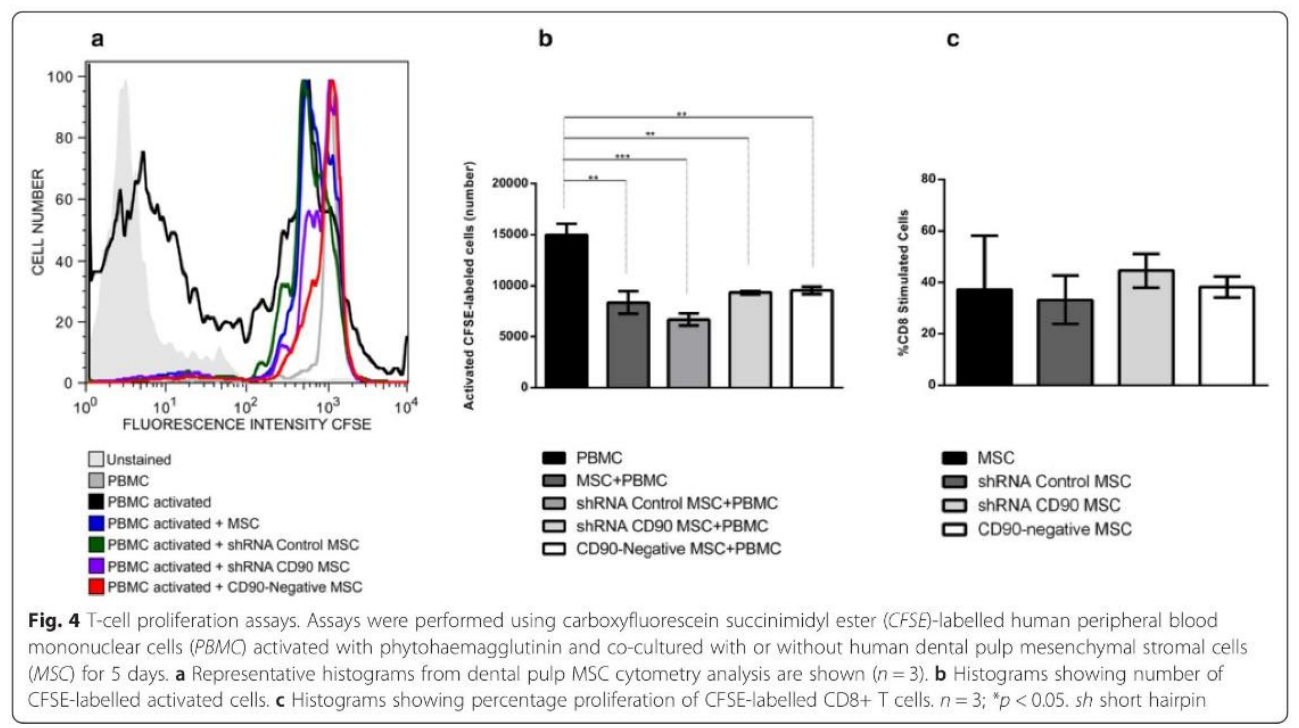

induction. The mineralized matrix was assessed by: a) Alizarin Red S Staining (AR); b) determination of calcium concentration; and c) alkaline phosphatase activity. According to previous data reported by other groups [7, 59, 60], mineral deposition was higher in MSCs isolated from dental pulp than in those isolated from lipoaspirate tissue (Fig. 6). The AR staining pattern obtained differs according to the level of CD90 expression (Fig. 6). The shRNA CD90 MSCs showed significantly higher production of osteogenic matrices, with the visualization of a higher concentration of AR dye in the samples, in comparison to both non-transduced MSCs and shRNA control MSCs (Figs. 6 and 7a). Even higher mineralization was observed in CD90-negative MSC samples. The effect of reduced CD90 expression on the osteogenic differentiation of MSCs was also assessed by monitoring alkaline phosphatase activity, which demonstrated an enhanced production of this enzyme in cells with reduced CD90 expression (Fig. 7b). The calcium production by shRNA CD90 MSCs was also higher than in non-transduced MSCs (Fig. 7b). The calcium concentration could not be adequately measured in samples originating from lipoaspirate tissue due the low calcium concentration in all samples.

The adipogenic differentiation capacity of the MSCs was also analysed using MSCs isolated from dental pulp, adipose tissue, and amniotic fluid (Fig. 8). All cell populations showed significant morphological changes compared to those that were not incubated in adipogenesis-inducing medium. The cells presented an oval shape, with lipid vacuoles in the cytoplasm, and the presence of many lipid droplets as evidenced by Oil Red staining (Fig. 8a). We observed an increase in the number of adipocyte-like cells in shRNA CD90 MSCs compared to the shRNA control MSCs, with an even higher number of adipocyte-like cells in CD90-negative MSCs. Independent of CD90 expression, we found that MSCs from adipose tissue produced higher amounts of lipid droplets when compared to cells obtained from the amniotic fluid and dental pulp. The most prominent adipocyte formation, revealed by Oil Red staining, was observed in CD90-negative MSCs isolated from adipose tissue (Fig. 8b).

\section{Discussion}

The biology of MSCs has been broadly studied [1, 22, 61, 62] because of their therapeutic potential. Therefore, we decided to study the function of CD90, one main immunophenotypical marker of MSCs, in order to better understand its relationship with MSC morphology, proliferation, and differentiation. Here, we used MSCs isolated from three sources (dental pulp, adipose tissue, and amniotic fluid) to verify whether the effects caused by CD90 ablation would be source-specific. We used lentivirusmediated CD90-shRNAi to stably reduce CD90 expression and further evaluate its function in MSCs. Here, we generated MSC lines transduced with lentivirus-carrying small hairpins (shRNA) targeting CD90. After the establishment of CD90-shRNA expressing MSCs (in shRNA CD90 MSCs), the reduction of CD90 expression was confirmed 

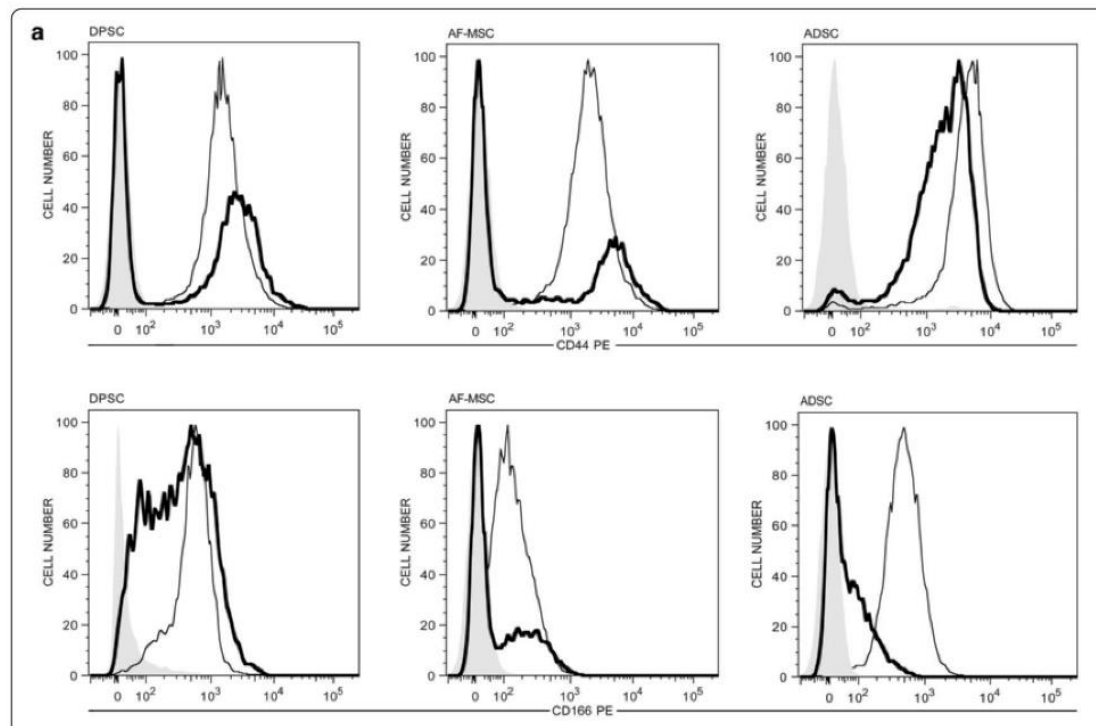

\section{$\square$ isotype}

昌 shRNA

b

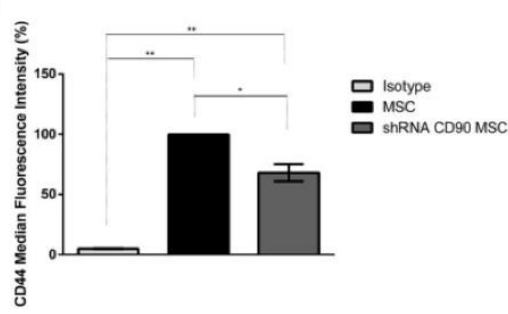

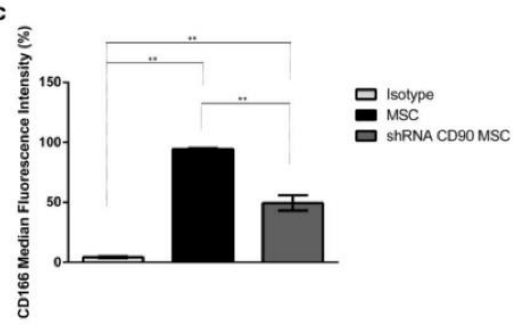

Fig. 5 Reduction of CD90 expression leads to a reduction in the expression of CD44 and CD166 in mesenchymal stromal cells (MSCS). a MSCS (slim line) and shRNA CD90 MSCS (thick line) were analysed by flow cytometry to evaluate their expression of CD44 and CD166. The results showed a significant reduction of CD44 and CD166 expression in shRNA CD90 MSCs from different tissue sources. An isotype control (shaded histogram) was used to establish the boundary between negative and positive fluorescent regions. Median fluorescence intensities (MFI) of b CD44 and c CD166 markers on MSCS are shown (MFI =MFI marker - MFI isotype); $n=7 ;{ }^{*} p<0.05$. ADSC adipose tissue mesenchymal stromal cell, AF-MSC amniotic fluid mesenchymal stromal cell, DPSC dental pulp mesenchymal stromal cell, sh short hairpin

in immunophenotypical analysis using flow cytometry (Fig. 1). We subsequently evaluated the immunophenotypic profiles of modified MSCs, in addition to CD90. As expected, we found that these cells expressed the positive MSC markers CD29, CD73, and CD105, and did not express the following cell markers: CD14, CD31, CD34, CD45, CD106, and HLA-DR (Additional file 2: Figure S1). Surprisingly, we found that a knockdown in CD90 expression in all CD90-shRNAi MSCs obtained here led to a reduction in the CD44 and CD166 expression (Fig. 5).

The role of CD166 in MSCs has not been determined to date. However, CD44 (hyaluronan receptor) [63] is expressed by a large number of cells and is involved in cell adhesion, migration, and homing in MSCs [64-66] Furthermore, CD44 has been recognized as a stem cell marker for several types of cancer and is strongly linked to metastatic spread. It has been shown that the reduction of CD44 in cancer stem cells caused them to differentiate into non-cancer stem cells [67]. The receptor CD166 (activated leukocyte cell adhesion molecule, ALCAM) is a member of the immunoglobulin superfamily of cell adhesion molecules $[68,69]$ and is present in undifferentiated MSCs and other cell types [70]. Like CD44, CD166 has been shown to participate in tumour invasion [71-73]. A recent study using liver cancer cell lines relates the close interaction between CD44 and 


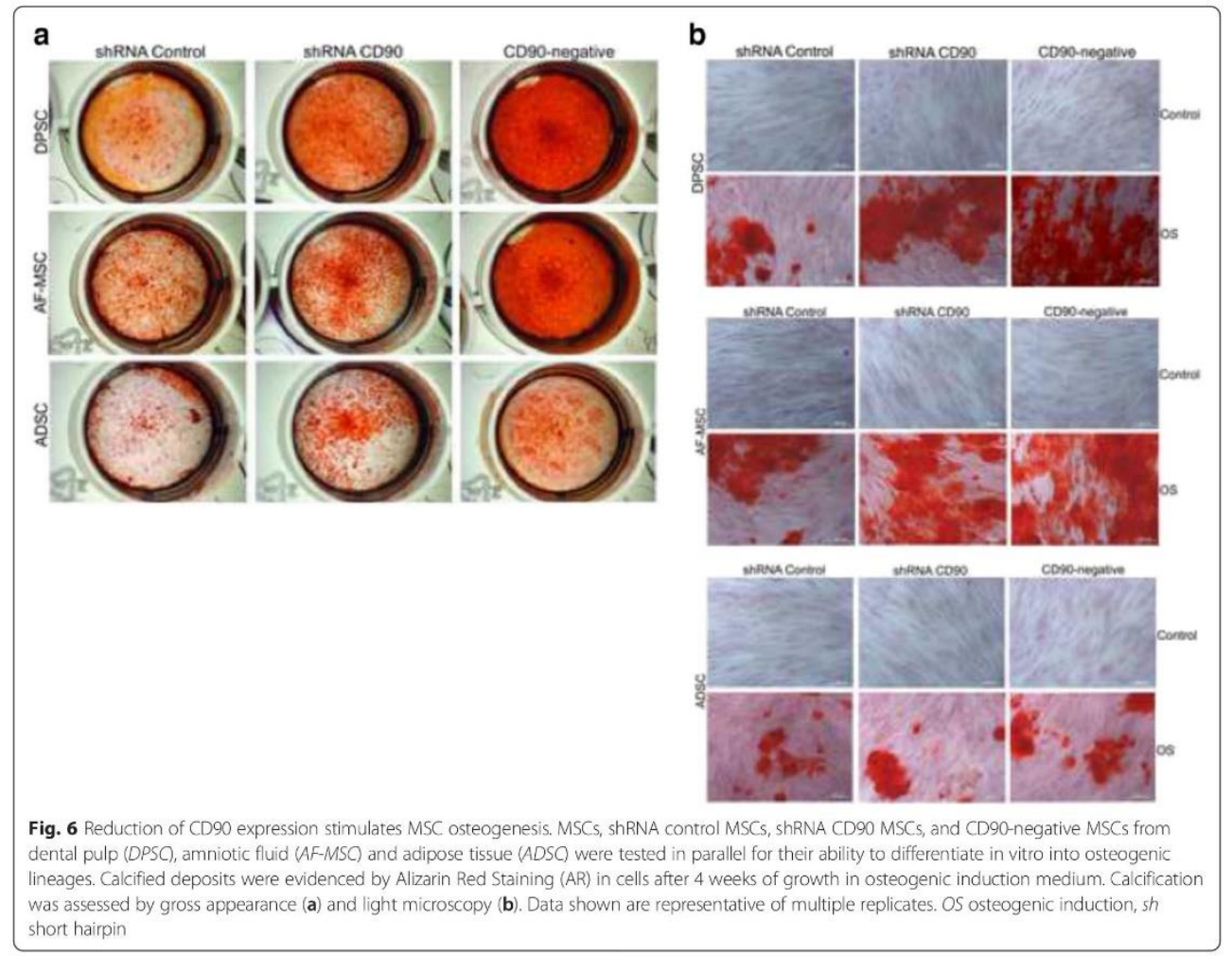

CD166. The authors showed that a knockdown of CD166 inhibits the expression of CD44 via the NFkB pathway [74].

CD90 has also been identified as a candidate marker for adult stem cells. Few studies have shown a functional association between CD90 and CD44 or CD166 markers. Strikingly, the few data showing association come from cancer stem cell research: CD90, CD44, and CD166 are notably considered cancer stem cell markers [44, 70, 71, 75]. Our results showed that the knockdown of CD90 leads to a decrease in CD44 and CD166 expression, which could indicate a shift in the stemness state of MSCs towards a state more susceptible to differentiation.

CD90 has been linked to the spindle-shape of lung fibroblasts. Observing lung fibroblasts sorted on the basis of CD90 expression, Phipps and co-workers [76] affirmed that the lung $\mathrm{CD}^{-} 0^{-}$fibroblast subpopulation showed a more polygonal shape than the spindle-shaped $\mathrm{CD} 90^{+} \mathrm{fi}-$ broblasts. In contrast to these observations, in our study, a reduction in CD90 expression in shRNA CD90 MSCs and CD90-negative MSCs did not present altered morphology or proliferation rate when compared to control cells (Fig. 3). Here, we also demonstrated that a reduced expression of CD90 does not affect the immunosuppressive activity of MSCs on lymphocyte proliferation in vitro (Fig. 5), a very important therapeutic MSC property.

We carried out assays to investigate the differentiation of CD90-ablated MSCs into osteogenic and adipogenic lineages. In our differentiation assays, shRNA CD90 MSCs and CD90-negative MSCs showed a higher rate of adipogenic differentiation when compared to the controls (Fig. 8). In the same way, an enhanced osteogenic differentiation was observed in samples of shRNA CD90 MSCs and CD90-negative MSCs. Alizarin Red S staining showed that $\mathrm{CD} 90$-negative $\mathrm{MSCs}$, the $\mathrm{CD} 90$ negative fraction of shRNA CD90 MSCs, accumulated more mineralized matrix than shRNA CD90 MSCs (Figs. 6 and 7). According to our results, the knockdown of CD90 expression in MSCs facilitates osteogenic and adipogenic differentiation.

Recently, Woeller and colleagues [77] showed that CD90 controls adipogenesis. They had previously 


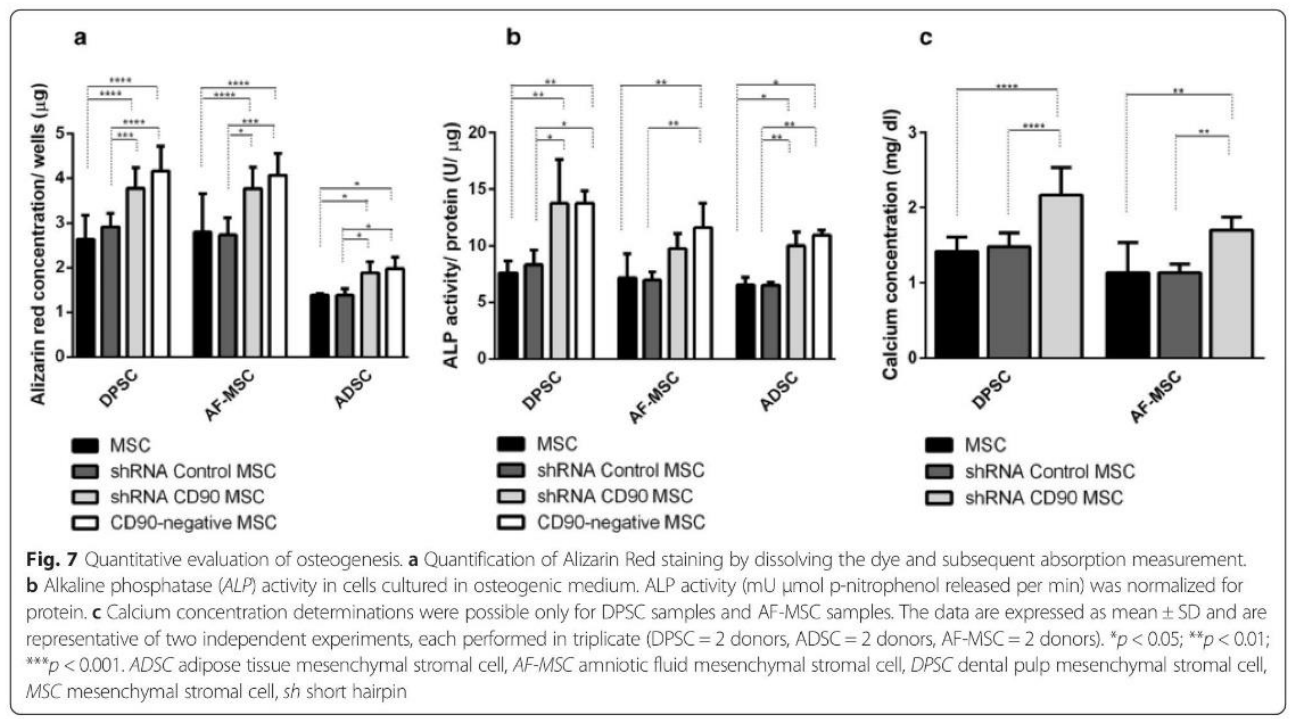

observed that CD90-null mice gain weight at a faster rate, and that ectopic overexpression of CD90 blocked adipogenesis [77]. They also stated that, although pre-adipocyte fibroblasts expressed CD90, fat adipocytes presented almost undetectable CD90 levels. In agreement with this study, we also observed that a loss of CD90 expression in MSCs increased the production of adipogenic matrix in vitro. Based on their study, Woeller and colleagues [77] suggest that CD90 could be a new therapeutic target for obesity. However, our results indicate that this differentiation facilitation related to decreased CD90 expression is not only for adipogenic differentiation, since we observed the same facilitation for osteogenic differentiation. Our data indicate that the knockdown of CD90 seems to lower the stemness guard of MSCs, thereby enabling further differentiation when in the presence of the specific stimuli.

The finding that the level of CD90 regulates both MSC adipogenesis and osteogenesis is very interesting, because it is well accepted that differentiation stimuli usually cause an "inverse relationship" between adipogenic and osteogenic differentiation [78], although the molecular pathways that can converge into adipogenesis and osteogenesis have not been completely elucidated. Here, we demonstrated that the production of mineralized matrix directly correlates with the level of CD90 ablation: higher in the samples of CD90-negative MSCs than shRNA CD90 MSCs. It is unclear how CD90 can affect adipogenesis. However, it has been demonstrated that CD90 also regulates RhoGTPase activity in fibroblasts. Exogenous expression on CD90-non-expressing fibroblasts results in Rho GTPase activation [42]. CD90 participates in many signalling pathways, and it is becoming clear that, although CD90 has been recognized as a plain cell marker, it is also an important regulator of MSC signalling [79]. In order to accurately understand the effects of CD90 on all cis- and trans-signalling networks that it participates in, significant further studies are required. Improving our knowledge of these mechanisms may allow a better understanding of MSC stemness and differentiation.

An increasing number of studies have shown that MSCs from different sources display significantly diverse properties and characteristics that may impact on their future therapeutic applications. The capacity of differentiation may vary according to the cell source $[7,59,60]$. In agreement with previous reports $[59,80-82]$, we observed that cells from the dental pulp tissue and aminiotic fluid produced a larger quantity of osteogenic matrix than cells from adipose tissue (Figs. 6 and 7). Despite the expected variance in the differentiation potential among MSCs from different tissues [83, 84], we confirm that a reduction in CD90 expression leads to a more efficient osteogenic differentiation, irrespective of the source.

CD90 is a GPI-anchored protein expressed in various cell types. In general, it appears to influence cell proliferation, differentiation, migration, and survival. The functions of CD90 are tissue- and cell-specific and, in the present work, we found that shRNAinduced knockdown in human MSCs increases the 


\section{a}
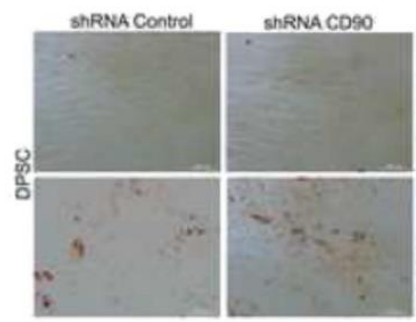

CO90-nesasive

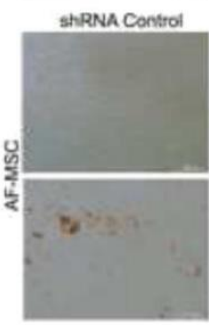

ShRNA CO90
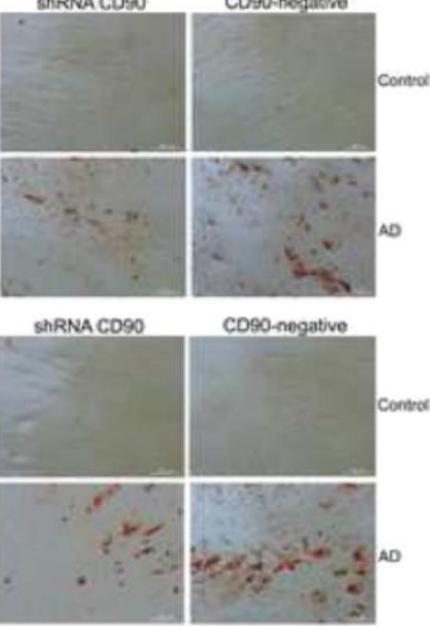

Coso-negative

hRNA Control

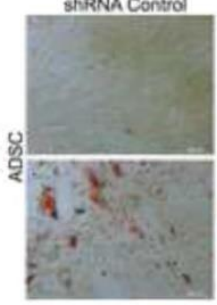

ShRNACOSO

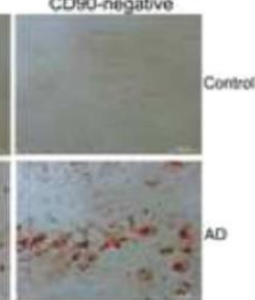

Co90-negative
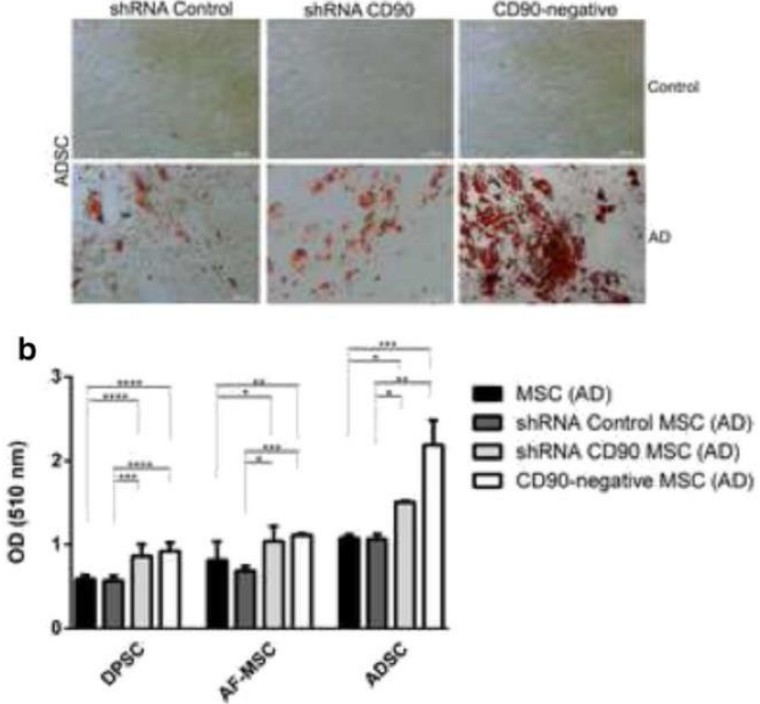

Fig. 8 Reduction of CD90 expression stimulates the adipogenesis of mesenchymal stromal cells (MSCs). MSCs, short hairpin (sh)RNA control MSCS, shRNA CD90 MSCs, and CD90-negative MSCs were tested for their ability to differentiate into adipogenic lineages. a Representative photomicrograph images show oil red staining indicative of adipogenic differentiation. MSCS from dental pulp (DPSC), amniotic fluid (AF-MSCS), and lipoaspirate (ADSC) were cultured in the non-differentiation medium MSCs (control) and adipogenic differentiation medium (AD). The images shown are representative of two independent experiments. b Oil red dye retained in the lipid vacuoles was measured by determining the optical density (OD) at $510 \mathrm{~nm}$. Data shown represent the mean \pm SD of one experiment performed in triplicate $(n=7) .{ }^{*} p<0.05 ;{ }^{* *} p<0.01 ;{ }^{* * *} p<0.001$

differentiation efficiency of these cells. Our group previously showed that CD90 expression could be used as an indicator to follow the differentiation commitment degree of MSCs. Immediately after the induction of differentiation, a progressive decrease in CD90 mRNA level correlates with the degree of differentiation observed [25]. It is 
important to reiterate that the ablation of CD90 expression did not result in a spontaneous differentiation. However, it facilitated MSC differentiation in the presence of inductors, indicating that CD90 may play an important role in maintaining the undifferentiated state of MSCs, perhaps by acting as an obstacle to be overcome during the early steps of cellular differentiation commitment.

\section{Conclusions}

Taken together, the current data indicate that the ablation of CD90 in MSCs represents a promising alternative strategy and an efficient approach to increase MSC differentiation efficiency in vitro; it may, therefore, be used in the future to improve MSC differentiation yields in cellular therapy. Further studies are needed to evaluate whether this approach facilitates all the in vitro differentiation protocols established for MSCs, and how the ablation of CD90 affects migration/homing and the therapeutic potential of those cells in in vivo MSC therapy models. Our results showed that the knockdown of CD90 leads to a decrease in CD44 and CD166 expression, which could indicate a shift in the stemness state of MSCs towards a state that is more susceptible to differentiation.

\section{Additional files}

Additional file 1: Table S1. Surface protein expression of transduced and non-transduced MSCs originated from dental pulp (DPSC $(n=3)$ amniotic fluid (AF-MSCS) $(n=2)$, and lipoaspirate (ADSC) $(n=2)$ were analysed by flow cytometry. Data shown represent the mean MFI \pm SD obtained in cytometry analysis performed in duplicate. (TFF $177 \mathrm{~kb}$ )

Additional file 2: Figure S1. Representative flow cytometry data to characterise transduced and non-transduced MSC groups studied in this work. One representative immunophenotypic analysis of groups obtained from the same dental pulp tissue is shown. Unstained MSC (grey shaded histogram), MSC (grey line), shRNA control MSCs (black slim line), and shRNA CD90 MSCs (black thick lines) were harvested and labelled with Ab against CD90, CD44, CD166, CD73, CD29, CD14, CD45, CD31, CD34, CD106, and HLA-DR as indicated. FACS analysis demonstrated that MSCs and shRNA CD90 MSCs were negative for CD14, CD 45, CD31, CD106, HLA-DR, and CD34, and were positive for CD105, CD73, and CD29. MSCS were positive for $\mathrm{CD} 90, \mathrm{CD} 44$, and CD166, whereas shRNA CD90 MSC showed a reduction in CD90, CD44, and CD166 expression. (TIF $8631 \mathrm{~kb}$ )

\section{Abbreviations}

ALP, alkaline phosphatase; CD, cluster differentiation; CFSE, carboxyfluorescein succinimidyl ester; CFU-F, colony-forming unit-fibroblast; HLA-DR, human leukocyte antigen - antigen D related; MSC, mesenchymal stromal cell; PBS, phosphate-buffered saline; PHA, phytohaemagglutinin; shRNA, small hairpi RNA

\section{Acknowledgements}

This work was supported by CNPq (Conselho Nacional de Desenvolvimento Cientifico e Tecnológico). We thank the Sabin Laboratory (Brasilia-DF, Brasil) for their technical help with calcium concentration analysis. We al so thank Felipe Saldanha-Araújo for technical help with lymphoproliferation assays and Raffael Castro for technical help with flow cytometry assays.
Funding

Conselho Nacional de Pesquisa (Brazil) funded this study. The funders had no role in study design, data collection and analysis, the decision to publish. or the preparation of the manuscript

Availability of data and materials

The authors confirm that all data underlying the findings are fully available.

\section{Authors' contributions}

DAM, TTS, LFP, JRS, RBA, and DMO contributed to the study design. DAM, $T T S, L F P, O A T, P Q A, A P-T, L M C, R S B$, and DMO contributed substantially to data collection, study execution, and data analysis and interpretation. DAM wrote the first draft of the manuscript; and PQA, RSB, OAT, TIS, LFP, LCM, $A P-T, J R S, R B A$, and DMO contributed to the preparation of the manuscript and editing. All authors read and approved the manuscript.

\section{Competing interests}

The authors declare that they have no competing interests.

\section{Ethics approval and consent to participat}

Human tissues were obtained under approval of the Ethical Committee of Health Sciences Faculty of the University of Brasilia (Brazil) (Project numbe CAAE 0020.0.012.000-08)

\section{Author details}

'Departamento de Genética e Morfologia, Universidade de Brasília, Brasilia, DF, Brazil. '2Departamento de Ciências da Saúde, Universidade de Brasília, Brasília, DF, Brazil. ${ }^{3}$ Departamento de Neurologia e Neurocirurgia, Universidade Federal de São Paulo, São Paulo, SP, Brazil. ${ }^{1}$ Hospital Israelita Albert Einstein, Instituto de Ensino e Pesquisa - Centro de Pesquisa Experimental São Paulo, São Paulo, SP, Brazil. ${ }^{5}$ IB-Departamento de Genética e Morfologia, Universidade de Brasilia - UNB, Campus Universitário Darcy Ribeiro, Asa Norte, Brasilia CEP 70910-970, Brazil. ${ }^{6}$ Centro Universitario do Distrito Federal UDF, Brasilia, DF, Brazil.

Received: 12 April 2016 Revised: 28 June 2016 Accepted: 4 July 2016 Published online: 28 July 2016

\section{References}

Pittenger MF, Mackay AM, Beck SC, Jaiswal RK, Douglas R, Mosca JD, et a Multilineage potential of adult human mesenchymal stem cells. Science 1999:284:143-7.

2. De Bari C, Accio FD, Tylzanowski P, Luyten FP. Multipotent mesenchymal stem cells from adult human synovial membrane. Arthritis Rheum. 2001:44 $1928-42$

3. Kadivar M, Khatami S, Mortazavi Y, Taghikhani M, Shokrgozar MA. Multilineage differentiation activity by the human umbilical vein-derived mesenchymal stem cells. Iran Biomed J. 2006;10:175-84.

4. Dominici M, Le Blanc K, Mueller I, Marini FC, Krause DS, Deans RJ, et al. Minimal criteria for defining multipotent mesenchymal stromal cells. The 2006:8315-7 do: 10:1080/14653240600855905.

5. Friedestein A, Deriglasosa U, Kulagina N, Panasuk A, Rudakowa S, Lurià E, et al. Friedestein A, Deriglasosa U, Kulagina N, Panasuk A, Rudakowa S, Luria E, et a. Precursors of fibroblasts in afforent populations of hematopoietic cells as

6.

Igura K, Zhang $X$, Takahashi K, Mitsuru A, Yamaguchi S, Takahashi TA. Isolation and characterization of mesenchymal progenitor cells from chorionic vilit of human placenta. Cytotherapy. 2004,6:543-53. doi:10.1080/465324041000536 Gronthos S, Mankani M, Brahim J, Robey PG, Shi S. Postnatal human dental pulp stem cells (DPSCS) in vitro and in vivo. Proc Natl Acad Sci U S A. 2000 97:13625-30. do: 10.1073/pnas 24030979/

8. Bi Y, Ehirchiou D, Kilts TM, Inkson CA, Embree MC, Sonoyama W, et a Identification of tendon stem/progenitor cells and the role of the extracellular matrix in their niche. Nat Med. 2007:13:1219-27. doi:10.1038/nml630

9. Shih DT, Lee D, Chen S, Tsai R, Huang C. Isolation and characterization of neurogenic mesenchymal stem cells in human scalp tissue. Stem Cells. 2005;23:1012-20. doi:10.1634/stemcells.2004-0125.

10. Zuk PA, Zhu M, Ashjian P, De Ugarte DA, Huang Jl, Mizuno H, et al. Human adipose tissue is a source of multipotent stem cells. Mol Biol Cell. 2002:13: 4279-95. doil:10.1091/mbc.E02 
11. Erices $A$, Conget $P$, Minguell J. Mesenchymal progenitor cells in human umbilical cord blood. Br I Haematol. 2000;109:235-42

12. Sarugaser R, Lickorish D, Baksh D, Hosseini MM, Davies JE. Human umbilical cord perivascular (HUCPV cells: a source of mesenchymal progenitors. Stem Cells, 2005:23:220-9 doi:10.1634/stemcells, 2004-0166

13. Wang $H$, Hung $S$, Peng $S$, Huang $C$, Wei H, Guo $Y$, et al. Mesenchymal stem cells in the Wharton's jelly of the human umbilical cord. Stem Cells. 2004;22 1330-7. doi:10.1634/stemcells.2004-0013.

14. Tsai M, Lee J, Chang Y, Hwang S. Isolation of human multipotent mesenchyma stem cells from second-trimester amniotic fluid using a novel two-stage culture protocol. Hum Reprod. 2004;19:1450-6. doi:10.1093/humrep/deh279.

15. Patki S, Kadam S, Chandra V, Bhonde R. Human breast milk is a rich source of multipotent mesenchymal stem cells. Hum Cell. 2010:23:3540. do: $10.1111 / j .1749-0774.2010 .00083 x$

16. Murphy MB, Moncivais K, Caplan Al. Mesenchymal stem cells: environmentally responsive therapeutics for regenerative medicine. Exp Mol Med. 2013:45:1-16 do: 10.1038/emm.2013.94.

17. Horwitz EM, Le Blanc K, Dominici M, Mueller I, Slaper-Cortenbach I, Marini $F C$, et al. Clarification of the nomenclature for MSC: The International $F C$, et al. Clarification of the nomenclature for MSC: The International
Society for Cellular Therapy position statement. Cytotherapy. 2005;7:393-5. Society for Cellular Therapy postion
doi:10.1080/14653240500319234.

18. Russel $\mathrm{K}$, Phinney D, Lacey M, Barrilleaux B, MMeyertholen KE, O'Connor KC. In vitro high-capacity assay to quantify the clonal heterogeneity in trilineage potential of mesenchymal stem cells reveals a complex hierarchy of lineage commitment. Stem Cells. 2010:28:788-98. doi:10,1002/stem.312

19. Lv F-J, Tuan R, Cheung K, Leung V. Concise review: The surface markers and identity of human mesenchymal stem cells. 5tem Cells. 2014;32:1408-19.

20. Miura M, Gronthos S, Zhao M, Lu B, Fisher LW, Robey PG, et al. SHED: stem cells from human exfoliated deciduous teeth. Proc Natl Acad Sci U S A. 2003:100:5807-12. doi:10.1073/pnas.0937635100

21. Huang G, Gronthos S, Shi S. Mesenchymal stem cells derived from dental tissues vs. those from other sources: their biology and role in regenerative medicine. J Dent Res. 2009;88:792-806. doi:10.1177/0022034509340867.

22. Kolf CM, Cho E, Tuan RS. Review: mesenchymal stromal cells biology of adult mesenchymal stem cells: regulation of niche, self-renewal and differentiation MSC markers. Arthritis Res Ther. 2007;9:1-10. doi: $10.1186 /$ ar 2116

23. Hiwase $S D$, Dyson $P G$, To $L B$, Lewis ID. Cotransplantation of placental mesenchymal stromal cells enhances single and double cord blood engraftment in nonobese diabetic/severe combined immune deficient engraftment in nonobese diabetic/severe combined imm Stem Cells. 2009:27:2293-300 do: 10:1002/stem 157.

24. Delorme B, Ringe J, Gallay N, Le Vern Y, Kerboeuf D, Jorgensen C, et al. Specific plasma membrane protein phenotype of culture-amplified and native human bone marrow mesenchymal stem cells. Hematopoiesis Stem Cells. 2008;111: 2631-5. doi:10:1182/blood-2007-07-09962

25. Sibov $T$, Severino P, Marti LC, Pavon LF, Oliveira DM, Tobo PR, et al. Mesenchymal stem cells from umbilical cord blood: parameters for isolation, characterization and adipogenic differentiation. Cytotechnology. 2012;64:511-21. doi:10.1007/510616-012-9428-3.

26. Williams AF, Gagnon I. Neuronal cell Thy-1 glycoprotein: homology with immunoglobulin. Science. 1982;216:696-703.

27. Raff M. Surface antigenic markers for distinguishing $T$ and $B$ lymphocytes in mice. Transplant Rev. 19716:52-80.

28. Rege TA, Hagood JS. Thy-1 as a regulator of cell-cell and cell-matrix interactions in axon regeneration, apoptosis, athesion migration cancer, and fibrosis FASEB in axon regeneration, apoptosis, adhesion, $r$ ing

29. Bradley JE, Ramirez G, Hagood JS. Roles and regulation of Thy-1, a context-dependent modulator of cell phenotype. Biofactors. 2009:35: 258-65, doi:10.1002/biof 41 .

30. Barboni E, Gormley AM, Rivero FBP, Vidal M, Morris R. Activation of T lymphocytes by cross-linking of glycophospholipid-anchored Thy-1 mobilizes separate pools of intracellular second messengers to those induced by the antigen-recepto CD3 3 complex Imm

31. Morris $R$, Tiveron $M$, Xue $G$. The relation of the expression and function of the neuronal glycoprotein Thy-1 to axonal growth. Biochem Soc Trans. 1991;20:401-5.

32. Jeng CJ, McCarroll SA, Martin TFJ, Floor E, Adams J, Krantz D, et al. Thy-1 is component common to multiple populations of synaptic vesicles. J Cell Biol. 1998; 140:685-98. doi:10.1083/jcb. 140.3.685.

33. Leyton L, Schneider P, Labra CV, Ruegg C, Hetz CA, Quest AFG, et al. Thy-1 binds to integrin $\beta 3$ on astrocytes and triggers formation of focal contact sites. Curr Biol, 2001;11:1028-38.
34. Hueber AO, Bernard AM, Battari CL, Marguet D, Massol P, Foa C, et al. Thymocytes in Thy $-1 \%$ mice show augmented TCR signaling and

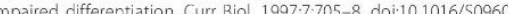
9822(06) 00300-9.

35. Lung HL, Bangarusamy DK, Xie D, Kwok A, Cheung L, Cheng Y, et al. THY1 is a candidate tumour suppressor gene with decreased expression in metastatic hasopharyngeal carcinoma. Oncogene, 2005;24.6525-32. doi:10.1038/5j.one 1208812

36. Lung HL, Cheung AKL, Cheng Y, Kwong FM, Lo PHY, Law EML, et al. Functiona characterization of THY1 as a tumor suppressor gene with antiinvasive activity in nasopharyngeal carcinoma. Int J Cancer. 2010;127:304-12. doi:10.1002/ijc.25047.

37. Abeysinghe HR, Pollock SJ, Guckert NL, Veyberman Y, Keng P, Halterman M, et al. The role of the THY1 gene in human ovarian cancer suppression based on transfection studies. Cancer Genet Cytogenet. 2004;149:1-10. do: 10.1016/50165-4608(03)00234-6.

38. Saalbach A, Anderegg U, Bruns M, Schnabel E, Hermann K, Haustein U. Novel fibroblast-specific monoclonal antibodies: properties and specificities. Soc Invest Dermatol. 1996:106:1314-9.

39. Fries $K$, Blieden $T$, Looney R, Sempowski G, Silvera $M$, Willis R, et al. Evidence of fibroblast heterogeneity and role of fibroblast subpopulations in fibrosis. Clin Immunol Immunopathol. 1994:72:283-92.

40. Zhou Y, Hagood JS, Murphy-ullrich JE. Thy-1 expression regulates the ability of rat lung fibroblasts to activate transforming growth factor- $\beta$ in response to fibrogenic stimuli. Am J Pathol. 2004; 65:659-69.

41. Hagood JS, Prabhakaran P, Kumbla P, Salazar L, Macewen MW, Barker TH, al. Loss of fibroblast Thy-1 expression correlates with lung fibrogenesis. Am J Pathol. 2005;167:365-79.

42. Barker TH, Grenett HE, MacEwen MW, Tilden SG, Fuller GM, Settleman J, et al. Thy-1 regulates fibroblast focal adhesions, cytoskeletal organization and migration through modulation of p190 RhoGAP and Rho GTPase activity. Exp Cell Res. 2004:295:488-96. doi:10.1016/jyexcr. 2004.01.026.

43. Jósvay K, Winter Z, Katona RL, Pecze L, Marton A, Buhala A, et al. Besides neuro-imaging, the Thy 7-YFP mouse could serve for visualizing experimental tumours, inflammation and wound-healing. Sci Rep. 2014;4:1-7. doi:10.1038/ srep06776.

44. Yang ZF, Ho DW, Ng MN, Lau CK, Yu WC, Ngai P, et al. Significance of CD90 + cancer stem cells in human liver cancer. Cancer Cell. 2008:13:153-66. doi: 10.1016/.ccr.2008.01.013.

45. Lu J-W, Chang J-G, Yeh K-T, Chen R-M, Tsai J.J, Hu R-M. Overexpression of Thy $1 / C D 90$ in human hepatocellular carcinoma is associated with HBV infection and poor prognosis. Acta Histochem. 2011;113:833-8. do: 10.1016 acthis.2011.01.001.

46. Sukowati CHC, Anfuso B, Torre G, Francalanci P, Crocè LS, Tiribelli C. The expression of CD90/Thy-1 in hepatocellular carcinoma: an in vivo and in vitro study. PLoS One. 2013;8:1-11. doi:10.1371/journal.pone.0076830.

47. Pascal LE, Ai J, Vêncio RZN, Vêncio EF, Zhou Y, Page LS, et al. Differentia inductive signaling of $\mathrm{CD} 90+$ prostate cancer-associated fibroblasts compared to normal tissue stromal mesenchyme cells. Cancer Microenviron. 2011;451-9. doi:10.1007/s1 2307-010-0061-4.

48. True LD, Zhang H, Ye M, Huang C-Y, Nelson PS, von Haller PD, et al. CD90/ THY1 is overexpressed in prostate cancer-associated fibroblasts and could serve as a cancer biomarker. Mod Pathol. 2010:23:1346-56. doi:10.1038/ modpathol.2010.122

49. He J, Liu Y, Zhu T, Zhu J, DiMeco F, Vescovi AL, et al. CD90 is identified as a candidate marker for cancer stem cells in primary high-grade gliomas using tissue microarrays. Mol Cell Proteomics. 2012:11:M111010744-4 do:10:1074 mcp.M111.010744

50. Zhu J, Thakolwiboon S, Liu X, Zhang M, Lubman DM. Overexpression of CD90 (Thy-1) in pancreatic adenocarcinoma present in the tumor microenvironment (Thy-1) in pancreatic adenocarcinoma present in the tumor

51. Ishiura Y, Kotani N, Yamashita R, Yamamoto H, Kozutsumi Y, Honke K. Anomalous expression of Thy $1(C D 90)$ in B-cell lymphoma cells and proliferation inhibition by anti-Thy1 antibody treatment. Biochem Biophys Res Commun. 2010;396:329-34. doi:10.1016/j.bbrc.2010.04.092

52. Maleki M, Ghanbarvand F, Behvarz MR, Ejtemaei M, Ghadirkhomi E. Comparison of mesenchymal stem cell markers in multiple human adut stem cells. Int J Stem Cells. 2014,7:118-26.

53. Saldanha-Araujo F, Ferreira FIS, Palma PV, Araujo AG, Queiroz RHC, Covas DT, et al. Mesenchymal stromal cells up-regulate CD39 and increase adenosine production to suppress activated T-lymphocytes. Stem Cell Res. 2011;7:66-74. doi:10.1016/iscr.2011.04.001. 
54. Gregory CA, Gunn WG, Peister A, Prockop DJ. An Alizarin red-based assay of mineralization by acherent cells in culture: comparison with cetylpyridinium chloride extraction Anal Biochem. 2004:329:77-84 do:10.1016/1ab2004:02002

55. Conconi MT, Tommasini M, Muratori E, Parnigotto PP. Essential amino acids increase the growth and alkaline phosphatase activity in osteoblasts cultured in vitco. Farmaco. 2001;56:755-61.

56. Lowry OH, Rosebrough NJ, Farr AL, Randall RJ. Protein measurement with the folin phenol reagent. J Biol Chem. 1951;193:265-75.

57. Gitelman J. An improved automated procedure of calcium in biological for the determination specimens. Anal Biochem. 1967;18:521-31.

58. Sekiya I, Larson BL, Smith JR, Pochampally R, Cui J-G, Prockop DJ. Expansion of human adult stem cells from bone marrow stroma: conditions that maximize the yields of early progenitors and evaluate their qual ity. Sten Cells. 2002;20:530-41.

59. Davies OG, Cooper PR, Shelton RM, Smith a J, Scheven BA. A comparison of the in vitro mineralisation and dentinogenic potential of mesenchyma stem cells derived from adipose tissue, bone marrow and dental pupa Bone Miner Metab. 2014:371-82.

60. Divya MS, Roshin GE, Divya TS, Rasheed VA, Santhoshkumar TR, Elizabeth $K E_{\text {, }}$ et al. Umbilical cord blood-derived mesenchymal stem cells consist of a unique population of progenitors co-expressing mesenchymal stem ce unique population of progenitors co-expressing mesenchymal stem cell and neuronal markers capable of instantaneous neu

61. Krampera M, Pasini A, Rigo A, Scupoli MT, Tecchio C, Malpeli G, et al. HBEGF/HER-1 signaling in bone marrow mesenchymal stem cells: inducing cel expansion and reversibly preventing multilineage differentiation. Blood. 2005;106:59-66. doi:10.1182/blood-2004-09-3645

62. Feng J, Mantesso A, De Bari C, Nishiyama A, Sharpe PT. Dual origin of mesenchymal stem cells contributing to organ growth and repair. Proc $\mathrm{Nat}$ Acad Sci U S A. 2011;108:6503-8. doi:10.1073/pnas.1015449108.

63. Lesley J, Hascall VC, Tammi M, Hyman R. Hyaluronan binding by cell surface CD44. J Biol Chem. 2000;35:26967-75

64. Zhu H, Mitsuhashi N, Klein A, Barsky LW, Weinberg K, Barr ML, et al, The role of the hyaluronan receptor CD44 in mesenchymal stem cell migration in the extracellular matrix. Stem Cells. 2006:24:928-35, doi:10. 1634/stemcells 2005-0186.

65. Puré E, Cuff CA. A crucial role for CD44 in inflammation. Trends Mol Med 2001:7:213-21.

66. Sapaeth EL Labaff AM Toole BP Klopp A Andreeff M Marini FC Mesenchymal CD44 expression contributes to the acquisition of an activated fibroblast phenotype via TWIST activation in the tumor microenvironment Cancer Res. 2013:73 (17) do:10.1158/0008-5472.

67. Pham PV, Phan NL, Nguyen NT, Truong NH, Duong TT, Le DV, et al. Differentiation of breast cancer stem cells by knockdown of CD 44: promising differentiation therapy. J Transl Med. 2011;9:209. doi:10.1186/1479-5876-9-209.

68. Bowen MA, Patel DD, Li X, Modrell B, Malacko AR, Wang W, et al, Cloning, mapping and characterization of activated leukocyte-cell adhesion molecule (ALCAM) a CD6 ligant. J Exp Med. 1995;181:2213-20.

69. Swart GW, Lunter $P C$, van Kilsdonk JW, van Kempen LC. Activated leukocyte cell adhesion molecule (ALCAM/CD166): signaling at the divide of melanoma cell clustering and cell migration. Cancer Metastasis. 2005;24:223-36. doi:10. 1007/s 10555-005-1573-0.

70. Bruder SP, Jaiswal N, Haynesworth SE. Growth kinetics, self-renewal, and the osteogenic potential of purified human mesenchymal stem cells during extensive subcultivation and following cryopreservation. I Cell Biochem 1997:64:278-94.

71. Lugli A, lezzi G, Hostettler I, Muraro MG, Mele V, Tornillo L, et al. Prognostic impact of the expression of purative cancer stem cell colorectal cancer. Br Cancer. 2010;103:382-90. doi:10.1038/s.bic.6605762.

72. Piscuoglio S, Lehmann FS, Zlobec I, Tornillo L, Dietmaier W, Hartmann A, et al. Effect of EpCAM, CD44, CD133 and CD166 expression on patient surviva in tumours of the ampulla of Vater. J Clin Pathol. 2011:1-6. doi:10.1136/ clinpath-2011-200043.

73. Fujiwara K, Ohuchida K, Sada M, Horioka K, lii CDU, Shindo K, et al CD166/ALCAM expression is characteristic of tumorigenicity and invasive and migratory activities of pancreatic cancer cells. PLoS One. 2014:9:1-11. doi:10.1371/journal.pone.0107247.

74. Ma L, Pan Q, Sun F, Yu Y, Wang J. Cluster of differentiation 166 (CD166) regulates cluster of differentiation (CD44) via NF-kB in liver cancer cell line Bel-7402. Biochem Biophys Res Commun. 2014;451:334-8. doi:10.1016/.bbrc 2014.07.128
75. Donnenberg VS, Donnenberg AD, Zimmerlin L Landreneau RJ, Bhargava $R$ Wetzel RA, et al. Localization of CD44 and CD90 positive cells to the Wetzel RA, et al. Localization of CD44 and CD90 positive cells to the
invasive front of breast tumors. Cytometry B Clin Cytom. 2010;78:287-301. invasive front of breast

76. Phipps RP, Penney DP, Keng P. Characterization of two major populations of lung fibroblasts: distinguishing morphology and discordant display of Thy-1 and class II MHC. Am J Respir Cell Mol Biol. 1989:1.65-74.

77. Woeller CF, O'Loughlin CW, Pollock SJ, Thatcher TH, Feldon SE, Phipps RP. Thy1 (CD90) controls adipogenesis by regulating activity of the Sic family kinase. Fyn FASEB. 2015;29:920-31. doi:10.1096/fj.14-257121.

78. James AW. Review of signaling pathways governing MSC osteogenic and adipogenic differentiation. Scientifica. 2013;2013:1-17. doi:10.1155/2013/684736.

79. Barker TH, Hagood IS. Getting a grip on Thy-1 signaling. Biochim Biophys Acta. 2009;1793:921-3. doi:10.1016/j.bbamcr.2008.10.004

80. Ito K, Yamada Y, Nakamura S, Ueda M. Osteogenic potential of effective bone engineering using dental pulp stem cells, bone marrow stem cells and periosteal cells for osseointegration of dental implants. Int I Oral Maxillofac Implants. 201 1;26:947-54.

81. Yu J, Wang Y, Deng Z, Tang L, Li Y, Shi J, et al. Odontogenic capability: bone marrow stromal stem cells versus dental pulp stem cells. Biol Cell. 2007;99:465-74.

82. Alge DL, Zhou D, Adams LL, Wiss BK, Shadday MD, Woods EJ, et al. Donor matched comparison of dental pulp stem cells and bone marrow-derived mesenchymal stem cells in a rat model. J Tissue Eng Regen Med. 2010:4773-81.

83. Chen XD, Qian HY, Neff L. Satomura K. Horowitz MC. Thy 1 antigen expression by cells in the osteoblast lineage. J Bone Miner Res. 1999;14:362-75. doi:10 1359/jbmr.1999.14.3.362.

84. Wiesmann A, Bühring H-J, Mentrup C, Wiesmann H-P. Decreased CD90 expression in human mesenchymal stem cells by applying mechanica stimulation Head Face Med 2006:2:1-6 do:101186/1746-160X-2-8

Submit your next manuscript to BioMed Central and we will help you at every step:

- We accept pre-submission inquiries

- Our selector tool helps you to find the most relevant journa

- We provide round the clock customer support

- Convenient online submission

- Thorough peer review

- Inclusion in PubMed and all major indexing services

- Maximum visibility for your research

Submit your manuscript at www.biomedcentral.com/submit

() Biomed Central 
ANEXO A- Documento de Aprovação pelo Comitê de Ética da Faculdade de Ciências da Saúde-Universidade de Brasília 


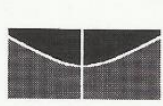

Universidade de Brasília

Faculdade de Ciências da Saúde

Comitê de Ética em Pesquisa - CEP/FS

\section{PROCESSO DE ANÁLISE DE PROJETO DE PESOUISA}

Título do Projeto: "ESTUdO DA FUNÇÃO DE CD90 NA PROLIFERAÇÃO E DIFERENCIAÇÃO DE CÉLULAS-TRONCO MESENQUIMAIS HUMANAS".

Pesquisadora Responsável: DANIELA ABREU DE MORAES

Data de Entrada: 01/09/2014

CAAE: CAAE: 13962813.5 .0000 .0030

Com base na Resolução 466/12, do CNS/MS, que regulamenta a ética em pesquisa com seres humanos, o Comitê de Ética em Pesquisa com Seres Humanos da Faculdade de Ciências da Saúde da Universidade de Brasília, após análise dos aspectos éticos e do contexto técnico-científico, resolveu APROVAR o projeto intitulado "Estudo da função de CD90 na proliferação e diferenciação de células-tronco mesenquimais humanas". Parecer no 378.509, em 30 de agosto de 2013.

Notifica-se o(a) pesquisador(a) responsável da obrigatoriedade da apresentação de um relatório semestral e relatório final sobre o desenvolvimento do Projeto, no prazo de 1 (um) ano a contar da data de aprovação.

Brasília, 20 de janeiro de 2014.

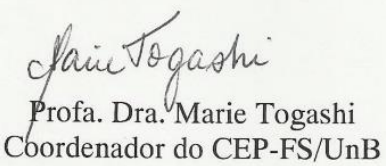

Comitê de Ética em Pesquisa com Seres Humanos - Faculdade de Ciências da Saúde

Universidade de Brasília - Campus Universitário Darcy Ribeiro - CEP: 70.910-900 Telefone: (61)-3107-1947 Email: cepfs@unb.br 
